Review

\title{
Light Responsive Polymer Membranes: A Review
}

\section{Fiore Pasquale Nicoletta ${ }^{1}$, , Daniela Cupelli ${ }^{1}$, Patrizia Formoso ${ }^{1}$, Giovanni De Filpo ${ }^{2}$, Valentina Colella $^{1,3}$ and Annarosa Gugliuzza ${ }^{3}$}

1 Department of Pharmaceutical Sciences, Università della Calabria, I-87036 Rende (CS), Italy; E-Mails: dcupelli@unical.it (D.C.); formoso@unical.it (P.F.); colella.va@libero.it (V.C.)

2 Department of Chemistry, Università della Calabria, I-87036 Rende (CS), Italy; E-Mail: defilpo@unical.it

3 Institute on Membrane Technology-National Council Research, ITM-CNR, I-87030 Rende (CS), Italy; E-Mail: a.gugliuzza@itm.cnr.it

* Author to whom correspondence should be addressed; E-Mail: nicolett@unical.it; Tel.: +39-0984-493194; Fax: +39-0984-493298.

Received: 20 December 2011; in revised form: 4 February 2012 / Accepted: 16 February 2012 / Published: 2 March 2012

\begin{abstract}
In recent years, stimuli responsive materials have gained significant attention in membrane separation processes due to their ability to change specific properties in response to small external stimuli, such as light, $\mathrm{pH}$, temperature, ionic strength, pressure, magnetic field, antigen, chemical composition, and so on. In this review, we briefly report recent progresses in light-driven materials and membranes. Photo-switching mechanisms, valved-membrane fabrication and light-driven properties are examined. Advances and perspectives of light responsive polymer membranes in biotechnology, chemistry and biology areas are discussed.
\end{abstract}

Keywords: membranes; valved-pores; photo-switching azo- and spiro-derivates; liquid crystals; polypeptides membranes; hydrogel membrane; light-driven devices; wettability; sensors; microfluidics

\section{Introduction}

Smart membranes are in high demand in many advanced fields of biotechnology, including drug delivery, biosensors, microfluidics, light-powered molecular machines, molecular shuttles and data 
storage. Responsive polymer membranes are systems that sense the changes in their environment as a stimulus and make a desired response. In all cases, either a controlled porosity or a texture and chemical composition is coupled with adaptive properties, such as $\mathrm{pH}-$, ionic strength-, thermo-, light-, electric-, and magnetic-response and molecular-recognition. The category of responsive membranes hosting reactive functions is large and includes flat and hollow-fiber membranes, nanocomposites layers, free-standing hydrogels, micro-capsules, switchable interfaces, core-shell structures, etc. A number of excellent books and reviews on membrane model systems have been published both on theoretical and applicative aspects [1-3], and many studies involving photo-induced effects on polymers have appeared [4,5]. The present review summarizes the recent developments in methods for the preparation of smart membranes and the mechanisms of their response to external stimuli with a particular attention to the behavior of light responsive polymer membranes.

\section{Photo-Switching Compounds and Mechanisms}

According to the subdivision of Kinoshita [3], typical photo-reactive guests in polymers are azobenzene, triphenylmethane and spiropyran groups, which have been entrapped [6-8], cross-linked [9,10], and introduced as a side chain or part of the main chain [11-15] in polymer matrices. Special mention is deserved to photo-responsive polypeptide membranes.

\subsection{Azobenzene-Based Systems}

Azobenzene, AZB, derivatives are very attractive systems due to their easy trans $\rightarrow$ cis isomerization. Azobenzene groups can undergo an isomerization from a trans form to a cis form upon UV irradiation. The trans form is generally the more stable (energy gap $\approx 50 \mathrm{~kJ} / \mathrm{mol}$ ). AZBs have an intense $\pi-\pi^{*}$ band in the UV region, and a weak $n-\pi^{*}$ band in the visible region. The reaction is reversible by heat or irradiation with visible light, as shown in Figure 1. It is known that azobenzenes reversibly change their geometry from a planar one to non planar upon irradiation with a drastic decrease in the distance between the para carbon atoms from $9.9 \AA$ to $5.5 \AA$ and a corresponding increase in the dipole moment from $0.5 \mathrm{D}$ to $3.1 \mathrm{D}$. As different geometries, polarities and electrical properties affect the two isomers, several functions can be photo-controlled including membrane dimensions, membrane potential, adsorption, solubility of polymer, wettability, swelling, enzyme activity, sol-gel transition of polymer, permeability, ion permeability, ion binding, photo-mechanical cycle, etc.

Figure 1. Photo-induced structure change in azobenzene molecule.
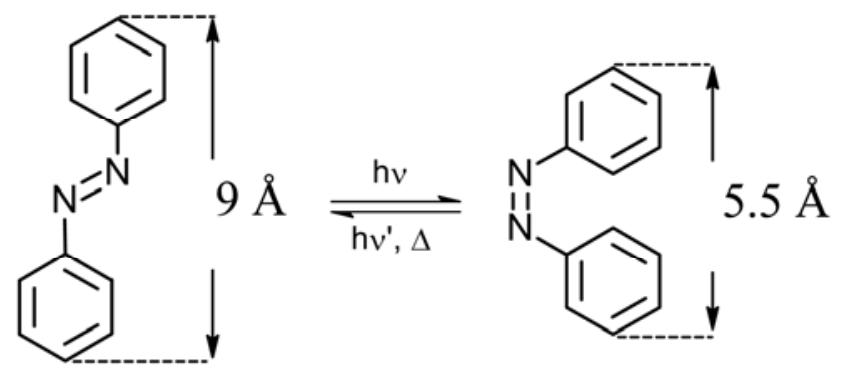


\subsection{Triphenylmethane-Based Systems}

Under UV irradiation, triphenylmethane groups (transparent form, Figure 2a) dissociate into ion pairs with the formation of triphenylmethyl cations (colored form, Figure 2b). The reaction is thermally reversible. Triphenylmethane leuco derivatives have been used in order to get photo-induced charges in polymer side chains, to obtain photo-induced changes in hydrophobicity, dilation and permeation through membranes.

Figure 2. Photo-induced structure change of a triphenylmethane molecule: (a) non-ionic form, and (b) cation form.

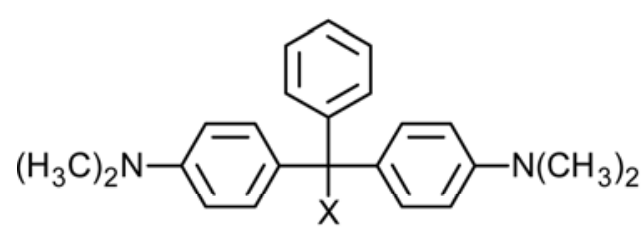

nonionic form

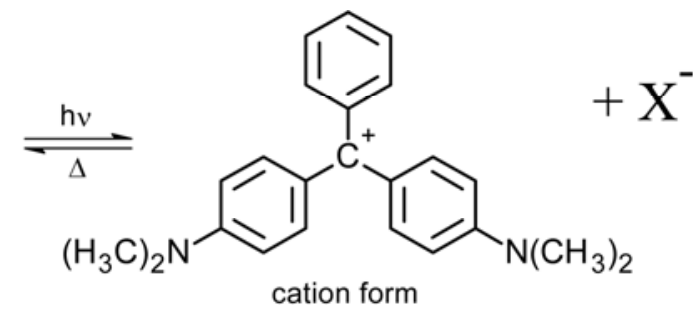

(b)

\subsection{Spiropyran-Based Systems}

Spiropyran, SP, is a well-known photo-chromic group that undergoes a heterocyclic ring cleavage at the $\mathrm{C}-\mathrm{O}$ spiro bond to form a planar and highly conjugated chromophore that absorbs strongly in the visible region, this being the merocyanine, $\mathrm{MC}$, isomer (Figure 3) [16,17]. The open-ring form returns to the initial close-ring form either by a thermal or photo-chemical process. Spiropyran derivatives can be entrapped, cross-linked, and introduced as side chain or part of the main chain in polymer matrices in order to gain a photo-regulation of membrane potentials. The $\mathrm{MC}$ isomer also binds $\mathrm{H}^{+}$[18], divalent metal ions [19], DNA [20] and amino acids [21] resulting in a shift in the absorbance spectrum, and a corresponding colour change. This binding is photo-reversible under the right conditions, as illumination with white or green light decouples the guest from the MC, which then reverts to the SP. Hence spatial and temporal photo-controlled (and colorimetric reporting) uptake and release of guest molecules is, for instance, possible using spiropyran-functionalized materials [22].

Figure 3. Photo-induced structure change of spiropyran.

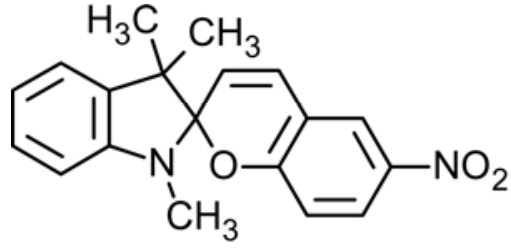

closed-ring form

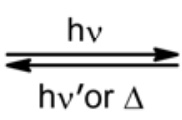

open-ring form<smiles>CN1c2ccccc2C(C)(C)C1/C=C\c1cc([N+](=O)[O-])ccc1[O-]</smiles> 


\subsection{Photo-Pesponsive Liquid Crystal Devices}

Thermotropic liquid crystals are well known anisotropic materials, which deserve particular mention for their applications as electro-optical devices. Nematics are liquid crystals characterized by a long orientational order along a preferential direction, called director, which give them optical, dielectric and magnetic anisotropies. Accordingly to the direction of alignment of the director in the liquid crystal cell, one can distinguish homeotropic alignment, when the director is perpendicular to the cell substrates, planar or homogeneous alignment when the director is parallel to the cell substrates, or random when no preferential alignment is shown by the director. It should be mentioned that the nematic phases lose their anisotropic properties on heating above a characteristic temperature, called clearing temperature, or by increasing doping with molecules, which destabilize the attractive interactions acting between liquid crystalline molecules, or by photo-isomerization of photo-responsive additives. In fact, it has been shown that cis isomer induces more disorder than the trans one allowing the opportunity of reversible nematic $\rightarrow$ isotropic phase transition in liquid crystal by simple UV irradiation [23].

It is usually important to align the liquid crystal director along a well defined direction, and, generally, the anisotropic properties of liquid crystals allow them to be easily aligned by an electric or magnetic field, by mechanical action, or by an alignment agent coated on the cell substrates (surfactants, lecithins, polyimides, etc.) [23]. Such initial alignment is changed by application of an external field like an electric or magnetic one, which exerts an electric or magnetic torque on the liquid crystal director. A different method of reversible liquid crystal alignment regulation has been reported for the first time by Ichimura and coworkers [24-26] using a photo-chemical reaction taking place on the substrate surfaces. In the particular case considered by Ichimura et al, the trans $\rightarrow$ cis photo-isomerization of photo-reactive units (UV light at $366 \mathrm{~nm}$ for some tens of seconds) is able to change the director alignment from a homeotropic to a planar state, while the cis $\rightarrow$ trans back-isomerization (Vis light at $436 \mathrm{~nm}$ for some tens of seconds) allows the reverse transition. The authors treated the liquid crystal cell substrates with photo-chromic layers prepared by several techniques, including silylation, Michael addition, spin coating of polymers, Langmuir-Blodgett films, and always found a reversible homeotropic to planar transition in nematic liquid crystal cells. As reported previously [24-26], the authors synthesized also a series of poly(vinyl alcohol) derivatives having AZB side chains with different lengths and investigated the photo-response of liquid crystal alignment as a function of molecular structure of the Langmuir-Blodgett films, number of deposited layers, 2D density of azobenzene units, deposition and irradiation method. They found that one Langmuir-Blodgett monolayer was sufficient to induce liquid crystal alignment changes if the AZB unit was linked to poly (vinyl alcohol) backbone by a sufficient long spacer. Photo-responsive cells were obtained using both vertical dipping and horizontal lifting deposition methods. The irradiation with linearly polarized UV light induced a reorientation of liquid crystal director along a direction perpendicular to the polarization plane and dependent on the spacer length and number of deposited layers (Figure 4). The response times could be reduced by using high intensity sources.

An important photo-effect in aligned nematic liquid crystals is the optical Freedericksz transition, i.e., the director reorientation by the electric field of the propagating wave. The effect can be enhanced in the presence of dyes (Janossy effect) and the optical Freedericksz threshold voltages can be lowered 
by two order of magnitude. Both effects have found interesting counterparts in polymer systems with liquid crystalline pendants [27-31].

Another interesting effect is the photo-control of layer thickness in lamellar liquid crystals, such as smectic A. The experimental results of Folks et al. have shown that the cis-trans isomerization of dispersed dyes can decrease the smectic layers' spacing. Lansac and coworkers have confirmed by computer simulations that the positional ordering of azo-solutes in a smectic phase depends strongly on their photo-chemical state $[32,33]$.

Figure 4. Photo-controlled alignment in liquid crystals.

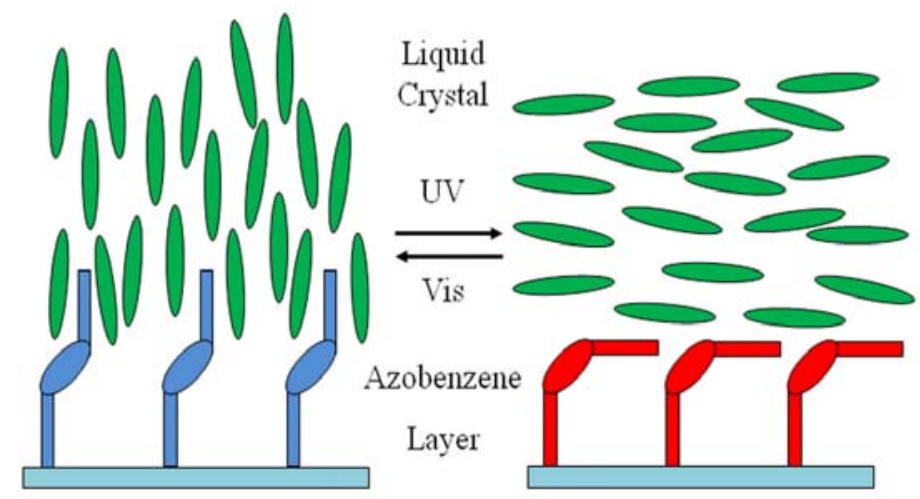

Voloschenko and Lavrentovich have investigated the light-induced phase separation phenomena in dye-doped liquid crystals and Chandran et al. have recently obtained the photo-control of colloidal-liquid crystal interfacial properties in solid colloids that were surface functionalized with photo-responsive azobenzene units and dispersed in liquid crystals [34,35].

Another class of liquid crystals is cholesterics. They have a helical structure which selectively reflects a light wavelength associated to the helical pitch. Several electro-optical cells have been designed in order to have multicolor devices, and recently, a new cholesteric film, obtained by oriented cholesteric liquid crystalline molecules confined in elliptic droplets dispersed in a monomer matrix, has been proposed [36]. The cholesteric mixture consists of a nematic liquid crystal, three chiral agents including the photo-tunable material (S)-1,1'-bis(2-naphthyl)-4-(4'-pentyloxyphenyl) benzoate, a photo-polymerizable monomer and an UV initiator. The fluid mixtures were subjected, first, to a thermally induced phase separation in order to confine liquid crystalline components in elliptic droplets, then to a fast polymerization of the monomer matrix. The reflected wavelength is centered at $480 \mathrm{~nm}$, but after UV irradiation with low energy density the peak moves to $550 \mathrm{~nm}$ and then, for higher energy density to $630 \mathrm{~nm}$, giving rise to different reflected color, Figure 5 . The change in the reflected peak is due to the progressive degradation of photo-sensitive chiral agent, which changes the helical twist power of cholesteric liquid crystal. 
Figure 5. Progressive degradation of photo-sensitive chiral agent by UV light and corresponding reflected colors.

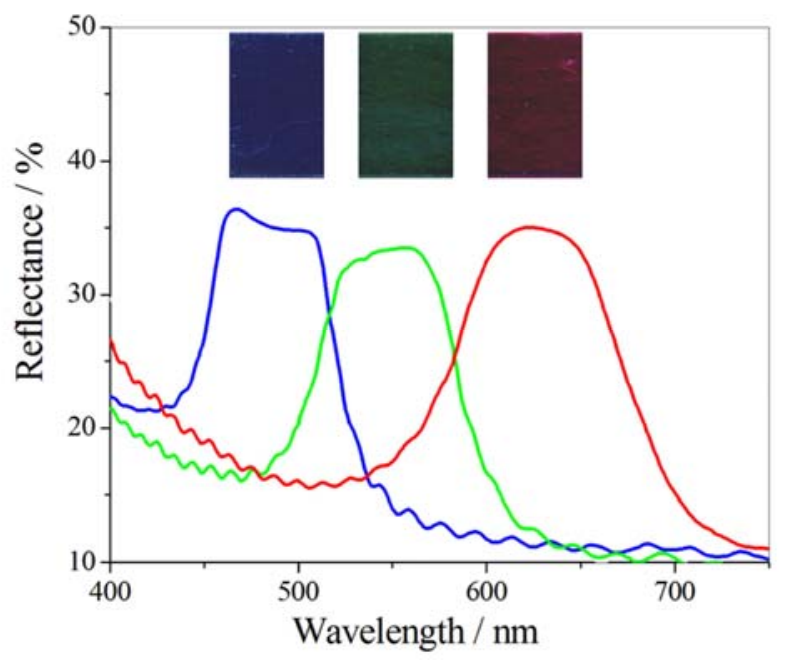

\subsection{Photo-Responsive Polypeptide-Based Systems}

In the last decades, much interest has risen in systems that could change the permeability across a membrane by a conformational change of polypeptides induced by photo-isomerization of the chromophore attached to the polypeptide.

As the photo-isomerization of the azobenzene groups from the trans- to the cis-form involves changes both in their geometry and polarity, photo-responsive polypeptide-based systems can undergo several conformational changes upon light irradiation including $\alpha$-helix $\rightarrow$ random coil and vice versa, left-handed $\alpha$-helix $\rightarrow$ right-handed $\alpha$-helix, $\beta$-form $\rightarrow$ random coil or $\alpha$-helix. These changes are dependent on the solvent composition and the amount of AZB incorporated in the system. In particular, Kinoshita et al. [37,38] have reported their investigations on a poly(L-glutamic acid) membrane, PGA, containing 14.0 mol\% azobenzene moieties in the PGA side chains and found, upon UV irradiation, an increase in water content of membrane as a consequence of the polarity changes of AZB groups. Changes both in membrane potential and cross-membrane conductance have also been observed as a consequence of the acceleration in the dissociation of L-glutamic acid groups. The change in the potential membranes indicates an increase in the membrane negative charge, whereas the variation in the conductance could be attributed to the increase of ion diffusion through the membrane. The photo-induced nature of the observed changes has been confirmed by the absorbance at $350 \mathrm{~nm}$ of the AZB moieties, which was correlated with the variation of membrane potential and permeability.

The introduction of azobenzenesulfonate moieties (14.1 mol\%) into PGA caused also a non-reversible $\alpha$-helix $\rightarrow$ random coil transition in PGA after UV irradiation [39-41]. The membrane potential in azobenzenesulfonate doped PGA membranes shows a decreasing behavior after UV exposure. On the basis of these results the same system has been adsorbed onto a porous support (Millipore filter with a pore size of $0.1 \mu \mathrm{m}$ ) and the photo-induced permeation change has been investigated. Photo-irradiation induced rapid changes in the water flux through the membrane due to the photo-induced conformational changes ( $\alpha$-helix $\rightarrow$ random coil, $\mathrm{pH} 4.0$ ) resulting from the trans $\rightarrow$ cis isomerization of the azobenzenesulfonate moieties. Also it has been shown that the photo-induced 
conformational changes are irreversible, i.e., the cis $\rightarrow$ trans back transition of the azobenzenesulfonate moieties was not able to restore the original $\alpha$-helix membrane structure.

A reversible photo-controlled (both in the conformation and functions) membrane was obtained by introduction of $10 \mathrm{~mol} \%$ of pararosaniline leucohydroxide moieties in a poly(L-glutamic) membrane (2-3 $\mu \mathrm{m}$ thick) [42-44]. The conformation change was induced by a $\mathrm{pH}$ increase due to the photo-dissociation of $\mathrm{OH}^{-}$ions from pararosaniline groups. Such system is characterized by a $\alpha$-helix ordered structure around near weak alkaline $\mathrm{pHs}(7.5<\mathrm{pH}<10.5)$, whereas it is in a random coil conformation at low $(\mathrm{pH}<7.5)$ and high $(\mathrm{pH}>10.5) \mathrm{pHs}$. From circular dichroism measurements it was established that the $\alpha$-helix structure is lost at low and high $\mathrm{pH}$ values due to the amphoteric nature of membrane side chains. In fact, the L-glutamic acid moieties are negatively ionized at high $\mathrm{pHs}$ and the pararosaniline groups $(\mathrm{pKa}=7.6)$ are positively charged at low $\mathrm{pHs}$, and, consequently, far from weak alkaline $\mathrm{pHs}$ large repulsion forces originate from side chains bearing same sign charges. In the $\mathrm{pH}$ range $7.5-10.5$ the polymer can form a $\alpha$-helix structure as the charged side chains neutralized each other.

Depending on $\mathrm{pH}$, UV irradiation could induce either an $\alpha$-helix $\rightarrow$ random coil or random coil $\rightarrow$ $\alpha$-helix transition in the membrane due to the increase of hydroxide ion concentration from the photo-dissociation of pararosaniline groups according to the reaction and to the acid dissociation of L-glutamic acid groups (Figure 6) with a consequent change in the $\mathrm{pH}$ value and in the conformational state of the membrane.

Synchronous changes in the permeability coefficient of styrene glycol and in the degree of hydration of a PGA membrane containing $15.5 \mathrm{~mol} \%$ pararosaniline groups were respectively around $+50 \%$ and $+3 \%$ after ten minutes of UV irradiation at $\mathrm{pH} 8.6$, i.e., the increase of the permeability could be correlated to the photo-induced increase in membrane hydrophobicity. Both the changes were reversible after a dark adaptation of 100 minutes, respectively.

Figure 6. Photo-dissociation of pararosaniline groups and acid dissociation of L-glutamic acid groups.

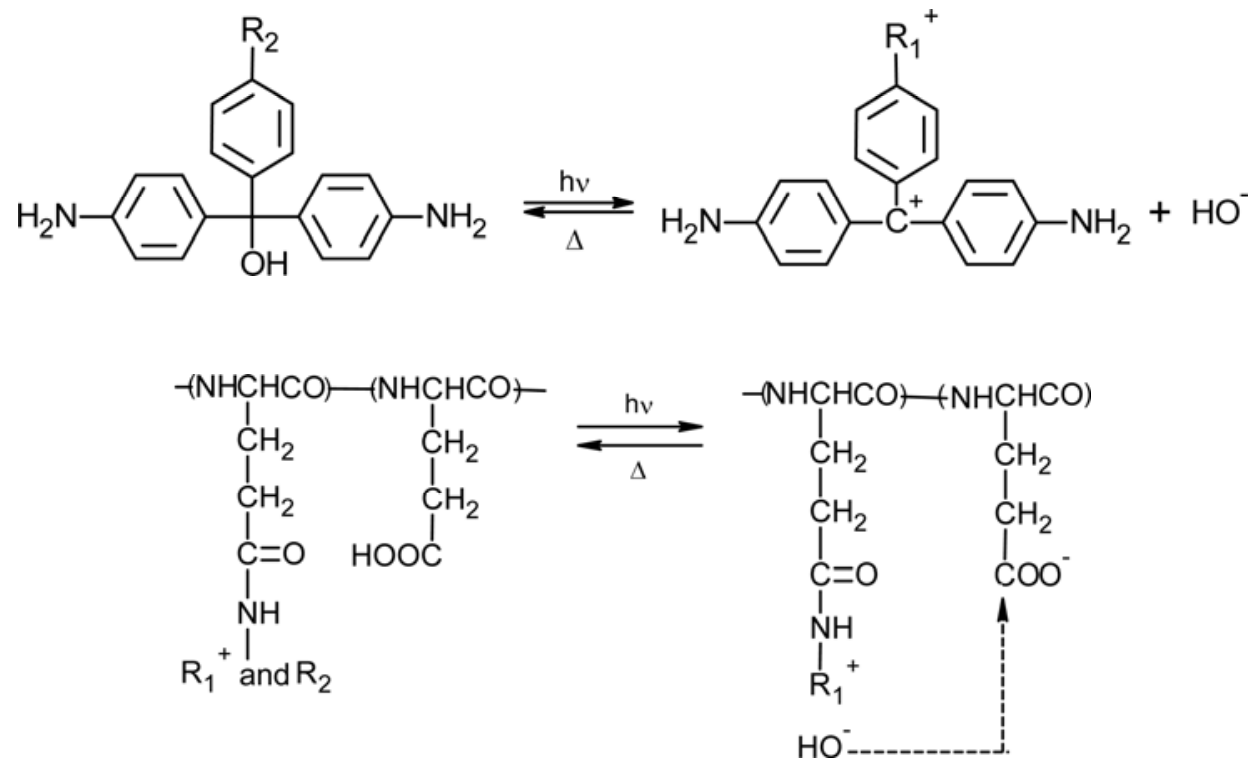


A further improvement in the photo-responsiveness of PGA membranes was obtained by using triarylmethane leucocyanide groups (pararosaniline leucocyanide moieties) in the side chains [45]. Upon UV irradiation, pararosaniline leucocyanide groups photo-dissociate and the electrostatic repulsion among cationic side chains induces the $\alpha$-helix $\rightarrow$ random coil transition of PGA membranes with $38.3 \%$ parosaniline leucocyanide moieties at $\mathrm{pH}$ 5.3. This transition results in an increase of the permeability coefficient of $\mathrm{KCl}$ across the above mentioned membrane by a factor 16 , while the change in the degree of membrane hydration was around $300 \%$ on a 30 minutes light irradiation. A full recovery of the initial values of both permeability and hydration was obtained after a dark adaptation of 15 hours. In this case the $\mathrm{pH}$ was not changed as the photo-irradiation determines just the dissociation of triarylmethane leucocyanide in triarylmethane cations and $\mathrm{CN}^{-}$ions, thus one of the main factors for the measured permeability coefficient is the increase in the free volume of the membrane due to the photo-induced swelling.

An example of photo-regulated permeability across a membrane by photo-induced conformational change of the polypeptide chains without any concomitant change in electrostatic repulsion along the polypeptide chain was achieved by Aoyama et al. [46,47]. They synthesized a new polyvinyl/ polypeptide graft copolymer composed of a photo-responsive copolypeptide branch from $\beta$-p-phenylazobenzyl L-aspartate and $\beta$-benzyl L-aspartate attached to a poly(butyl methacrylate) backbone. They found that the permeation rates (in $\% \mathrm{~h}^{-1}$ ) of some polar and non-polar solvents across the membrane (30 $\mu \mathrm{m}$ thick) increased with UV irradiation and were suppressed on irradiation with visible or with dark adaptation. In particular, the permeation rates increased by a factor ranging from 1.5 to 3.7 with a maximum value for the permeation rate of mandelic acid across the membrane immersed in trimethyl phosphate, which was 5.7 times higher than that in the dark. The photo-induced permeability changes were correlated to the conformational change of the polypeptide chains in the membrane as confirmed by circular dichroism, CD, spectra. In fact, the UV irradiation changed the sign of the CD band within 15 min (the positive CD band at $215 \mathrm{~nm}$ change in a negative CD band centered at $222 \mathrm{~nm}$ ), indicating the inversion of the helix sense of the polypeptide from left-handed to right-handed. The original CD profile could be recovered by irradiation ( $5 \mathrm{~min}$ ) with visible light or by dark adaptation (5 days).

The introduction of photo-responsive units in supramolecular systems may be important for their practical applications. Higuchi and Kinoshita $[48,49]$ synthesized and characterized a photo-responsive amphiphilic polypeptide formed by two amphiphilic $\alpha$-helical polypeptides, poly[ $(\gamma$-methyl L-glutamate)-co-(L-glutamic acid)], bringing an AZB moiety which was responsible of changes of aggregate structure in aqueous solution upon irradiation with UV light. In particular, when the polypeptides were incorporated into lipid membranes, they formed transmembrane bundle in the dark, acting as an ion-permeable pore through the membrane. The trans $\rightarrow$ cis photo-isomerization of the AZB linkers induced reversible changes in the pore structure allowing the photo-regulation of ion-transport across the membrane. The polypeptides self associated in water to form globular aggregates with an average diameter of $10 \mathrm{~nm}$ in dark conditions. Over a certain light intensity threshold the trans $\rightarrow$ cis photo-isomerization of the AZB linkers induced a bending of polypeptide rod and a consequent structure disaggregation of globular aggregates in smaller and disordered ones (around $3 \mathrm{~nm}$ ). 


\section{Light-Switching Functions}

Light can be considered as a clean stimulus that allows remote control without physical contact or a mechanical apparatus. It is attractive because it enables one to change the geometry and dipole moment of photo-switching molecules causing macroscopic variations of molecularly organized structures by small perturbations. These changes can affect final properties such as wettability, permeability, charge, 3-D shape, color, binding, and alignment. A fine-tuning of these changes can be done through a series of sophisticated techniques listed in Table 1 [50].

Table 1. A list of some techniques used to monitor morphology and property changes due to photo-irradiation.

\begin{tabular}{llc}
\hline Technique & Property & Reference \\
\hline UV-Vis spectroscopy & Isomerization & {$[51]$} \\
Ellipsometry & $\begin{array}{l}\text { Variation of the average thickness of the sample } \\
\text { in fair agreement with the calculated geometries } \\
\text { of the molecules. }\end{array}$ & {$[52]$} \\
& Switching in real time under ambient conditions & {$[53]$} \\
$\begin{array}{l}\text { Surface plasmon resonance } \\
\text { spectroscopy }\end{array}$ & $\begin{array}{l}\text { Switching wetting of the surfaces } \\
\text { Contact angle measurements } \\
\text { Adsorption of molecules/particles } \\
\text { from solution }\end{array}$ & Control of adsorption on surfaces \\
Atomic force microscopy & Switching in individual molecules & {$[50]$} \\
Kelvin probe measurements & Changes in the work function of functionalized & {$[50]$} \\
Measurements of electrical & surfaces & Azobenzene switching controls electrical \\
properties & properties of SAMs & {$[50]$} \\
Electrochemical methods & Quantitative isomerization by cyclic & {$[55]$} \\
Surface-enhanced Raman & voltammetry & {$[56]$} \\
spectroscopy & Isomerization on the surface & \\
\hline
\end{tabular}

\subsection{Light-Driven Wettability}

The wettability is a surface property detectable by contact angle, CA, measurements. The apparent contact angle is a result of attractive and repulsive interactions at the solid/liquid/gas interfaces, expressed by polar and non-polar contributions to the overall surface free energy [57]. Based on Young's equation, hydrophilicity conventionally refers to CA of less than $90^{\circ}$ on solid surfaces, while hydrophobicity refers to CA higher than $90^{\circ}$. However, this distinction appears to be too simplistic if one considers that the apparent contact angle depends on both the surface chemistry and morphology. Then, membranes prepared from chemically analogous compounds can exhibit different wettability depending on the degree of surface roughness.

Considering light-driven systems, the variation of dipole moment associated to the trans-isomer in azo-switching compounds and to the mero form in spiropyran derivates can produce dramatic changes in surface free tension, resulting in enhanced surface wettability. 
It has been observed that a variation of $10^{\circ}$ can be induced on azo-functionalized smooth and flat surfaces by photo-isomerization [58]. Tylkowski et al. [59] proposed a study about the light-driven wettability of novel asymmetrical poly(vinyl alcohol)-co-ethylene membranes blended with azobenzene polymers. A reversible variation of wettability $\left(\theta_{E}-\theta_{Z}=26^{\circ}\right)$ was estimated as a consequence of dramatic changes in surface roughness moving from isomer $\mathrm{E}$ to isomer $\mathrm{Z}$. An increase in hydrophilicity was ascribed to the migration of azo polymer towards the top surface as well as to the conformational change in co-polymer caused by photo-irradiation.

Polymers containing spiropyran moieties have been grafted onto membrane surfaces, causing reversible wettability-switching [60] and protein adhesion [61]. Similarly, Vlassiouk and coworkers [62] fabricated nanoporous alumina membranes bringing spiropyran-terminated linkers (Figure 7).

Figure 7. UV-Vis induced changes in wettability (Adapted from Vlassiouk [62]).
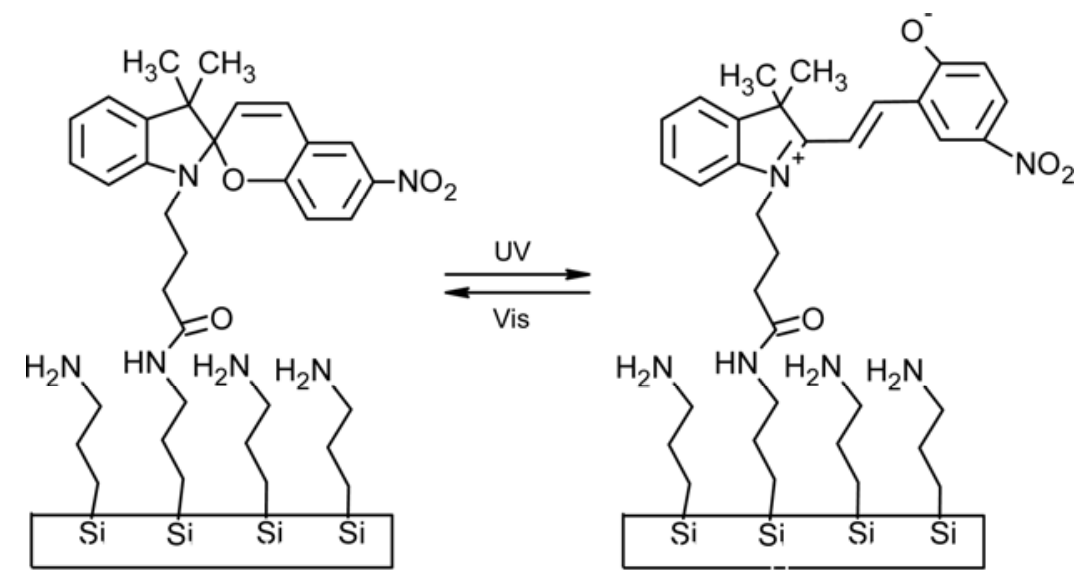

Upon exposure to UV light, a reversible switching from non-polar to polar form produced higher wettability allowing water and ions to diffuse through the pores. In this case photo-chromic molecules acted as on/off valves via reversible wetting mechanisms.

Also, photo-isomerization of diarylethene molecules has been demonstrated to direct the surface wettability moving from CA of $163^{\circ}$ to $\mathrm{CA}$ of $120^{\circ}$ [63].

Photo-switchable nanoporous multilayer films have been realized anchoring fluorinated AZB molecules, 7-[(trifluoromethoxyphenylazo)phenoxy]pentanoic acid, on a film prepared from poly(allylaminehydrochloride) and $\mathrm{SiO}_{2}$ via layer-by-layer techniques. Changes in dipole and surface roughness addressed the surface at hydrophilic and superhydrophilic zones using selective UV irradiation through an aluminum mask [64].

Switching wettability is an attractive issue with the construction of molecular shuttles [65]. Light-driven motion of individual droplets is a very striking item, if one considers that conventional fluid control components, such as valves and pumps, are not easily scalable to the small dimensions of the future fluidic chips $[58,66,67]$. Photo-isomerization of AZB-active surfaces has been demonstrated to shift millimeter liquid droplets along pathways under a gradient in surface free energy generated via imbalance of contact angles on both the edges of the droplets, Figure 8 [68].

However, surface hysteresis and surface defects could cause the liquid droplet to not move itself under spatially controlling UV/Visible irradiation. Light-driven motion of the droplet can be induced when the forces exceed the droplet pinning on the smooth surface. This needs the establishment of a 
gradient of wettability by irradiating one-half of the droplet with UV light and the other half with visible light (Figure 8). When the forces go over the hysteresis, the droplet will be pulled towards UV irradiation if the advancing contact angle of half droplet with $c i s$-isomers $\left(\theta_{\mathrm{adv}}^{\mathrm{UV}}\right)$ is lower than the receding contact angle of half droplet with trans-isomers $\left(\theta_{\text {rec }}{ }^{\text {vis }}\right)$.

Figure 8. Photo-driven motion of individual liquid droplets (Adapted from [68]).
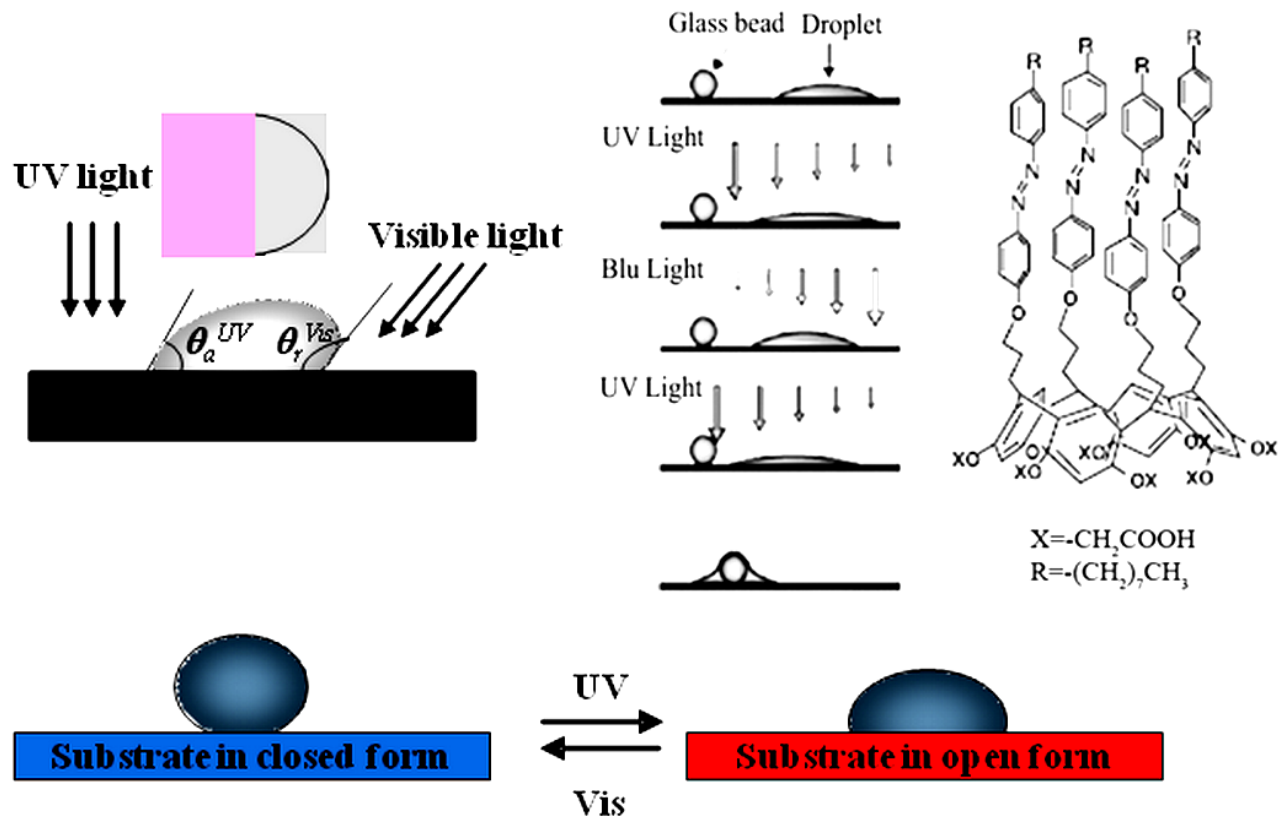

This means that light-induced contact angles should be greater than contact angle hysteresis ( $\left.\Delta \theta=\theta_{\mathrm{adv}}-\theta_{\mathrm{rec}}\right)$ in the trans state [69]. In this respect, it is instructive to describe the equations that express the forces for the light-driven liquid motion. The unbalanced Young's force for a section of the droplet of width $\mathrm{dx}$ is given by

$$
d F_{y}=\left[\left(\gamma_{S V}-\gamma_{S L}\right)_{U V}-\left(\gamma_{S V}-\gamma_{S L}\right)_{V I S}\right] d x
$$

where $\gamma_{S V}$ and $\gamma_{S L}$ are the surface free energies of the solid-vapor and solid-liquid interfaces after UV or visible irradiation of the surface and $d x$ is the thickness of the section of the droplet. If $\theta_{v i s}$ and $\theta_{U V}$ represent the local contact angles at the edges on the two sides of the droplet, then, Equation 1 can be written as

$$
d F_{y}=\gamma_{L V}\left(\cos \theta_{A D V}-\cos \theta_{R E C}\right) d x
$$

where $\gamma_{L V}$ is the surface free energy of the liquid-vapor interface. Therefore, the net force $\left(F_{y}\right)$ on the droplet can be expressed by the difference in the advancing and receding contact angles on the two sides of the droplet and by integrating Equation 2 over the width of the droplet $(w)$.

$$
F_{y}=w \gamma_{L V}\left(\cos \theta_{A D V}^{U V}-\cos \theta_{R E C}^{V I S}\right)
$$

\subsection{Light-Adaptative Membrane Gates}

Valved-membranes are considered as smart artificial channels for selective and programmable mass transfer, including ions, liquids and gases. The possibility of programming molecular transport for 
ions, liquids, metals and gases in response to photo-irradiation opens the way to build up miniaturized nanodevices including (bio)sensors, autonomous drug-delivery systems, microfluidic valves and flow switches, 'lab-on-a-chip' systems, (bio)fuel cells and so on. Different successful approaches to realize light-driven membrane pores have been proposed over the years and hereafter are illustrated.

\subsubsection{Photo-Controlled Ion Permeation through Membranes Gates}

Poly(styrenesulfonate) and a polyacrylamide copolymer containing a photo-chromic chromophore, 2-nitro-4'-methoxyazobenzene, have been cast via layer-by-layer on porous alumina in order to form light-valved membranes [70]. In this case, an increase of 1.6 times in $\mathrm{SO}_{4}{ }^{2-}$ permeability has been observed under UV irradiation, suggesting a strong sensitivity of the pore size to the voluminous expansion and contraction of the azo compound. Similarly, photo- and thermo-responsive membrane gates have been realized by introducing a spirobenzopyran residue into $\mathrm{N}$-isopropylacrylamide-based hydrogels [71]. The precision to regulate on a microscale the membrane allowed the construction of light controllable devices or microfluidics (Figure 9).

Figure 9. Light-controllable devices for microfluidics.
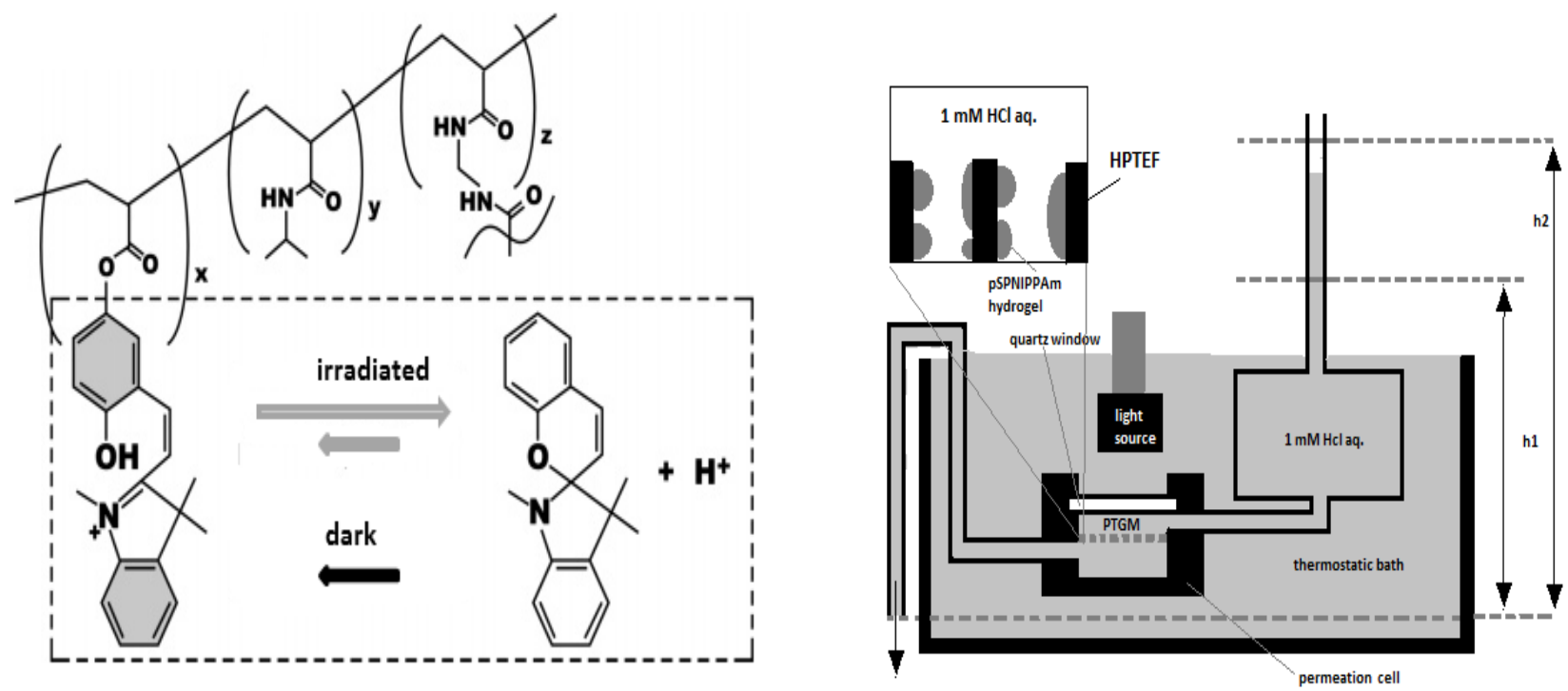

Alternatively, photo-responsive compounds have been covalently anchored to the walls of membrane pores in order to leave enough free volume to motional freedom and, then, to isomerize [72-74]. Also, AZB derivatives have been anchored inside magadiite, causing a reversible change in $d$-spacing of $0.6 \AA$ upon UV-Vis irradiation [75]. Hexagonal mesoporous silica has been doped in 1,2-bis(4-pyridyl)ethylene solutions [76]. In this case, switchable moieties have been preferred to layered polymers for realizing 3D nanocomposite hybrid structures through which mass transfer can be controllated easily.

Liu and coworkers [77] have proposed the synthesis of surfactant-directed self-assembly of a novel photo-responsive azobenzene-containing organosilane, 4-(3-triethoxysilylpropylureido) azobenzene, into an ordered, periodic silica framework to make photo-responsive nanocomposites. A variation of 
pore size of $6.8 \AA$ together with a significant change in the dipole moment (0-3D) suggested these hybrid systems to be promising ion-channel membranes.

Similar systems have been processed by using ferrocene dimethanol or ferrocene dimethanol diethylene glycol as a molecular probe [78]. In particular, the steady-state oxidative currents at constant potential was monitored for the reactions taking place on the working electrode surface (Figure 10).

Figure10. Photo-responsive nanocomposites proposed in [78].

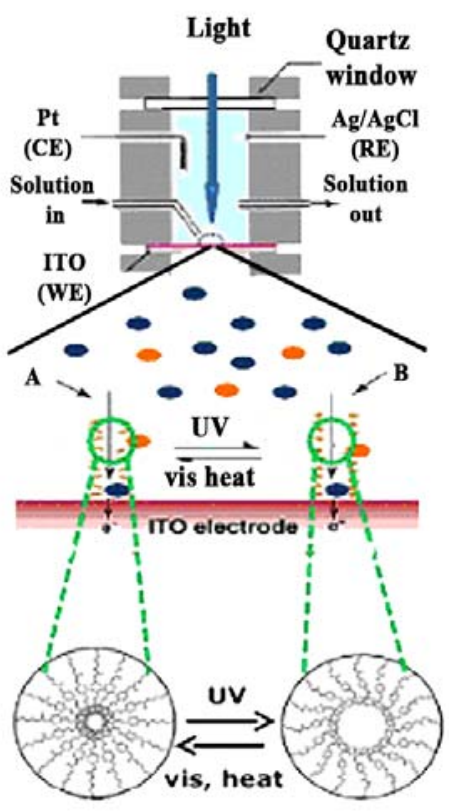

The build up of valved membranes is one of the most attractive issues also in the area of biotechnology, if one considers the possibility to command biological functions through artificial light-sensitive ligands. The literature refers to some chemical modifications to physiologically relevant ion channels that make them light-sensitive enabling them to work in an "artificial sense" [79]. Specifically, nicotinic acetylcholine receptor (Figure 11a), gramicidin A (Figure 11b), a voltage-gated potassium channel (Figure 11c), an ionotropic glutamate receptor (Figure 11d), and $\alpha$-haemolysin (Figure 11e) have been considered for optical manipulation with a high degree of spatial and temporal control. In the first case, a light-gated nicotinic acetylcholine receptor uses a photo-switchable tethered agonist conjugated to the channel surface via an AZB linker such that the trans isomer activates the channel (Figure 11a). Figure 11b shows a light-gated gramicidin A using a photo-switchable tethered ammonium ion pore blocker conjugated to the C-terminal ethanolamide via AZB linker such that the cis isomer blocks the channel. In the light-gated potassium channel the photo-switchable tethered blocker is an ethyl ammonium ion pore conjugated to the channel surface via an azobenzene linker such that the trans isomer blocks the channel (Figure 11c). An example of light-gated ionotropic glutamate receptors is depicted in Figure 11d and uses a glutamate analogue conjugated to the channel surface via AZB linker such that the cis isomer activates the channel. Finally, the light-gated $\alpha$-haemolysin is functionalized with a sulfonated azobenzene conjugated to the channel lumen such that the trans isomer impedes conductance more than the cis isomer. 
In all cases a straightforward functionalization of the chromophore changes the wavelength sensitivity, affecting the thermal stability, extending the photo-conversion between isomers and reducing the photo-toxicity often associated with UV irradiation for biological systems.

Figure 11. Light responsive ion channels mimicking "artificial sense".

(a)

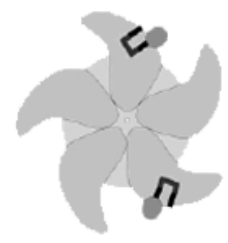

(c)

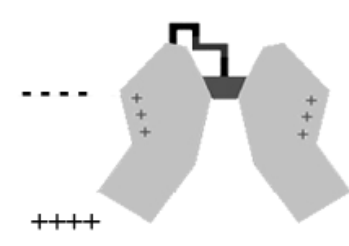

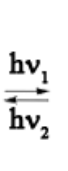

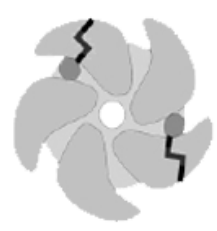

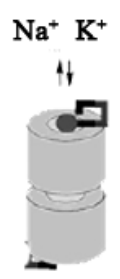
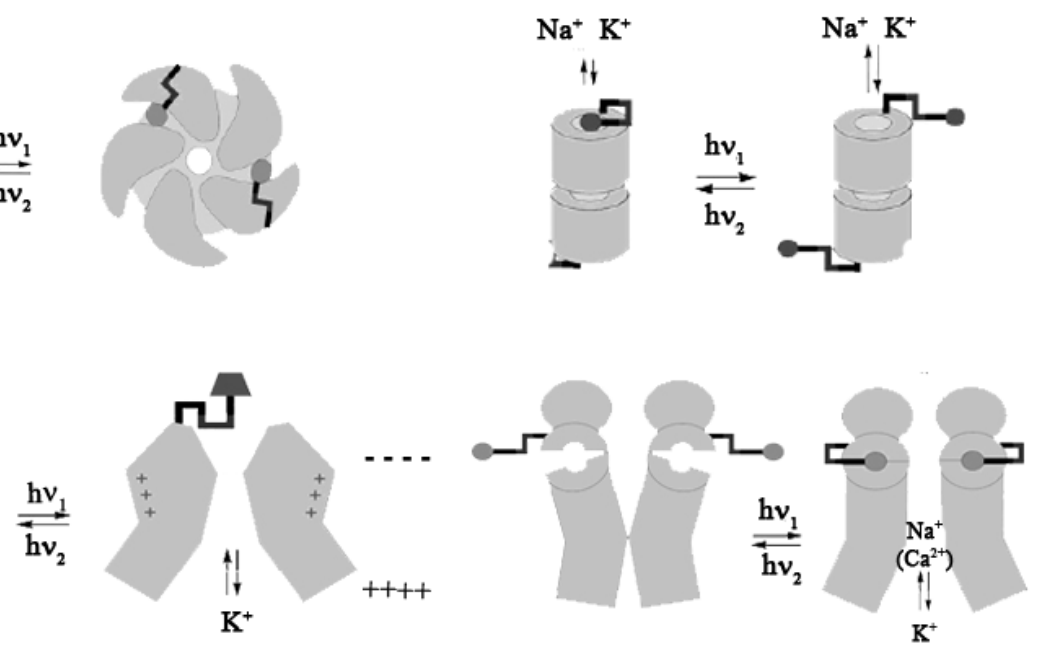

(e) (b)

(d)

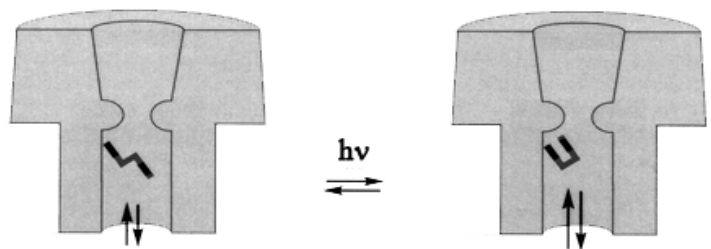

Sata et al. [80] reviewed studies on anion exchange membranes and electrodialysis methods to permeate specific anions through the membranes, also by photo-irradiation.

It is well known that viologen compounds such as 1,10-dimethyl-4,40-bipyridinium dichloride are reduced to monocation radical and then biradical by the irradiation of UV around $320 \mathrm{~nm}$ as shown in Figure 12. Namely, dication changes in monocation and then the monocation changes into uncharged compounds in a reversible way.

Figure 12. Reversible reduction and oxidation of a viologen moiety of the anion exchange membrane.
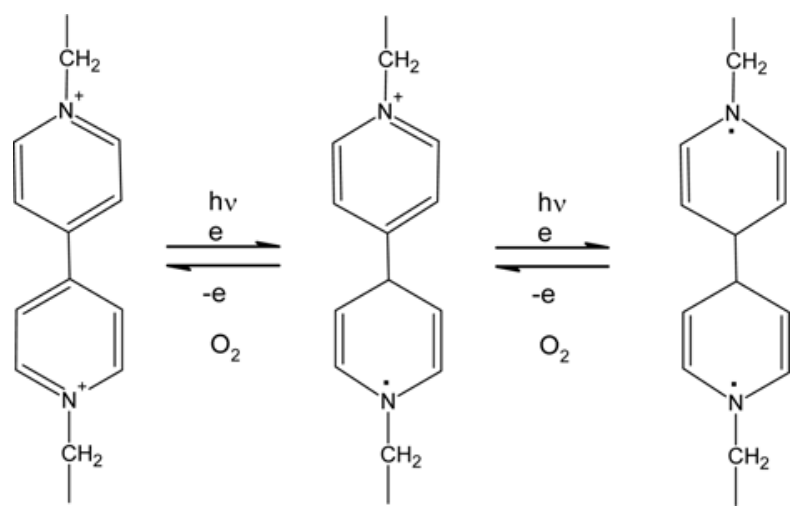
When a cross-linked copolymer membrane bringing chloromethyl groups reacts with 4,40-bipyridine, pyridinium groups are introduced as anion exchange groups and cross-linking reaction occurs due to diamine.

When light from a xenon lamp is irradiated on this membrane in pure water, $0.50 \mathrm{~N}$ sodium chloride solution or other salt solutions, new absorbance peaks at 406 and $615 \mathrm{~nm}$ appear, which are based on the formation of monocation radical - the color of the membrane changes from slightly pale yellow to deep blue - and these peaks decrease by further irradiation, which means the formation of biradical $[81,82]$. On the other hand, the blue color of the membrane bleaches by diping it into non-degassed salt solution or exposure to air. Namely, dications, monocation radicals and biradicals are reversibly formed in the membrane by photo-irradiation or exposure to oxygen, which means that the amount of anion exchange groups can be controlled by photo-irradiation. The membrane should shrink or swell by photo-irradiation and then pore size of the membrane is expected to change.

Membrane having a viologen moiety as anion exchange groups showed the change of permselectivity of anions (as $\mathrm{SO}_{4}{ }^{2-}$ or $\mathrm{Br}^{-}$) when electrodialysis was carried out in the presence of photo-irradiation after the membrane had been previously irradiated for a given period [82]. In particular, the transport number of anions apparently decreases by photo-irradiation when compared with that of the membrane without irradiation. This is thought to be due to surface shrinking and decrease in hydrophilicity of the membrane, because of the decrease in anion exchange groups.

The transport number between anions through the membrane having an AZB moiety is expected to change due to the trans $\rightarrow$ cis transformation of the moiety by photo-irradiation [83].

Recently, Byrne et al. [84] have synthesized two photo-responsive linear polymers of different molecular weights based on benzospiropyran, BSP, and polymethylmethacrylate, PMMA. As the merocyanine isomer, $\mathrm{MC}$, of BSP has a phenolate site to which transition metal cations can bind (such as $\mathrm{Cu}^{2+}$ and $\mathrm{Co}^{2+}$ ) and this reversible process can be optically controlled, these systems have been used to bind transition metal ions. The binding of a transition metal ion requires two units of the $\mathrm{MC}$ isomer to form the most thermodynamically stable $\mathrm{MC}_{2}-$ metal ion complex [85,86]. Fries et al. [87] recently published the synthesis of a chemo-responsive co-polymer of PMMA and spiropyran methyl methacrylate and demonstrated that different metal ions give rise to unique colorimetric responses that are dependent on the amount of spiropyran co-monomer contained in the polymer backbone.

Zhou [72] described the metal chelation mechanism formation and disassociation as follows: $\mathrm{BSP}+\mathrm{MC}+\mathrm{Cu}^{2+} \rightarrow \mathrm{MC}_{2}-\mathrm{Cu}^{2+}$. The $\mathrm{MC}$ isomer reacts readily with the $\mathrm{Cu}^{2+}$ ions as it is thermally formed from BSP and this formation process is the rate-determining step in the reaction sequence, with the $\mathrm{Cu}^{2+}$ ion concentration having little effect on the reaction rate.

Byrne et al. analysed UV-Vis spectra of their BSP-PMMA after addition of $\mathrm{Cu}\left(\mathrm{NO}_{3}\right)_{2}$ solution and observed, after the formation of the corresponding complex, significant rearrangements of the polymer chains which affect the physical and chemical properties of the system. This process is completely photo-reversible, as when [MC-PMMA $]_{2}-\mathrm{Cu}^{2+}$ is irradiated with white light the MC photo-isomerizes back to the closed BSP isomer, ejecting the $\mathrm{Cu}^{2+}$ ion. 


\subsubsection{Photo-Controlled Organic Liquids Permeation through Membrane Gates}

Porous membranes with polymer brushes have the advantages of mechanical strength and quick response to an external signal over the hydrogel membrane. In addition, the signal-responsiveness of permeation through a porous membrane is apparently opposite to that estimated through hydrogel membranes.

Hydrogels contract or expand in response to environmental conditions such as $\mathrm{pH}$, temperature, photo-irradiation, solvent, or chemicals. The hydrogel swells in the ionized state to facilitate permeation of solutes, and deswells in the de-ionized state to suppress permeation (Figure 13, top). On the other hand, several polymer-brush membranes have been synthesized, in which pores turn open or close in response to environmental conditions. In particular there are several examples of photo-responsive porous membrane devices (Figure 13, bottom) [88].

Figure 13. Regulation of water and solute permeation through a hydrogel membrane and a polymer brush-grafted porous membrane.

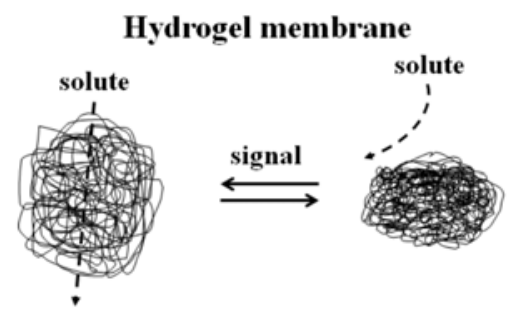

Polymer brush membrane

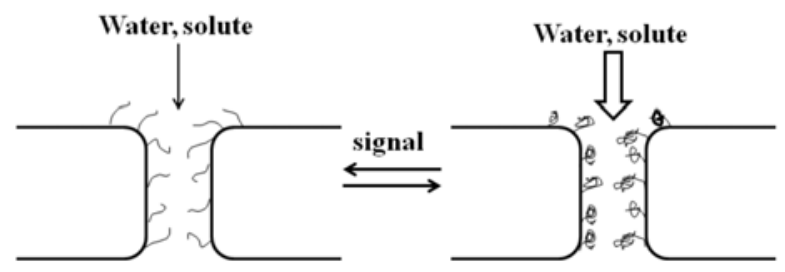

Irie et al. [89,90] reported the solubility alteration, in cyclohexane, by photo-irradiation of polystyrene carrying spiropyran groups in the side chains. The permeation of organic liquids through the glass filter with and without surface grafts was studied with and without photo-irradiation. The glass filter with the copolymer grafts changed the permeability of toluene. On the contrary, the permeation of toluene through the same glass filter without grafts was not affected by photo-irradiation.

The permeability results were obviously related to the solubility of the graft copolymer. The absence of solubility change in $N, N$-dimethylformamide, DMF, led to the absence of permeability change by photo-irradiation. The copolymer graft in either the zwitterionic or the neutral state was soluble in DMF, so that the graft chains were well extended in DMF to close pores on the glass filter and the DMF permeation was irrespective of photo-irradiation. On the other hand, in a non-polar solvent such as toluene, the zwitterionic merocyanine form shows contracted graft chains and, consequently, open pores with an increased permeation of toluene. Because the neutral spiropyran 
form was soluble in toluene, the graft chains were extended to cover the pores of the glass filter, thus reducing the permeation of toluene in this case.

Recently, Balazs et al. [91] showed by theoretical and computational modeling that the application of an external gradient in light intensity causes the dynamic reconstruction of a three-component membrane. In particular, they found that the photo-sensitive domains preferentially reorient along the gradient direction. They also found that this imposed gradient effectively controls the transport of a non-reactive component within the membrane. This non-reactive component migrates along the gradient intensity towards the higher values of intensity and the speed of this migration is defined by the actual value of the gradient.

\subsubsection{Permselectivity of Gases through Photo-Switching Membrane Gates}

Weh et al. [92] observed the permeation characteristics of a membrane made from AZB in a polymethacrylate matrix. The photo-isomerization of AZB molecules causes changes in their molecular size and geometry as well as in their dipole moment. It can be expected, therefore, that the transport behavior of gases through such a membrane can be influenced.

It is known that bilayer membranes, which contain AZBs, can change their ion permeability by irradiation [93]. Balasubramanian et al. [94] reported the photo-induced variation of the electric resistance of a membrane, which consists of AZB containing water/oil microemulsions. By trans/cis switching of AZB in Langmuir-Blodgett films, the electric conductivity can be changed [95].

A photo-induced change of the potential and ion permeability in a polyvinyl chloride membrane, which contains AZB modified crown ethers, has been described by Anzai et al. [96].

Weh et al. [92] prepared polymethacrylate membranes, which contained AZB, as thin films supported on porous ceramic carriers. They measured the flux rates and trans/cis permselectivities for hydrogen, methane, n-butane, sulfur hexafluoride, and methanol. For a polymethacrylate membrane, which contains chemically bound AZB, characteristic changes of the permeation properties have been found by photo-chemical trans/cis switching of the AZB.

Among the three types of polymer membranes tested, only the membrane with AZB chemically bound to the side chain of the polymethacrylate showed a modified permeation behavior for different gases and methanol vapor when the AZB was photo-chemically switched into the trans or cis state. Due to the switching effect of the mass transport, this type of membrane acts like a microvalve. Possible applications of this membrane could be in microreactors for the controlled dosing of the educts or for the light controlled removal of products.

\section{Photo-Responsive Membranes: Classes of Adaptive Materials and Their Applications}

\subsection{Photo-Responsive Polyelectrolyte Multilayer Membranes}

Polyelectrolyte multilayer membranes present an interesting suitability for gas/salt separations [97], pervaporation from water/organic solvent mixtures [98-100], and reverse osmosis membranes [101,102]. Recently, there has been an increasing interest for this type of membranes also as gating membranes [103-109] considering that a current challenge is the construction of reversible 
valved-membranes, through which ion flow [110], capture and release of molecular targets [111] and energy transfer can externally be triggered.

Kumar et al. have prepared photo-responsive multilayered membranes on a porous alumina support using layer-by-layer deposition of a negatively charged poly(styrenesulfonate) and positively charged polyacrylamide copolymer containing 2-nitro-4'-methoxyazobenzene (PNA, Figure 14), since efficient photo-chemical control of ion flow was expected through them [70].

Figure 14. Polyacrylamide copolymer containing 2-nitro-4'-methoxyazobenzene, PNA, used in [70].

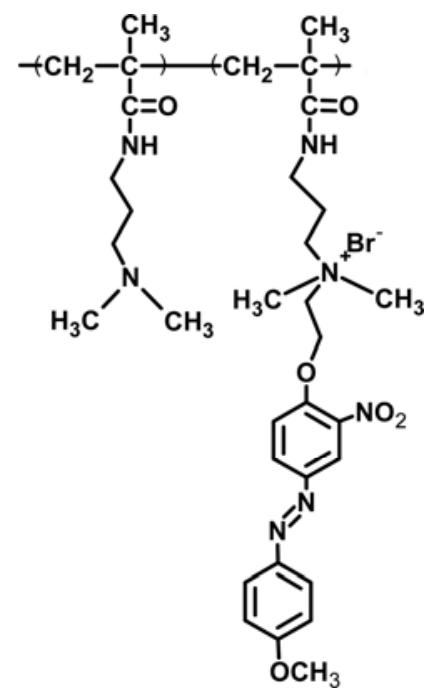

Nanoporous alumina substrates were also used to fabricate a photo-responsive polyelectrolyte membrane by using spin-coating electrostatic self-assembly, a rapid technique which allows a precise control of the film thickness on a solid substrate [70]. Unblocked free pores (with a size of $\sim 0.02 \mu \mathrm{m}$ ) were formed on bottom part of poly(styrenesulfonate)/PNA bilayers, whereas the top surface of the porous alumina membrane was completely covered with the pinhole-free smooth film.

UV irradiation $\left(\lambda=360 \mathrm{~nm}, \mathrm{P}=2 \mathrm{~mW} / \mathrm{cm}^{2}\right)$ on the polyelectrolyte membrane induced trans $\rightarrow$ cis isomerization of the nitroazobenzene species and enlarged pores inside the membrane as a result of the cis bent molecular structure, thus making sulfate and chloride ion transport easier. Subsequent exposure to visible light $\left(\lambda=450 \mathrm{~nm}, \mathrm{P}=100 \mathrm{~mW} / \mathrm{cm}^{2}\right)$ restored the original dense state of the membrane matrix, which in turn restrains the ion flow.

The permeability of the bulky $\mathrm{SO}_{4}{ }^{2-}$ ions was more sensitive to the channel sizes. The ion-permeation rate of $\mathrm{Cl}^{-}$ions increased only 1.2 times after $\mathrm{UV}$ irradiation of the polyelectrolyte membrane, whereas the one of the $\mathrm{SO}_{4}{ }^{2-}$ increased about 1.6 times.

\subsection{Photo-Responsive Polymer-Grafted Porous Membrane}

The photo-isomerization of photo-chromic groups incorporated into polymeric systems allows light-induced variations in polymer structure, conformation, and solvation because of the altered interactions between photo-chromic groups and polymer chains, solvent molecules, or polymer side 
groups. Thus, photo-reversible controlled solution viscosity [112], colloidal stability [113-115], surface wettability [116,117], solvent permeability [118,119] are some of the potential applications.

Park et al. grafted a spirobenzopyran methylmethacrylate copolymer (SPMMA/MMA) on a porous glass membrane filter (nominal pore size $=5 \mu \mathrm{m}$ ) to control permeation of organic liquid by photoirradiation [118]. After graft copolymerization, the surface wettability resulted altered, but no significant difference of wettabilities of graft-polymerized membrane was observed before and after UV-light irradiation. The permeation of $N, N$-dimethylformamide (DMF) through the grafted glass membrane did not depend on photo-irradiation. The permeability is obviously related to the solubility of the graft copolymer. The absence of a permeability change by photo-irradiation was attributed to the absence of solubility change of SPMMA/MMA copolymer in DMF by UV/Vis irradiation. The copolymer grafts in either the zwitterionic or neutral states of the pendant spirobenzopyran groups were soluble in DMF, i.e., the graft chains were well extended in DMF to close the pores of the glass filter with unchanged DMF permeation irrespective of photo-irradiation. On the contrary, a variation in the toluene permeation was observed in response to photo-irradiation. As the zwitterionic merocyanine form of the copolymer grafts is not soluble in toluene, the graft chains were in a bend state, thus increasing the pores on surfaces of glass filter and then the permeation of toluene (Figure 15).

Figure 15. Permeation rate of toluene with a naive representation of copolymer grafts of [118].

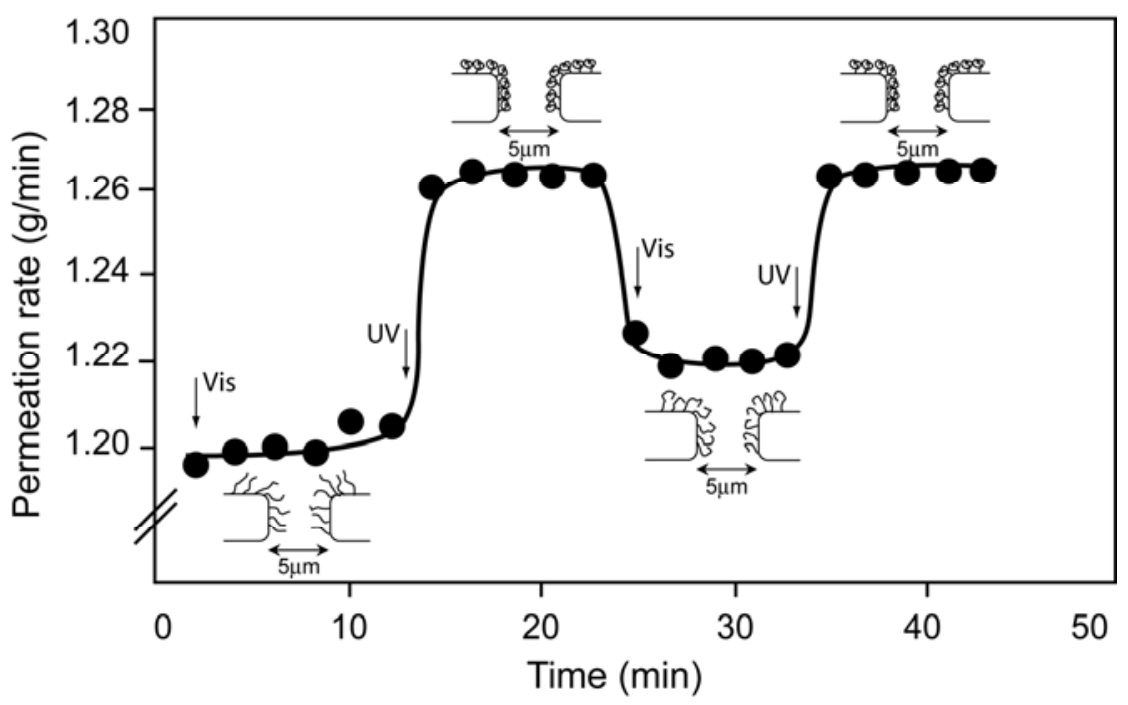

Colloidal silica particles modified with end-grafted spiropyran-co-methylmethacrylate polymer brushes show also light responsive aggregation behavior, whereas surfaces exhibit photo-actuated changes in wetting properties [115]. These core-shell silica colloids form stable suspensions in toluene when the spirobenzopyran pendants are in their closed, non-polar form. After exposition to UV irradiation $(\lambda=366 \mu \mathrm{m})$, a rapid aggregation and sedimentation follows (Figure 16) due to UV-induced photo-switching to the open, polar merocyanine isomer. Because the SP ring-opening reaction is highly sensitive to the local environment and interactions with solvent molecules, core-shell silica particles dispersion stability depends on solvent polarity. An appreciable UV enhancement of sedimentation rate was recorded for tetrahydrofuran, o-xylene, benzene, and toluene $0.5 \% \mathrm{v} / \mathrm{v}$ suspensions of $927 \mathrm{~nm}$ silica spheres. In particular, sedimentation was 1.1 times faster in 
tetrahydrofuran, 6 times faster in o-xylene, 16 times faster in benzene, and 335 faster in toluene. The largest photo-induced aggregation effect in a given solvent can be achieved through the optimization of SP content, e.g., $20 \mathrm{~mol} \%$ for toluene.

Figure 16. UV-induced aggregation and sedimentation of colloidal silica nanoparticles with spiropyran brushes.

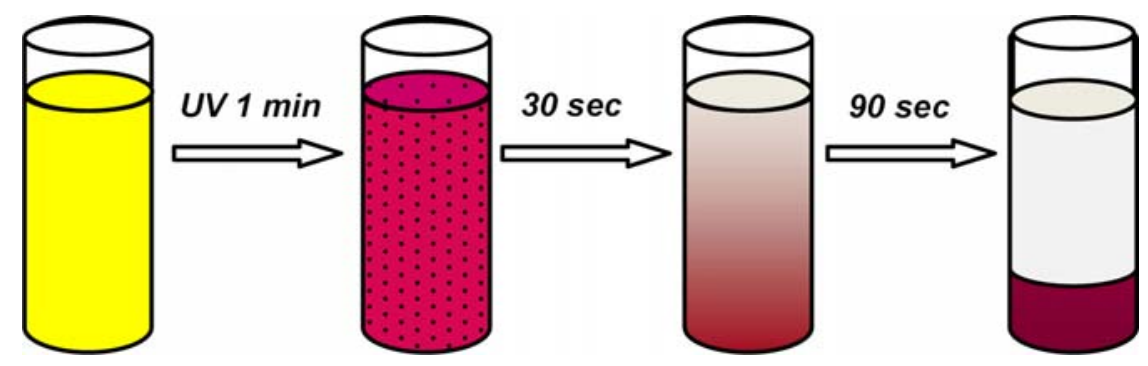

SP to MC conversion caused a significant attraction between particles suspended in a poor-solvent medium, resulting in a UV-induced flocculation as a consequence of the change in particle surface polarity. The sedimentation may be associated to interparticle association of MC and SP moieties into dimers, $\left(\mathrm{SP}_{n} \mathrm{MC}\right)_{m}$, and $\mathrm{MC}_{\mathrm{n}}$ intrachain complexes formed as products of photo-induced aggregation in $\mathrm{SP}(\mathrm{x})$-MMA copolymers [120]. $\mathrm{MC}_{\mathrm{n}}$ complexes are organized into stack structures having an antiparallel orientation of molecular dipoles that result in the appearance of an additional shoulder $(\lambda=545-550 \mathrm{~nm})$ in UV/Vis spectra, which are generally characterized by a main peak around $578-598 \mathrm{~nm}[115,120]$. The UV-induced flocculation process is fully reversible after visible light exposure $(\lambda>450 \mathrm{~nm})$ and agitation (short sonication for less than 1 min or vigorous shaking).

The rheological response of SP(20)-MMA-coated colloids was investigated upon alternating UV/Vis light irradiation. The viscosity of the $\sim 30 \% \mathrm{v} / \mathrm{v}$ toluene suspension of $927 \mathrm{~nm}$ core silica particles (with $25 \mathrm{~nm}$ thick SP(20)-MMA brushes) was reversibly modulated by $\sim 50 \%$ through successive irradiation with UV and visible light. The first UV/Vis treatment yielded slightly larger response than subsequent cycles, probably due to the difference between the initial equilibrium network structure and the one formed during shearing [115]. The UV-induced aggregation exhibits first-order kinetics and is significantly faster than visible-induced redispersion. This latter depends on combination of two relaxation processes with time constants differing by a factor of $\sim 10$ and suggests the formation of interparticle bonds with varying strength. The SP(20)-MMA-coated colloidal particulate dispersion viscosity increases as a consequence of photo-induced attractive interparticle interactions.

Kimura et al. applied a crown ether-spirobenzopyrans copolymer of methacrylate $(\mathrm{m}: \mathrm{n}=1: 1)$, Figure 17, to a macroporous membrane in order to photo-control solvent permeation $[121,122]$.

In copolymer 1 the isomerization induced by UV light irradiation of the spirobenzopyran moiety to the corresponding more polar zwitterionic form may cause an appreciable rheology change due to an increased merocyanine association. Thus, photo-isomerization brings polymer chain contraction/extension and interpolymer crosslinking. A blue shift of the merocyanine absorption indicates the formation of H-type aggregates [123]. UV-light irradiation on macroporous (pore size $10-100 \mu \mathrm{m}$ ) polyethylene membranes coated by the crown ether-spirobenzopyran copolymer leads to 
a significant decrease of the permeation rate of hexane through the membrane, due to increased hydrophilicity of its surface.

Figure 17. Chemical formula of crown ether-spirobenzopyrans copolymer of [121].

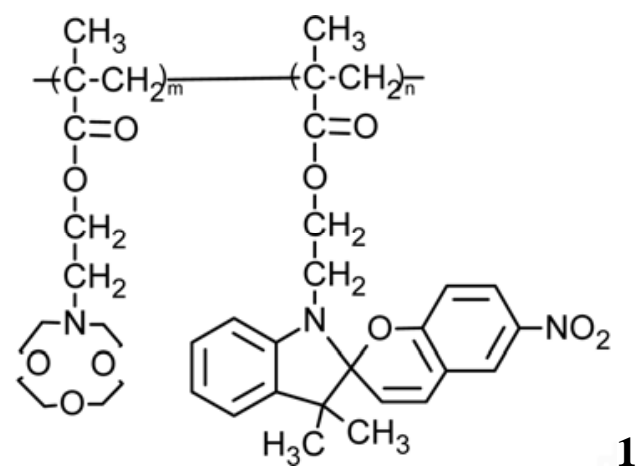

When visible light is irradiated on crown ether-spiropyran copolymer coated polyethylene membrane, the initial permeation rate value is regained by isomerization back to the electrically neutral spiropyran form. Conversely, the permeation of ethanol through the membrane is decreased by visible light due to a reduction in the apparent membrane pore size induced by the polymer chain extension and increased by UV light. There was no photo-response in the solvent permeation with uncoated polyethylene membranes, while similar photo-responses in the permeation rate of non-polar and polar solvents were attained with a sintered glass filter modified chemically by both silane-coupling reagents containing distinct crown ether and spirobenzopyran moieties [122].

Crown ethers present selective cation-complexing properties, especially for alkali and alkaline-earth metal ions [124,125]. The cation-complexing selectivity and sensitivity of crown ethers bearing a photo-chromic functional group can also be controlled and enhanced photo-chemically $[121,126]$. Thus, photo-chromic crown ethers, as crowned spirobenzopyrans 2-4 and bis-spirobenzopyrans 5, 6 (Figure 18), are used in metal ion extraction and membrane transport to photo-chemically controllable determination, separation, and sensing of monovalent alkali metal ions [126,127].

Figure 18. Chemical formula of photo-chromic crown ethers.

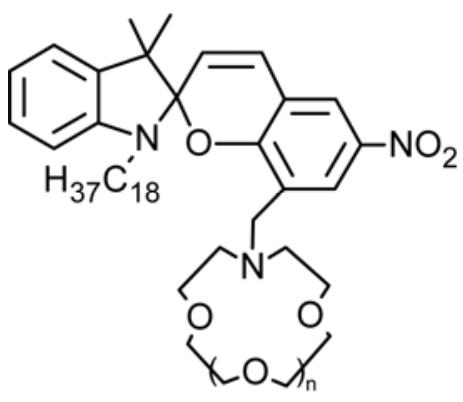

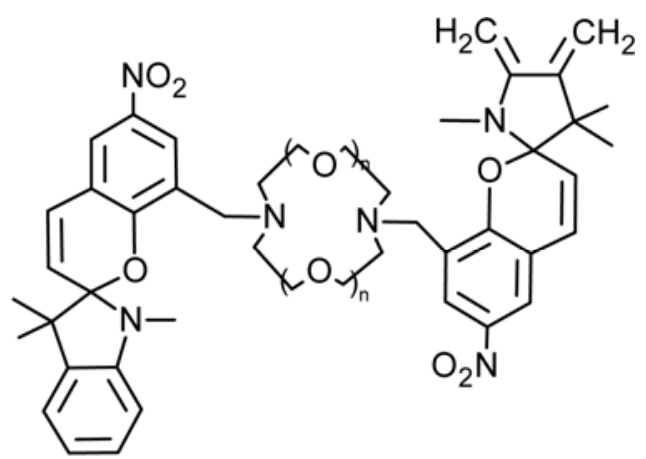

$$
\begin{aligned}
& 2 n=1 \\
& 3 n=2 \\
& 4 n=3
\end{aligned}
$$

\section{$4 \mathrm{n}=3$}$$
5 \mathrm{n}=1
$$$$
6 \mathrm{n}=2
$$ 
Crowned spiropyrans 2-4 can be photo-isomerized reversibly to corresponding crowned merocyanine by UV irradiation. Their ability to complex a particular metal ion increases by UV-light and decreases by visible-light irradiation or under dark conditions [127] (Figure 19).

Figure 19. Photo-isomerization of crowned spirobenzopyran.
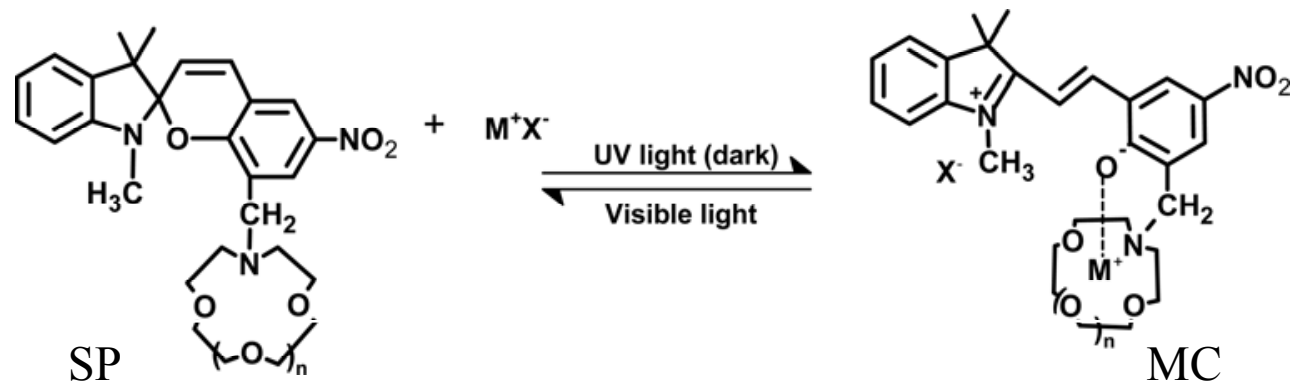

A high charge density on cations promotes specific ionic interactions between MC and metal ions, such as with $\mathrm{Li}^{+}$, which contribute to the isomerization because these intramolecular interactions are probably stabilized by six-member chelate formation of crown-ether-ring-nitrogen and phenolate-oxygen atoms with $\mathrm{Li}^{+}$. The cation-complexing ability and selectivity of crowned spiropyrans SP are obtained only if the crown ether cavity size matches the cation diameter. This accounts why $\mathrm{Na}^{+}$and $\mathrm{K}^{+}$hardly induce the isomerization. Upon visible light irradiation, the spiropyran form is retained, thus decreasing the $\mathrm{Li}^{+}$complexing ability, as confirmed by ${ }^{7} \mathrm{Li}-\mathrm{NMR}$ spectroscopy [126] and electrospray ionization mass spectrometry [127,128].

Multivalent metal cations, such as $\mathrm{Ca}^{2+}$ and $\mathrm{La}^{3+}$, preferably are complexed by incorporating more than one spirobenzopyran moiety into a crown ether ring $(5,6)$. UV induced photo-isomerization of crowned bis(spirobenzopyrans) increases the stability of $\mathrm{Ca}^{2+}$ and $\mathrm{La}^{3+}$ complexes because of the stronger ionic interactions between two phenolate anions of the merocyanine form and metal ions. On the other hand, visible light can switch the ion selectivity of 5, 6 from $\mathrm{La}^{3+}$ to $\mathrm{K}^{+}$.

\subsection{Photo-Responsive Molecularly Imprinted Membranes}

Molecular imprinting has been demonstrated to be a useful technique for the preparation of molecular recognition materials, which have specific binding sites for target molecules [129-135].

A typical molecular imprinting process usually involves the formation of a complex between a template molecule and a functional monomer via non-covalent interactions, e.g., metal-ion chelating interactions, hydrophobic interactions, hydrogen bonds and ionic interactions, or via reversible covalent bonds, ketal and acetal, Schiff base, or boronate ester. The monomer is subsequently copolymerized with a crosslinking monomer in the presence of a suitable porogenic solvent. After polymerization, the template is removed from crosslinked polymer network, leading to a molecularly imprinted polymer, MIP, with binding cavities complementary to the shape, size and functionality of the template. For the formation of defined recognition sites within MIPs, the structural integrity of the monomer-template assemblies must be preserved during polymerization to allow the functional groups of the polymer to be fixed in space in a stable arrangement that is complementary to the template. However, a polymer matrix must not only contain the binding sites in a stable form, but also be porous 
enough for easy access of the template (or other analytes) to these sites. Porosity is achieved by carrying out the polymerization in presence of a solvent (a porogen) [136-139].

Molecularly imprinted polymers have often been compared to antibodies, receptors, and enzymes, and also applied to various fields ranging from analysis to catalysis. Despite the tremendous progress made in the molecular imprinting field, many challenges still remain to be addressed, especially in the design of advanced MIP materials mimicking the biological receptors [140-142].

The rational use of certain special co-functional monomers, e.g., $N$-isopropylacrylamide, acrylic acid, and azobenzene monomers, in molecular imprinting together with the appropriate choice of amounts of crosslinkers allows obtaining responsive MIPs towards different stimuli such as temperature, $\mathrm{pH}$, and light [143].

Photo-responsive polymers are a promising route to switchable MIPs. In particular, incorporation of AZB moieties into polymers can result in materials that are photo-responsive [144-149].

Minoura et al. [150,151] described the first preparation of azo-containing MIP membranes with photo-regulated template binding properties by using a polymerizable derivate of AZB, p-phenylazoacrylanilide as the functional monomer, dansylamide as template and mixtures of tetraethylene glycol diacrylate and ethylene glycol dimethacrylate as cross-linkers. The affinity of dansylamide-specific recognition sites within these MIP membranes can reversibly be changed upon UV or visible light. In this system, binding activity and selectivity were not high, since the functional monomer may not form strong hydrogen bonds with the target molecule.

Marx-Tibbon and Willner, on the other hand, reported the use of another photo-responsive system for molecular-imprinting purposes. They used an acrylate derivatized merocyanine monomer for the imprinting of tryptophan in a molecularly imprinted membrane, which exhibited photo-controllable selective transport properties towards the imprinted amino acid [152].

Gong et al. [153] reported the fabrication of a photo-responsive MIP for photo-regulated release and uptake of caffeine by using 4-((4-methacryloyloxy)phenylazo)benzoic acid as the functional monomer. The trans $\rightarrow$ cis photo-isomerization properties of 4-((4-methacryloyloxy)phenylazo)benzoic acid are retained after incorporation into the rigid 3D crosslinked polymer matrix. The MIP material enabled to release and take up caffeine molecules upon irradiation at 365 and $440 \mathrm{~nm}$, respectively, as reported in Figure 20. The photo-regulated release of bound caffeine from the MIP material by $365 \mathrm{~nm}$ irradiation is attributed to the photo-induced trans $\rightarrow$ cis isomerization of AZB chromophores in the MIP receptor sites, resulting in a change in the receptor geometry. The host-guest interaction is therefore weakened, and the bound caffeine is released back into the solution. This can be viewed as an affinity switching of the MIP receptor sites from a high to a low level by photo-isomerization of their azobenzene chromophores. Irradiation of the MIP material at $440 \mathrm{~nm}$ after the completion of the photo-regulated caffeine release caused the uptake of caffeine back into the MIP material.

The photo-regulation process is generally reversible, but the extent of substrate release and uptake seems to decrease gradually. This may be caused by the slow deformation of the MIP receptors during the course of repetitive photo-switchings. The results of Gong's work also suggest the potential of stimuli-responsive MIP materials as smart chemicals and drug-delivery systems.

Later, Gong and coworkers [144,145] prepared photo-responsive molecularly imprinted hydrogels for the photo-regulated release and uptake of pharmaceuticals in aqueous media by using a water-soluble azo-functional monomer, 4-((4-methacryloyloxy)phenylazo)benzenesulfonic acid. 
$\mathrm{N}$-(4-hydroxyphenyl)acetamide, a common analgesic and antipyretic drug known as paracetamol was selected as the molecular template for the imprinting. In this work the authors showed that reorientation of the stimuli-responsive units within the imprinted receptor sites in the hydrogel matrix is sensitive to the nature of the cross-linker used.

Figure 20. Schematic photo-regulated release and uptake of caffeine.

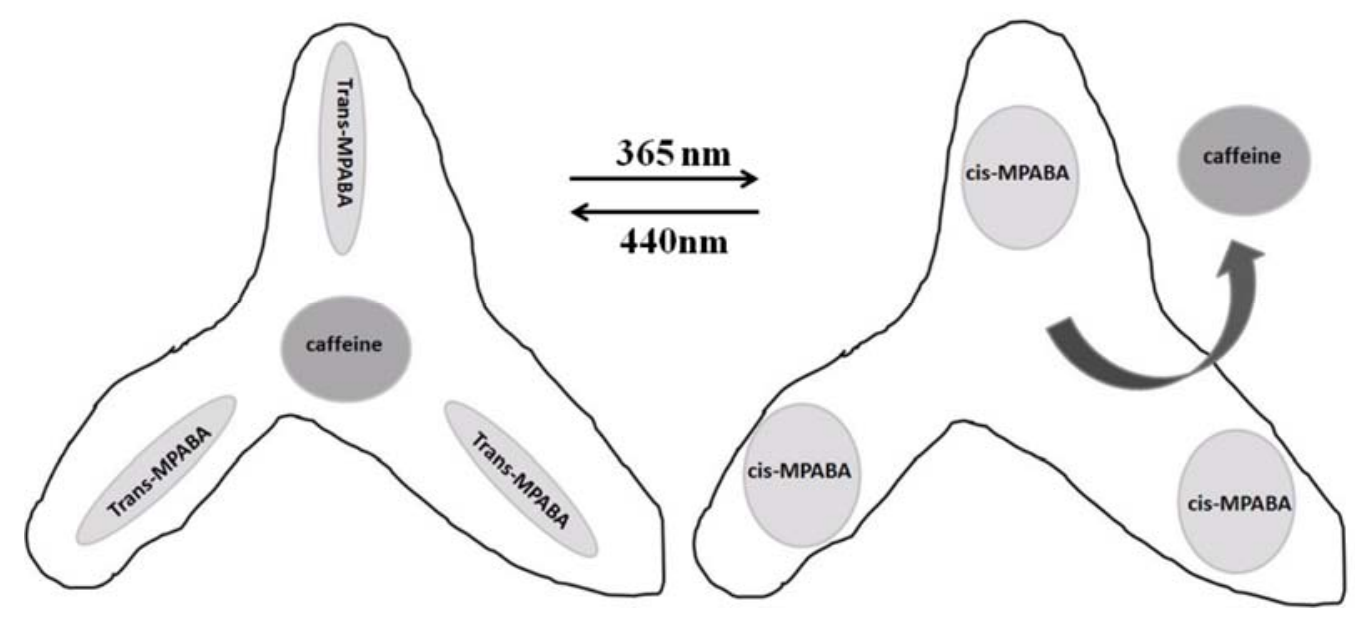

Cross-linkers with their polymerizable end-groups separated by longer spacers produce hydrogels that are less restrictive to the stimuli-induced conformation changes of the responsive elements within the materials. In this case, the 4-((4-methacryloyloxy)phenylazo)benzenesulfonic acid-containing polyacrylamide hydrogel fabricated from the cross-linker $N, N^{\prime}$-hexylenebismethacrylamide was found to afford good optical transparency in the aqueous media, reasonable substrate binding affinity, and fast photo-respond rate. Upon irradiation at $353 \mathrm{~nm}, 83.6 \%$ of receptor bound paracetamol was released from the imprinted hydrogel. Subsequent irradiation at $440 \mathrm{~nm}$ caused $94.1 \%$ of the released paracetamol to be rebound by the hydrogel again. Such a photo-regulated release and uptake process are reversible.

Gomy and coworkers [146] developed a new azo monomer di-(ureidoethylenemethacrylate) azobenzene and successfully prepared a photo-responsive MIP. They used bis(TBA)- $N$-Z-L-glutamate, a methotrexate analogue, as template. The photo-isomerization properties of the AZB chromophore are retained in the rigid polymer. Photo-induced cis $\rightarrow$ trans isomerization of the azobenzene-containing polymer backbone is able to regulate the receptor sites geometry and can regulate the release and uptake of a substrate (Figure 21). This new cross-linking monomer combines interactive monomer functionality with a cross-linking format: it is readily copolymerizable under mild conditions and gives non-covalent MIPs with potential improved performance.

Takeuchi and coworkers [148] synthesized a photo-responsive porphyrin-imprinted polymer by using a novel azo functional monomer bearing a diaminopyridine group. In particular, they used the photo-responsive functional monomer 4-\{4-[2,6-bis(n-butylamino)pyridine-4-yl]-phenylazo $\}$-phenyl methacrylate, FM, for preparing photo-responsive MIP for porphyrin derivatives with carboxylic acids. Multiple hydrogen bonds could be formed between the template and FM, facilitating the assembly of FM with the template in appropriate positions by polymerization and yielding selective imprinted 
cavities, complementary to the target molecule. The reversible binding of target molecules to the imprinted polymer was directly investigated by using optical waveguide spectroscopy [154-160].

Figure 21. Schematic photo-regulated release and uptake of bis(TBA)- $N$-Z-L-glutamate.

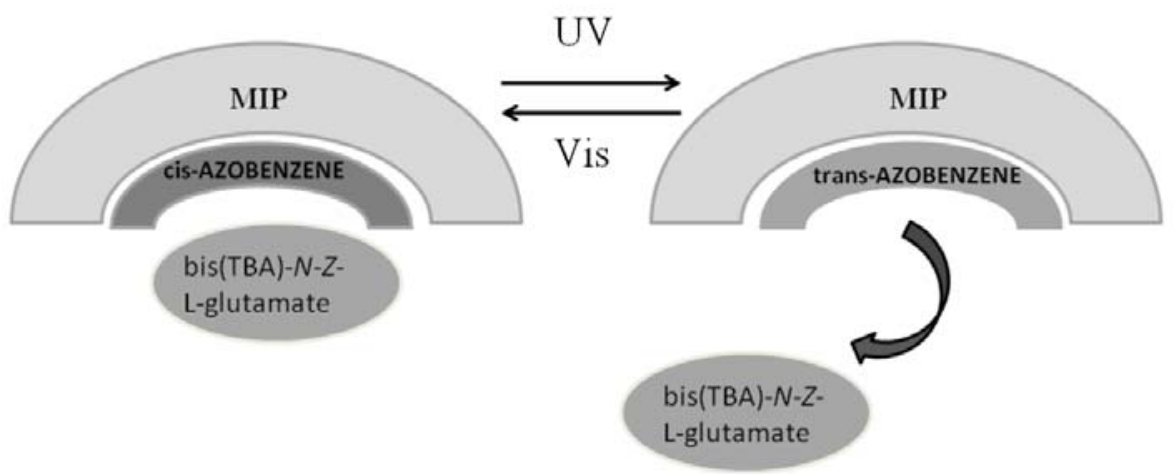

Fang et al. [161] described for the first time the successful preparation of azo-containing MIP microspheres with photo-responsive template binding properties. A methacrylate azo functional monomer, with a pyridine group, 4-((4-methacryloyloxy)-phenylazo)pyridine and a good solubility in acetonitrile, allowed the implementation of molecular imprinting via precipitation polymerization, leading to azo-containing MIP microspheres (number-average diameter $=1.33 \mu \mathrm{m}$ ) (Figure 22).

Figure 22. Representation of preparation of azo-containing MIP microspheres with photo-responsive binding sites.

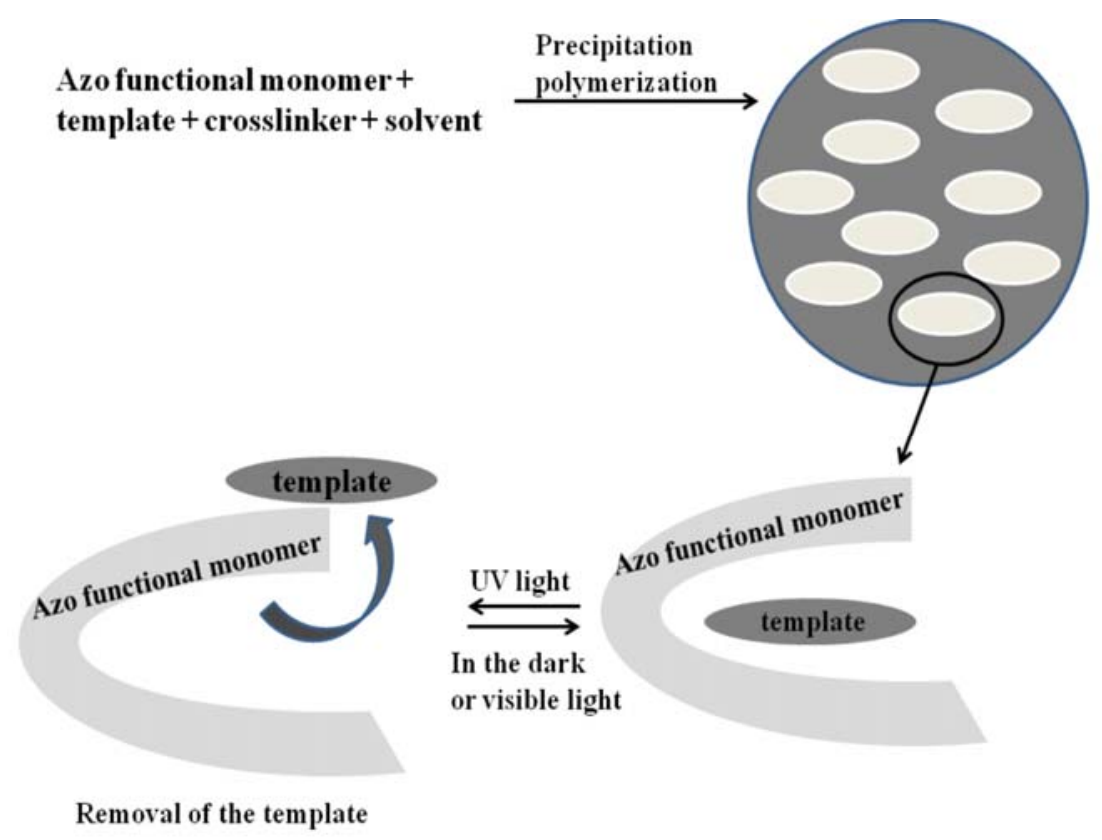

The binding affinity of the imprinted sites in azo-containing MIP microspheres was found to be photo-responsive towards the template: it decreased upon UV light irradiation, whereas it could be recovered during the subsequent thermal (or visible light-induced) back-isomerization. 
Recently, a novel molecularly imprinted organic-inorganic hybrid AZB material [162] was synthesized by sol-gel route. This MIP was able to release and selectively bind 2,4-dichlorophenoxyacetic acid upon irradiation at 360 and $440 \mathrm{~nm}$, respectively.

\subsection{Photo-Responsive Hydrogel Membranes}

Environmentally sensitive hydrogels are promising materials for separation and controlled drug delivery. Various stimuli such as $\mathrm{pH}$ [163-166], ionic strength [163,167,168], temperature [169-172], electric field [167], and magnetic field [173] have been utilized as triggers for drug release.

Andreopoulos et al. [174] reported the synthesis of hydrogels via the photo-polymerization of water-soluble poly(ethylene glycol), PEG, molecules. In the later work [175], they examined the diffusive characteristics of light sensitive PEG-based hydrogel membranes by monitoring the permeation rates of model proteins through the membranes. Briefly, the end groups of star-polyethylene glycol molecules were modified with cinnamylidene acetate groups, which crosslink upon exposure to light. Photo-polymerization of cinnamylidene acetate modified PEG molecules, PEG-CA, in water provides a straightforward route to prepare hydrogel membranes in absence of potentially toxic photo-sensitizers and/or photo-initiators. These hydrogels exhibit photo-reversible behavior, and upon exposure to UV light $(254 \mathrm{~nm})$ the gels photo-degrade. Consequently, light may be used as a trigger for the release of drugs or other pharmacological agents from a hydrogel matrix. In particular, it has been seen that PEG-CA hydrogels' swellability is a function of irradiation light $(\lambda>300 \mathrm{~nm})$ and degree of modification of the PEG molecules. The effect of light on the permeation fluxes of myoglobin, hemoglobin, and lactate dehydrogenase through PEG membranes was also assessed and the diffusion coefficients of the proteins were determined accordingly. Therefore, UV light was used as a trigger to control the mesh size of the membranes, and thereby the permeation fluxes of myoglobin, hemoglobin, and lactate dehydrogenase. Equilibrium swelling experiments with membranes prepared under different irradiation conditions were performed, and the Flory-Huggins model was utilized to determine the mesh size and the average molecular weight between crosslinks of the synthesized hydrogels.

Polyacrylamide hydrogels containing bis-[4-\{dimethylamino\}phenyl]\{4-vinyl-phenyl\}methyl leucohydroxide, TPMLH, have been studied as ion selective membranes [176].

In previous works, Irie et al. [177-179] studied the properties of polyacrylamide, PA, gels containing TPMLH as pendant groups. TPMLH dissociates in a cation (leuco cation) and a hydroxyl anion upon UV light irradiation (270-400 nm). The leuco cation and the hydroxyl anion recombine on sitting in the dark for about $20 \mathrm{~h}$ at $\mathrm{pH}$ 6.6.

When PA/TPMLH gels were swollen in pure water, photo-dissociation caused a 3-fold volume increase. This swelling was dependent on the crosslink density and the number of counter ions per bridging polymer chain [180]. Sasaki et al. [181] and Willner et al. [182] studied the facilitated transport of anionic permeants such as methyl orange by a triphenyl methane derivative in a liquid membrane system. The rate of transport was reported to triple on photo-dissociation of the leucohydroxide. The increased transport was shown to result from the strong binding affinity of the leuco cations for the anionic permeants. This suggests that a photo-responsive ion-exchange membrane 
could be produced by immobilizing the TPMLH in a polymer matrix. Indeed, Willner et al. [183] studied PA/TPMLH gels as enzyme supports and as membranes.

Kodzwa et al. [176] studied TPMLH containing polyacrylamide hydrogels as photo-responsive and ion selective membranes. They analyzed factors affecting the ionic diffusion rates based on photo-chromism. They observed that the transport of an anionic permeant was enhanced by the production of photo-cations during irradiation. An increase in methyl orange (anionic) flux after UV irradiation was observed and mainly due to the photo-induced generation of fixed cationic charges in the membrane. On the contrary, the flux of 4-dimethylamino pyridine (a neutral species) was essentially unchanged after irradiation.

\subsection{Photo-Responsive Polymer Gels}

Stimuli responsive polymer gels are some of the most attractive responsive materials because they can be easily tailored to respond to different kinds of stimuli. Non-covalent interactions such as $\pi-\pi$ interactions, hydrogen bonds and ionic bonds have been widely explored for preparation of stimuli-responsive polymer gels.

Photo-responsive organogels have been prepared incorporating azo moieties into small molecular gelators [184-192] or as pendant groups into main chain polymers [193-197]. Azo groups often exist in tightly-packed aggregates formed by strong intermolecular hydrogen-bonding or $\pi-\pi$ interactions. They easily appear in stacking forms named J-aggregates and H-aggregates, [198] which can be distinguished from the spectral shift in their UV-Vis absorption spectra. H-aggregation shows a blue shift due to parallel interaction of azochromophores, whereas a red shift is assigned to J-aggregation (head-to-tail) of azo-groups. H-aggregation has been studied in monolayers, Langmuir-Blodgett films, [199] membranes, bilayers, dispersion, [200] and vesicles [201].

Chen et al. [202] prepared multiresponsive reversible gels with a carboxylic azopolymer, $\mathrm{PM} 6 \mathrm{AzCOOH}$. Due to the specifically designed molecular structure of the polymer PM6AzCOOH, the obtained gel showed multiresponsive behaviors to several stimuli, such as temperature, solvent polarity, and light. The specific molecular structure of $\mathrm{PM} 6 \mathrm{AzCOOH}$ enables formation of both $\mathrm{H}$-aggregates and hydrogen bonds in solvents with high polarity. The sol-gel phase transition was obtained by heating, or adding solvents with low polarity or UV irradiation (Figure 23). The gel could then be reformed by reverse processes with full reproducibility.

Figure 23. Organogels prepared with $\mathrm{PM} 6 \mathrm{AzCOOH}$ in dimethylsulfoxide.

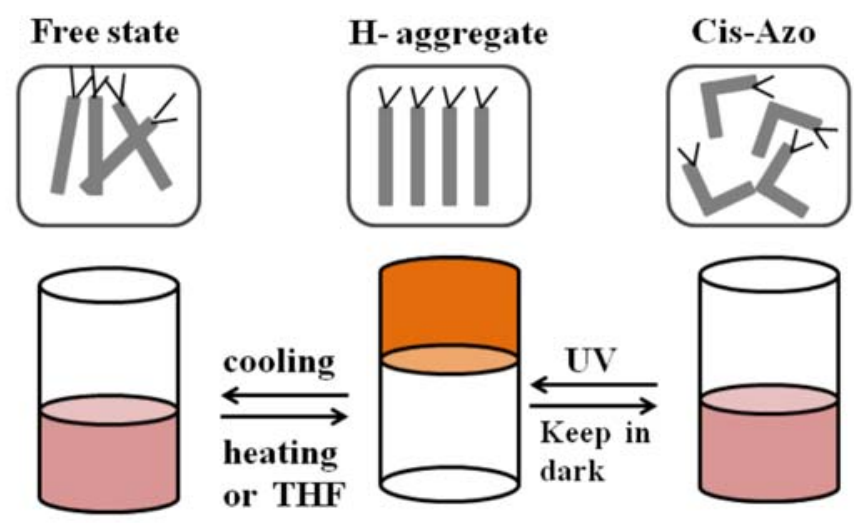


Byrne et al. [84] described a polymeric gel modified with a photo-chromic moiety and showed that it is possible to utilize photo-chromic molecules for performing sensing and actuating functions.

Sumaru et al. showed that a spiropyran-functionalized poly $(N$-isopropylacrylamide $)$ could undergo photo-sensitive solubility switching [203]. These hydrogels showed the ability to control the permeability of a porous membrane optically [71]. These materials have significant limitations because they cannot operate in an open atmosphere or over a wide range of temperatures, due to water loss from the polymer network. On the contrary, the ability of ionic liquid-based polymer gels to perform such volume phase transitions could usher in a new era of environmentally stable polymer gels, as the swelling/shrinking behavior should be possible in an open atmosphere over much broader temperature ranges and timescales, due to the inherent non-volatility of many ionic liquids. So Byrne et al. [84] synthesized photo-responsive ionogels based on poly( $N$-isopropylacrylamide), $N, N$-methylenebis(acrylamide) and protonated benzospiropyran, co-polymerized within several phosphonium based ionic liquids to create hybrid materials for advanced functions. Apart from the advantage of being non-volatile, another advantage of impregnating photo-responsive gels with ionic liquids over aqueous media is the possibility to tailor the properties of the gels using different combinations of anions and cations (polarity, viscosity, etc.). Byrne et al. observed a photo-responsive contraction of gels under visible irradiation, due to photo-isomerization of the $\mathrm{MC}-\mathrm{H}^{+}$to the non-polar BSP isomer that generates a much more hydrophobic environment. As a consequence, bulk water is expelled from the ionogel and causes the physical contraction of the material. These photo-responsive ionogels can be integrated as task-specific optical actuators in microfluidic devices for pumping and valving [204].

\subsection{Photo-Responsive Dendrimers}

Dendrimers are macromolecules made of branched monomers associated around a central core by an iterative process and are characterized by a well defined and highly functionalized 3D architecture. Dendrimers are characterized by a generation number, which refers to the number of repeated branching cycles that are performed during their syntheses. Dendrons are dendritic wedges with one functional group as the core. AZBs can be linked in various places to the structure of dendrimers and dendrons. They can constitute either the terminal groups or the core of the dendrimers (or dendrons), but they can be also incorporated as branches of dendrimers or dendrons.

AZB group location in dendritic structures affects the isomerization properties: they depend on the physical state of the dendrimers/dendrons (solutions, films, monolayers, nanoparticles, vesicles, fibers, and gels) and the level where the azobenzenes are placed inside the structure (the inner the level, the lower the percentage of isomerization, but the larger the influence on size modifications). The steady state is generally reached after few minutes of UV irradiation and the equilibrium cis/trans ratio depends on the used wavelength. The cis $\rightarrow$ trans transition is slower and induced by thermal treatment. The generation number influences the trans $\rightarrow$ cis rate, being lower for higher generations. The reverse rate is not sensitive to generation. Also the hydrodynamic volumes are dependent on the isomerization state of AZB groups: the trans $\rightarrow$ cis isomerization induces drastic reduction of volume for larger generations [205]. 
Thin films of AZB dendrimers and dendrons can be obtained by spin coating, and LangmuirBlodgett techniques. Changes in resistivity, surface area, and molecular hyperpolarizability can be observed upon UV irradiation.

Azobenzene-containing amphiphiles can self-assemble in water into different aggregates such as micelles and bilayer structures, which show interesting photo-responsive properties. The strong interaction of AZB into aggregates is generally confirmed by a spectral shift of the maximum absorption band. A parallel head-to-head alignment (H type) of AZB molecules is detected as a blue shift in the maximum absorption band; on the contrary a red shift is indicative of a head-to-tail arrangement ( $\mathrm{J}$ type). The different aggregation state strongly affects the aggregate morphology. Dendrimers are polymers with a 3D molecular architecture and a starburst topology, which can bear photo-responsive moieties in order to be sensitive to a light stimulus. As an example, Zhang et al. [206] have synthesized from first to the third generation (G0, G1, and G2, see Figure 24) of azobenzene-containing dendrimers with amphiphilic properties and investigated their aggregation behavior in water and light response including morphology changes and drug delivery.

Figure 24. First and second generation of azobenzene-containing dendrimers investigated in [206].
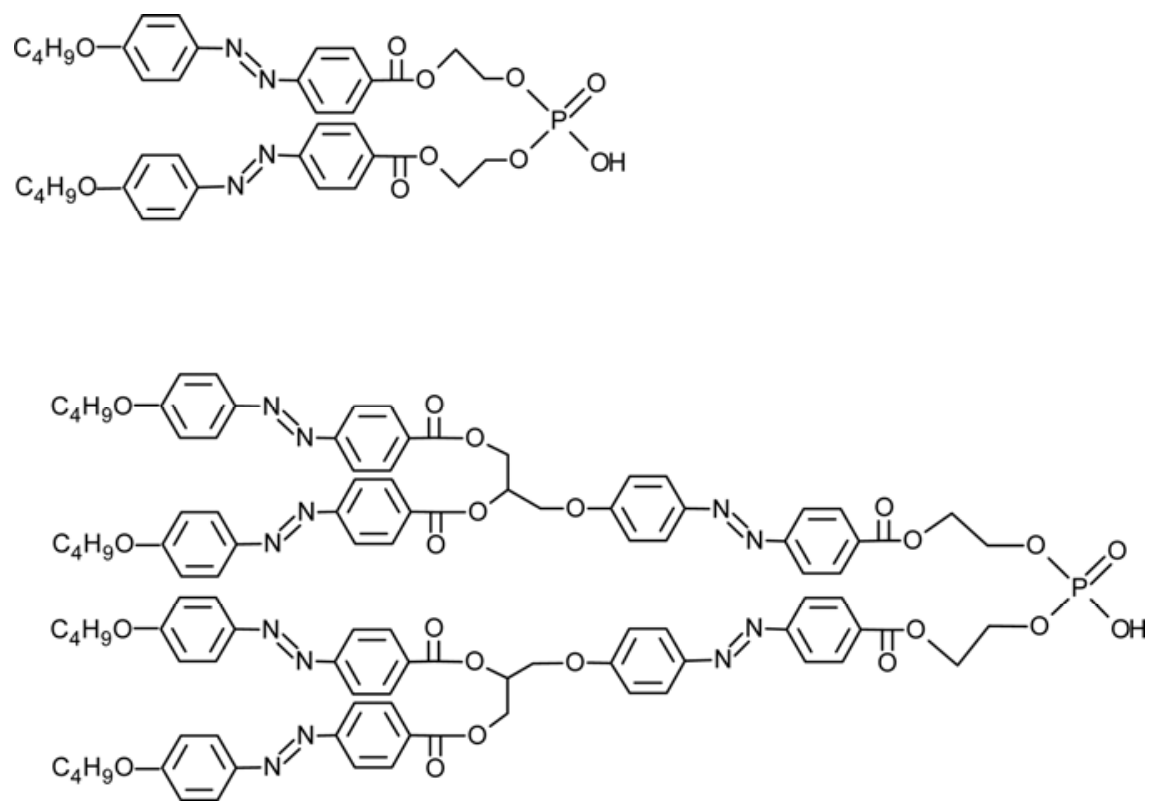

The aggregates were prepared by both a dilution and sonication method, giving similar dimensions but with a smaller distribution for the latter method. Smaller blue shifts were found for aggregates prepared by sonication indicating that different aggregation state are formed by the two preparation approaches. In fact, the larger blue shifts are indicative for the formation of $\mathrm{H}$ aggregates with dilution method, the smaller for looser $\mathrm{H}$-aggregation states. G2 aggregation from the sonication method showed multiple aggregation states. After UV irradiation no significant change was observed in the spectroscopic and morphology behavior of G0 aggregates indicating that the strong $\mathrm{H}$ interaction could not be disrupted by UV light. On the contrary, both G1 and G2 aggregate surfaces had significant morphology changes after UV irradiation. 
The release of calcein versus time was monitored for G1 aggregates upon irradiation. Two different irradiation wavelengths were used: $340 \mathrm{~nm}$ responsible for the direct isomerization of H-aggregates and $395 \mathrm{~nm}$ responsible for the J-aggregation disruption due to an isomerization of AZB chromophores from trans to cis state. The release of calcein was faster after a $340 \mathrm{~nm}$ irradiation.

Photo-responsive dendrimers and dendrons self-arrange in liquid crystalline structures. In most cases the observed mesophase is the smectic A, while nematic phase is easily found with small dendrimers. Upon UV irradiation, the liquid crystallinity is lost and the systems become isotropic. The irradiation with linearly polarized light induces a photo-orientation of the terminal AZB groups.

Other types of self-assembly are multilayered vesicles, both small and giant ones. Irradiation of AZB dendritic vesicles can induce a photo-controlled release of guest molecules either from the interior or from the membrane of the vesicles, as the cis azobenzene moieties in the vesicle membrane enhance the bilayer permeability.

\subsection{Photo-Responsive Nanoporous Silica Membranes}

Periodic mesoporous organosilicas, PMO, including zeolites have been of great interest in the past decade because of their potential applications in membrane separations, adsorption, catalysis, and chemical sensing [207-212]. Their ordered periodic architecture defines channels of very regular dimensions in the nanometric scale [213-215] with the potential to control pore size and, as a consequence, transport behavior with nanometer-scale precision if appropriate organic functional groups are covalently incorporated onto the pore surfaces of the rigid mesoporous silica framework. PMOs with tunable porosity can serve as size-selective membranes allowing the passage through them of particles and species with dimensions larger than the pores [216-225]. To expand the range of applications various "switchable" functional groups have been covalently incorporated into PMOs. These membranes with "active" functionality would enable properties to be dynamically controlled by external stimuli, such as light or $\mathrm{pH}$ [75,76,215,226-231].

Zeolites are transparent 3D-nanostructured porous materials, which are well suited to host guest molecules. AZB molecules have been adsorbed in several zeolite membrane types [229,232] and exhibited reversible photo-switchable permeation properties due to their trans $\rightarrow$ cis isomerization. The intrazeolitic photo-isomerization causes changes of molecular size and geometry as well as of dipole moment which affect the permeation of gases such as $\mathrm{H}_{2}, \mathrm{CH}_{4}, \mathrm{~N}_{2}, \mathrm{O}_{2}, \mathrm{CO}_{2}, \mathrm{n}-\mathrm{C}_{4} \mathrm{H}_{10}, \mathrm{SF}_{6}$, and gas mixtures such as $\mathrm{N}_{2} / \mathrm{CO}_{2}$ and $\mathrm{CH}_{4} / \mathrm{CO}_{2}$. Weh et al. [229] measured trans/cis selectivity, $\mathrm{S}_{\text {trans/cis, }}$ and mixture separation factors, $\alpha_{(\mathrm{a} / \mathrm{b})}$, for various gas. $\mathrm{S}_{\text {trans } / \text { cis }}$ and $\alpha_{(\mathrm{a} / \mathrm{b})}$, were defined as follows:

$$
\begin{gathered}
\mathrm{S}_{\text {trans/cis }}=\text { Permeation (trans) } / \text { Permeation (cis) } \\
\alpha_{(\mathrm{a} / \mathrm{b})}=\left(\mathrm{x}_{\mathrm{a}} / \mathrm{x}_{\mathrm{b}}\right)_{\text {permeate }} /\left(\mathrm{x}_{\mathrm{a}} / \mathrm{x}_{\mathrm{b}}\right)_{\text {retentate }}
\end{gathered}
$$

where $\mathrm{x}$ are the mole fractions of gases $\mathrm{a}$ and $\mathrm{b}$.

The authors found that results were dependent on the irradiation wavelength, the membrane type, and the amount of adsorbed azobenzene molecules.

Larger permeations of single gas and larger separation factors for equimolar gas mixtures were obtained when AZB molecules were in their trans form rather than in their cis form. After the switching back to the trans form all the permeations increased to the original values. The permeation 
reversibility was verified over several switching cycles. In addition to steric effects, it was found that electrostatic interactions had to be taken into account for polar gases. $\mathrm{S}_{\text {trans/cis }}$ values larger than 2.5 were found for all used gases (except $\mathrm{H}_{2}$ ) in the case of FAU zeolites with larger AZB adsorption as the cis form is bulkier and blocks more pore volume. The change in permeation values was more evident for bulky permeant gases $\left(\mathrm{S}_{\text {trans/cis }} \approx 5\right.$ for $\left.\mathrm{CO}_{2}\right)$. Larger $\alpha$ values were found for $\mathrm{N}_{2} / \mathrm{CO}_{2}$ mixture. Experimental results were in agreement with theoretical prediction of Monte Carlo simulations.

Photo-responsive periodic mesoporous organosilicas can be prepared by means of differently substituted AZB ligands as pendant groups within a porous silica framework.

PMOs containing photo-active azobenzene moieties covalently linked to the inorganic silica porous structure by propyl linkers, AZ1-PMO, or carbamate groups, AZ2-PMO, were synthesized from tetraethyl orthosilicate (Figure 25). Preparation was carried out under typical synthetic conditions for PMOs using cetyltrimethylammonium as the structure directing agent [233]. Both PMOs showed periodic mesoporous structure as confirmed by powder XRD and isothermal nitrogen adsorptions.

The AZB containing PMOs exhibit a photo-chemical trans to cis one-way isomerization of the azo group upon irradiation at $358 \mathrm{~nm}$.

Figure 25. Synthesis paths for AZ1-PMO (top) and AZ2-PMO (bottom).

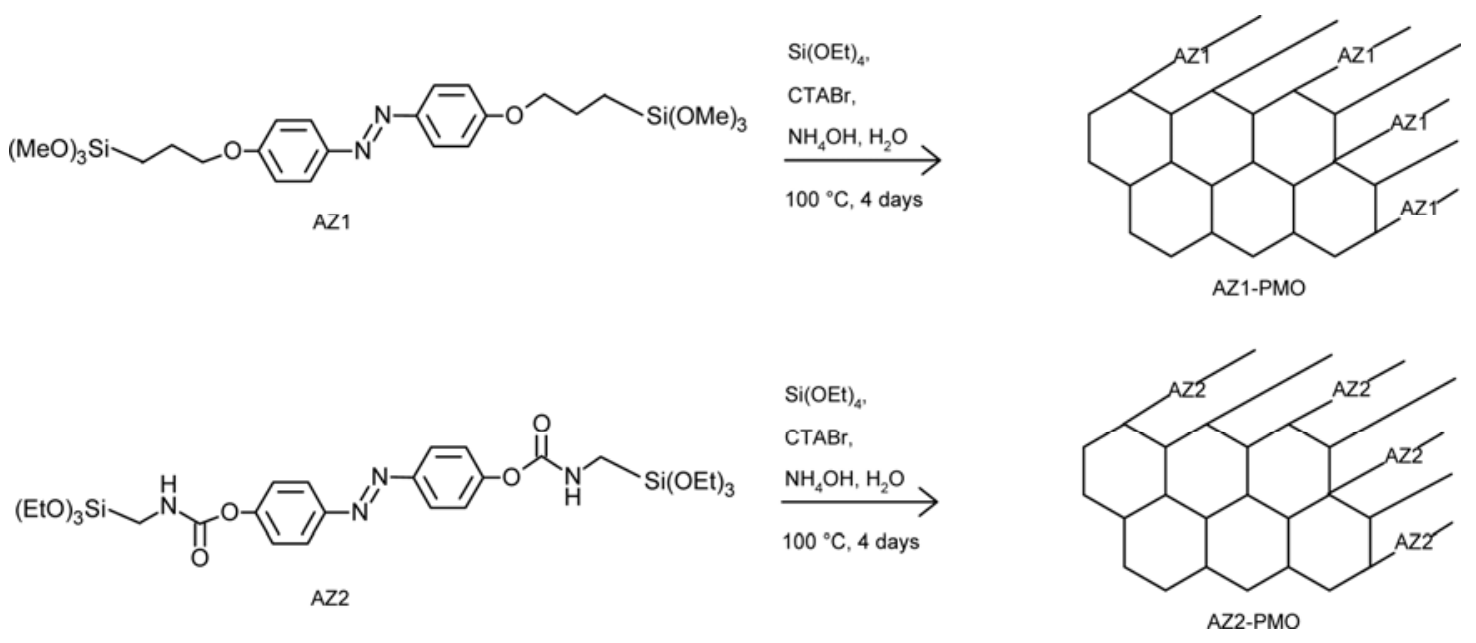

The photo-chemical-thermal cycle is reversible and no fatigue of the trans/cis interconversion has been observed after 5 cycles. As a consequence of trans/cis isomerization, a reduction of pore size occurs immediately after irradiating for a long time. Variation of the porosity and pore size distribution caused changes in the adsorption capacity of the azobenzene-containing PMOs before and after irradiation.

Colloidal gold nanoparticles have been also included inside the pores of AZ1-PMO (2.6 nm) and AZ2-PMO $(3.0 \mathrm{~nm})$. After irradiation, the gold nanoparticles adsorption capacity of the cis-configured azobenzene PMO was significantly increased. The photo-chemical trans/cis isomerization is thermally reversible and upon storage in the dark the population of cis-azobenzene decay back to the trans isomer and the adsorption capacity is gradually restored within few days.

Mesoporous materials can be made by surfactant-directed self-assembly [207,208,212]. 
Liu et al. used an azobenzene-modified silane, 4-(3-triethoxysilylpropylureido)azobenzene, to modify the working electrode of an electrochemical cell [78]. The highly ordered mesostructure obtained showed a reversible photo-regulated mass transport to alternate UV and room light exposures. Upon UV irradiation the AZB moieties isomerize to the more compact cis form, which increase the pore size and, then, the diffusion rate of probing molecules. Figure 26 shows typical current-time photo-responses.

Figure 26. Photo-responsive behavior of nanocomposite film [78] under alternate exposure to UV and visible light.

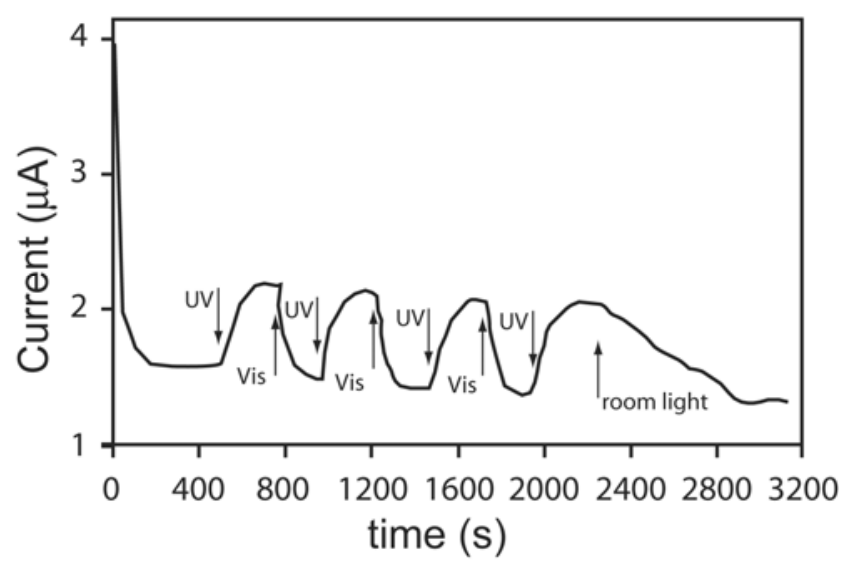

\section{Photoresponsive Membrane Highlights in Technologically Sophisticated Applications}

\subsection{Light-Valved Microfluidics}

Amongst key sophisticated technologies, the microfluidics are challenging for integrated analytical systems on microchip. Drug dispensing, transport of liquids, gases and their mixtures, microreactor feeds, microseparation and purification, and movement of liquids at sub-microliter volumes are any few of the attractive examples of molecular machines based on microfluidics. The realization of membrane microvalve is one of the critical issues for the build up of these integrated devices. Light-controlled valves represent an attractive item because flow control by light irradiation enables non-contact fluid control and flow control by local light irradiation enables independent control of multiple fluids. Low-cost biomimetic platforms can be realized using soft polymer actuators in place of external pumps and valves [84]. A poly( $N$-isopropylacrylamide) containing a spirobenzopyran chromophore has been, for example, implanted in a micropattern by in situ photo-polymerization at the desired positions in microchannels (Figure 27).

Local light was irradiated onto discrete microvalves allowing independent control of three photo-responsive polymer gel microvalves in a single microchip. This enabled one to open the microvalves within 18-30 s of light irradiation [234].

Ionic liquid polymer gels (ionogels) incorporating benzospiropyran units and phosphonium-based ionic liquids have been introduced as photo-actuated valves into micro-fluidic manifolds, forming four micro-valves [204]. The ionogels have been photo-polymerized in situ in the channels of a poly(methyl methacrylate) micro-fluidic device and actuated by light irradiation. Depending on 
ionogel composition each single microvalve can be open at a different time under similar irradiation conditions. A relatively fast opening (few seconds) of the channels and a slow expansion (minutes) suggested this system is practical for single-actuation events.

Figure 27. Light-controlled valves.

(a)

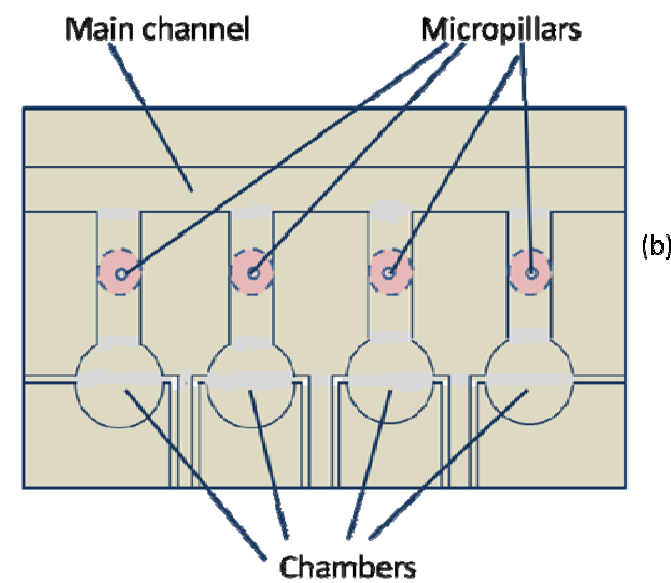

(b)

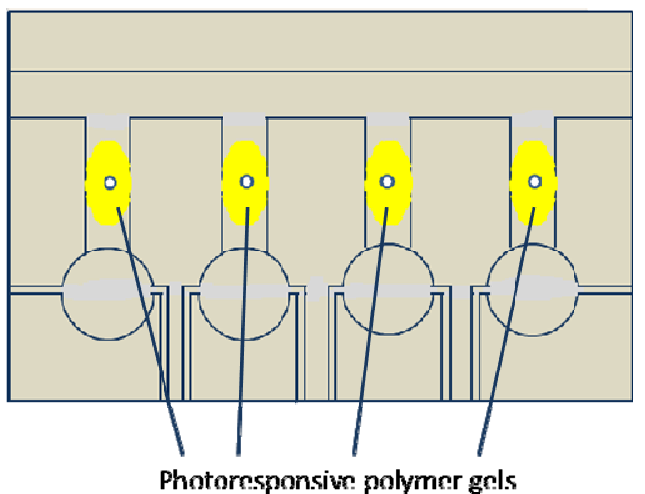

\subsection{Photo-Catalytic Membranes}

Organic pollutants found in biologically treated wastewaters have to be removed completely due to public health concerns. Advanced oxidation processes are characterized by the generation of the highly reactive hydroxyl radicals that can tackle and mineralize dissolved organic pollutants.

Among the advanced treatment technologies, $\mathrm{TiO}_{2} / \mathrm{UV}$ photo-catalysis has attracted intensive studies in recent years due to its non-toxic properties [235]. In a photo-oxidation process, hydroxyl radicals are generated when the catalyst, $\mathrm{TiO}_{2}$, is illuminated by ultraviolet light and, then, organic compounds are mineralized into $\mathrm{CO}_{2}, \mathrm{H}_{2} \mathrm{O}$ and inorganic constituents [236,237]. Titanium dioxide is the most commonly used photo-catalyst material due to its strong redox ability, chemical stability, and availability at low cost [238]. Recently, the idea of integrating photo-catalysis with low-pressure submerged membrane has attracted growing attention. Semiconductor photo-catalysis helps to reduce membrane fouling from photo-mineralizing compounds [236,239].

Ho et al. [240] investigated the effect of photo-catalytic oxidation coupled with a low-pressure microfiltration in removing effluent organic matter from treated sewage effluents. Integrating photo-oxidation for organic degradation and membrane filtration the authors obtained an enhancement in the filtration flux of the submerged membrane reactor.

\subsection{Photo-Responsive PDLCs and Membranes}

Among liquid crystal-based systems polymer-dispersed liquid crystals, PDLCs, deserve a particular mention. They are formed by either micron-sized liquid crystal droplets embedded in a polymer matrix ("Swiss cheese" morphology), or by liquid crystal that fills the voids and crevices of a polymer network ("polymer ball" morphology), which gives them a solid-like nature [241]. The physical operation principle of a PDLC is the electrically driven reorientation of liquid crystal directors. In the opaque OFF state of a PDLC, liquid crystal directors are randomy oriented, but they can align parallel 
to an external electric field and give rise to a transparent device. In both morphologies, the polymer matrix can be considered as the most important component, which gives the device a solid-like characteristic, some important features such as rheological, electrical, and optical properties and the opportunity to host additives to enhance the performances of the obtained devices or to add new functionalities.

Glowacki et al. [242] have filled track-etched membranes with cylindrical pores with liquid crystal mixtures doped with mesogenic azo-dyes (14-15 wt\%). Liquid crystalline materials act as photo-active elements with response times of a few seconds to UV and visible radiation. In the case of samples with 400-nm pores, membranes have ensured a linear and reversible nitrogen permeability/pressure relationship both in the liquid crystalline and isotropic phase. The nitrogen permeability photo-control was achieved by irradiating samples at 365 and $420 \mathrm{~nm}$. The composition of mesogenic materials and the kind of LC alignment (parallel or perpedicular to pore walls) were shown to influence the nitrogen permeability coefficients through membranes.

Recently, bifunctional films have been obtained. They are able to modulate both the light intensity, by means of the reorientation of the liquid crystal molecules resulting from the application of an external electric field, and the color by UV irradiation, by using small amounts of Photosol ${ }^{\circledR}$ photo-chromic dyes [243,244]. Photosol ${ }^{\circledR}$ dyes are available in various colors and belong to naphthopyran and oxazine classes. Their colorless form contains a spiro-carbon atom which is $\mathrm{sp}^{3}$ hybridized and separates the molecules into two halves. In such a geometry (closed form) the molecules absorb in the UV region of the light spectrum (Figure 28 state $\mathrm{I}$ ). The groups, $\mathrm{R}_{\mathrm{i}}$, may be selected as described elsewhere [244]. The exposure to ultraviolet radiation causes the rupture of the carbon-oxygen single bond of the oxazine ring (Figure 28 state II).

Figure 28. UV-induced structural changes in Photosol ${ }^{\circledR}$ dyes.

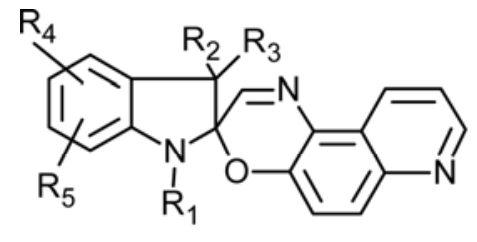

State I

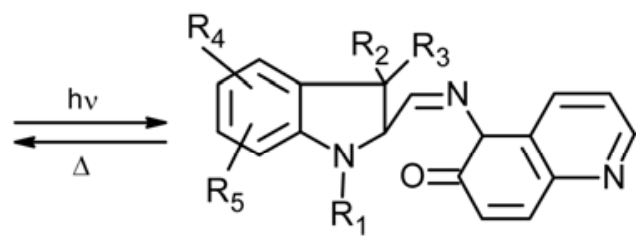

State II

As a consequence, the molecular conformation changes into a planar configuration (open form) and the molecular absorption falls in the visible part of the light spectrum. If the UV radiation is removed the carbon-oxygen bond reforms and the molecules relax to the colorless closed form within a few seconds.

It was possible to tune both the transparency and the color of devices by selecting the UV intensity (color tuning) and the electric field strength (transparency tuning) according the following Table 2. The colored state is achieved in a few seconds on exposure to sunlight or UV, while the bleaching of devices requires several minutes.

Resistivity is another important property of PDLCs that can be changed by doping polymer matrices with conductive additives. In particular, both nematic emulsions and PDLCs have been doped by small amounts of conductive molecules and oligomers [245,246]. It was found that the electrical 
conductivity in polymer-dispersed liquid crystals can be finely adjusted and the electric field across the nematic liquid crystal droplets can be increased with a consequent large reduction in the reorientation fields and relaxation times. Furthermore, such simple doping of the polymer matrix does not alter the other properties such as optical and rheological properties of the devices.

Table 2. Transparency and color tunability in PDLCs.

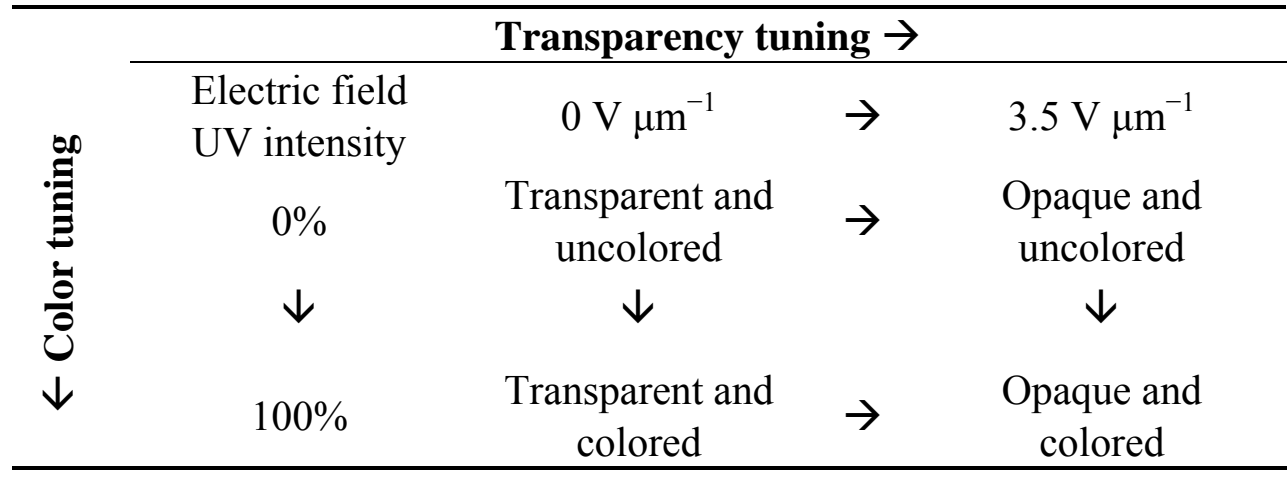

PDLCs can self adjust their transparency by a change of the light intensity [247,248]. Such devices have been fabricated by doping both direct-mode and reverse-mode operation polymer-dispersed liquid crystal films with small amounts of either photo-chromic or photo-conductive molecules (e.g., Photosol ${ }^{\circledR}$ dyes, zinc or dilithium phtalocyanine) in order to change the device conductivity by light in a controlled way and to gain an optically controllable transparency. It was found that in both operation mode films, the electro-optical response changed towards lower switching fields for increasing UV intensity exposures (Figure 29) due to the increase of polymer matrix conductivity. In fact, the field across liquid crystal droplet increased according to the following equation:

$$
E=\frac{3 \sigma_{\text {matrix }}}{2 \sigma_{\text {matrix }}+\sigma_{L C}} E_{\text {appl }}
$$

where $E_{\text {appl }}$ is the applied external field and $\sigma_{\text {matrix }}$ and $\sigma_{\mathrm{LC}}$ are, respectively, the electric conductivities of polymer matrix and liquid crystal.

Figure 29. Electric field dependent transmittance as a function of applied UV power: (a) $0 \mathrm{~mW} / \mathrm{cm}^{2}$, (b) $2.5 \mathrm{~mW} / \mathrm{cm}^{2}$, (c) $5 \mathrm{~mW} / \mathrm{cm}^{2}$, and (d) $10 \mathrm{~mW} / \mathrm{cm}^{2}$.

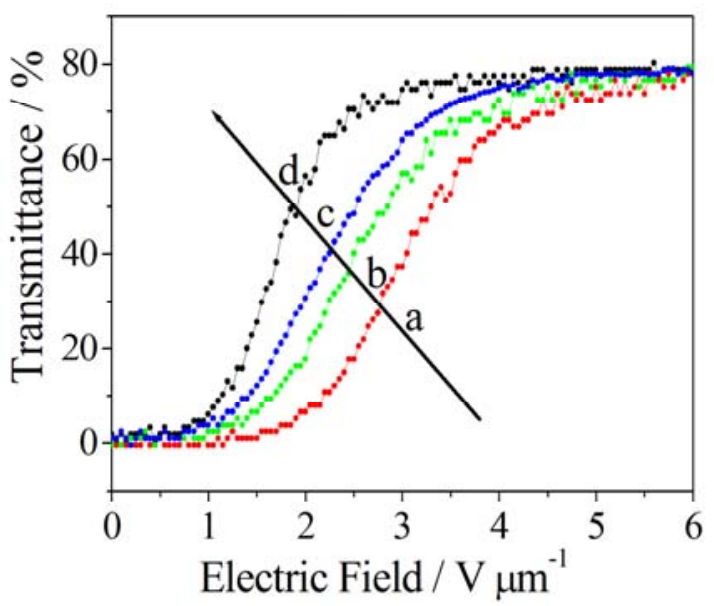


Figure 30 shows the transmittance dependence on the applied electric field in the dark (curve a) and under UV irradiation (curve b) conditions for a direct-mode (on the left) and a reverse-mode (on the right) operation PDLC. In the dark the initial state A will be opaque/transparent depending on the operation mode of the device. If one applies an electric field lower than the threshold one, in the dark conditions the film will still appear opaque/transparent, but the initial state, A, has moved to an intermediate state, B. After irradiation with a light beam, the film becomes transparent/opaque due to the increase of polymer matrix conductivity and the rise of the effective local electric field across droplets. The device comes back to the opaque/transparent state if either the light source (path $\mathrm{C} \rightarrow \mathrm{B}$ ) or the electric field (path $\mathrm{C} \rightarrow \mathrm{A}$ ) is turned off.

Figure 30. Transmittance dependence on the applied electric field in the dark (red curves) and under UV irradiation (blue curves) for a direct mode PDLC (left) and a reverse mode PDLC (right).

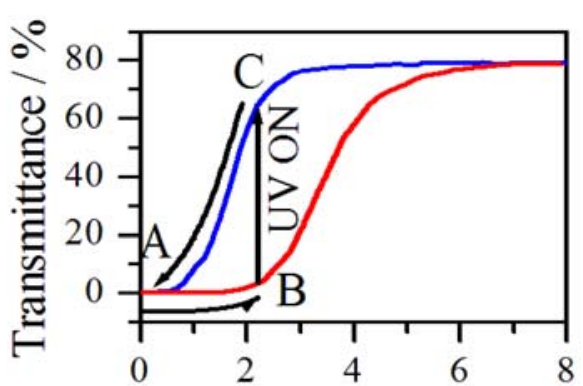

Electric field / $\mathrm{V} \mu \mathrm{m}^{-1}$

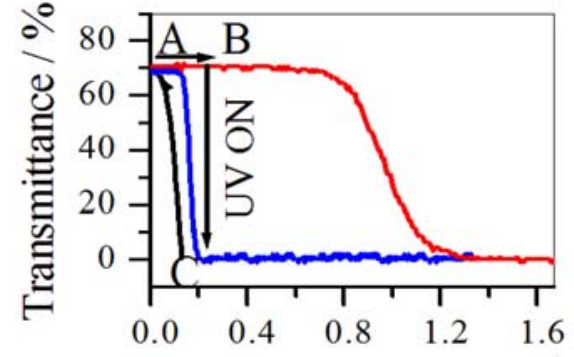

Electric Field / V $\mu \mathrm{m}^{-1}$

\subsection{Photo-Electrochromic Systems}

It is known that some materials can change color on absorption of light (photo-chromic materials) and others on application of an external electric field (electro-chromic materials). Photo-electrochromics are materials that are able to change their color both on absorption of light and on application of an external electric field.

Recently, a new organic photo-electrochromic film has been developed [249,250] in which the same molecule, methylene blue (MB), can change its color from blue to transparent on absorption of Vis light and change back blue thanks to an oxidation reaction induced by an external electric field. The major advantage of such a device is the use of two distinct techniques for performing bleaching and coloring at own will. When a MB molecule absorbs red light (maximum absorption peak at around $660 \mathrm{~nm}$ ) it undergoes a transition to an excited singlet state, ${ }^{1} \mathrm{MB}^{{ }^{*+}}$, which can come back to the initial state, ${ }^{1} \mathrm{MB}_{0}{ }^{+}$, or convert to an excited triplet state, ${ }^{3} \mathrm{MB}^{*+}$. The excited triplet state reduces in the presence of an electron donor species, $: \mathrm{NR}_{3}$, changing its initial blue color into a transparent one according to Scheme 1.

At the same time, methylene blue mixed with an oxidative agent in an appropriate solvent can change its color in response to an electrical stimulus. Consequently, it is possible to write on the film by means of a red laser beam and to erase by means of an electrical impulse.

When cycling the writing and erasing processes up to 500 times no change in the chromatic properties of films was found (Figure 31). In addition, it was found that: 
(1) Different bleaching rates are due to the different electron donor abilities of the amines and the dimensions of the alkyl substituents on the nitrogen. Samples with a tertiary amine show a faster bleaching rate than samples with either a secondary or primary amine. Samples with triethylamine show a faster bleaching rate than samples with tripropylamine or tributylamine.

(2) The coloring time can be reduced by using rougher substrates as they offer a larger surface for the electrochromic reactions (Figure 32).

Scheme 1. Photo-chromic reactions in methylene blue.

$$
\begin{gathered}
{ }^{1} \mathrm{MB}_{0}^{+} \leftrightarrow{ }^{1} \mathrm{MB}^{*+} \rightarrow{ }^{3} \mathrm{MB}^{*+} \\
{ }^{3} \mathrm{MB}^{*+}+: \mathrm{NR}_{3} \rightarrow \mathrm{MB}^{*}+\mathrm{NR}_{3}^{+} \\
\text {(transparent) } \\
{ }^{3} \mathrm{MB}^{*+}+\mathrm{O}_{2} \rightarrow{ }^{1} \mathrm{MB}_{0}^{+}+\mathrm{O}_{2} \\
\text { (blue) }
\end{gathered}
$$

The ${ }^{3} \mathrm{MB}^{*+}$ can react with $\mathrm{O}_{2}$ giving the $\mathrm{MB}$ ground state, ${ }^{1} \mathrm{MB}_{0}{ }^{+}$.

Figure 31. Transmittance behavior on a cyclic red light and electric pulse.

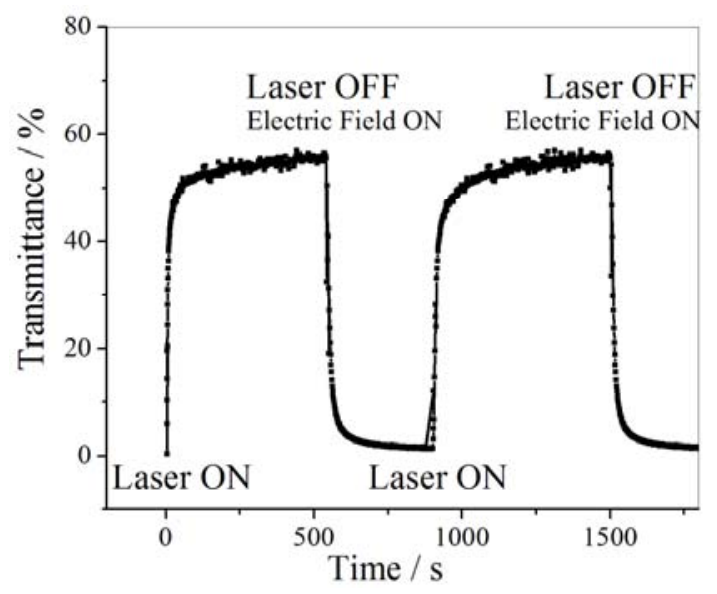

Figure 32. Coloring time as a function of substrate roughness.

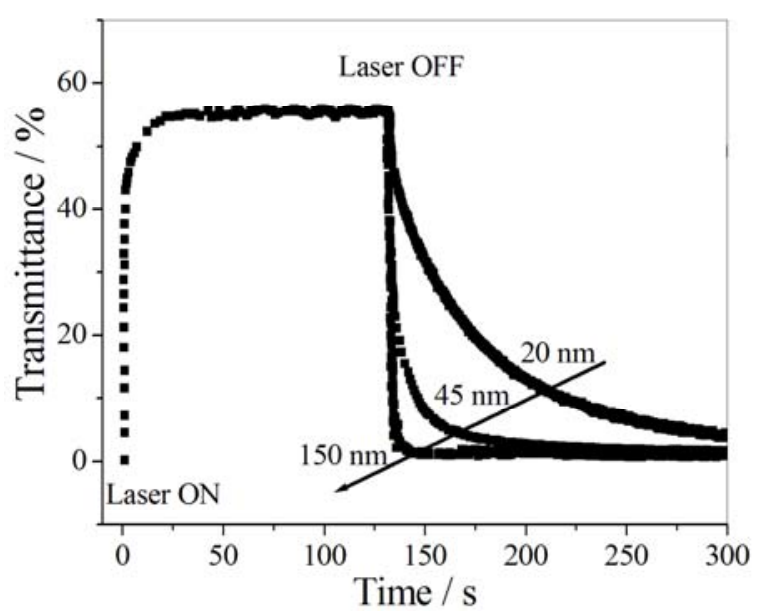


An important development of the above-described film is reported [251]. In that paper a nanophoto-electrochromic film cast on flexible supports and characterized by faster coloring times was presented.

A colloid solution of $\mathrm{TiO}_{2}$ was spin coated on the conductive surface of the PET film and hydrothermally treated. Then phosphate groups were bounded to the surface of the $\mathrm{TiO}_{2}$ nanospheres and, finally, the MB molecules to give the PET-TiO $2-\mathrm{PO}_{4}-\mathrm{MB}$ film.

The electrolytic solution was absorbed through the pores of a microporous polar membrane. Afterward, the membrane was put between PET- $\mathrm{TiO}_{2}-\mathrm{PO}_{4}-\mathrm{MB}$ and PET substrates, and the entire device was irradiated with UV light for 5 min to perform the polymerization of the acrylate monomer and to link in a stable way the flexible supports of PET-TiO $-\mathrm{PO}_{4}-\mathrm{MB}$ and PET to the Nafion membrane. In addition to flexibility of PET substrates, the overall process is very fast. Indeed, the oxidation rate is not dependent on the diffusion rate of the molecules toward the electrode. Besides to be able to transport electrical charges, $\mathrm{TiO}_{2}$ nanoparticles, because of their dimensions (25 $\mathrm{nm}$ in diameter), offer a very high surface area $\left(50 \mathrm{~m}^{2} / \mathrm{g}\right)$. In this way it has been possible to oxidize a great amount of MB molecules per surface and time unit, Figure 33.

Figure 33. Enhancement in the response of photo-electrochromic devices by using nanostructured electrodes.

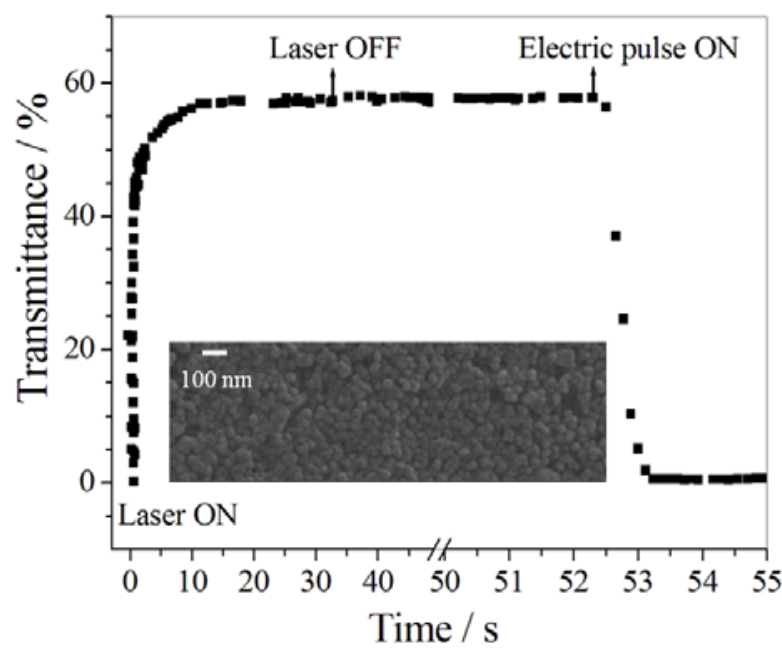

It is known that the use of conductive polymers allows the manufacture of flexible photo-electrochromic films at low costs [252]. In [253] a new nanostructured and self-supplied photo-electrochromic device was manufactured and characterized. The photo-electrochromic film was obtained by coating dye functionalized $\mathrm{TiO}_{2}$ nanoparticles on a layer of $\mathrm{WO}_{3}$ nanoparticles acting as an electrochromic layer. In order to improve their electrical conductance, both the dye- $\mathrm{TiO}_{2}$ and $\mathrm{WO}_{3}$ layers were properly doped with single wall carbon nanotubes bearing $\mathrm{COOH}$ groups and a layer of poly(3,4-ethylenedioxythiophene)/poly(styrenesulfonate) was cast between the dye- $\mathrm{TiO}_{2}$ layer and the counter electrode. In such a way, all layers were characterized by an increased electrical conductivity, and both coloration and bleaching times were decreased to a few tens of seconds. In addition, an excellent contrast ratio was gained (see Figure 34), and the film had an all-solid nature as no fluid component was used. 
Figure 34. Response of an all-solid photo-electrochromic device.

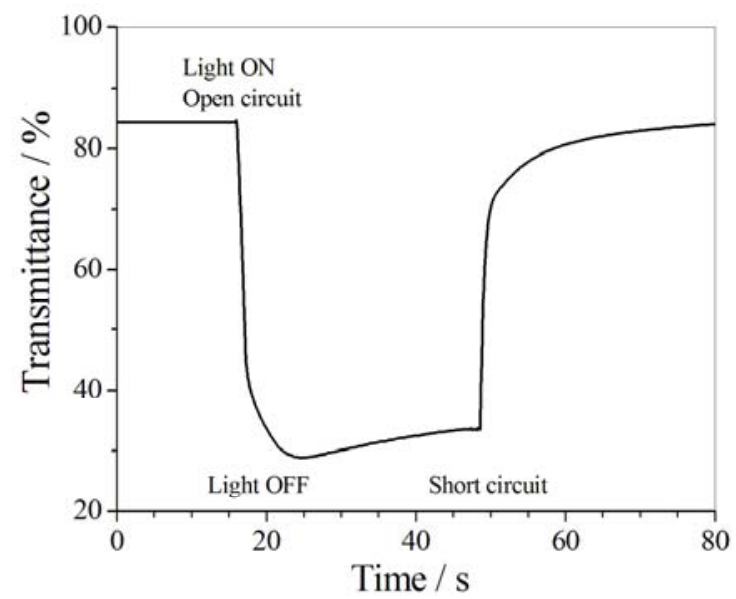

\section{Biological Applications}

Photoresponsive membranes find also advanced application in the area of biology. Higuchi et al. [254] have synthesized a copolymer of nitrobenzospiropyran and methyl methacrylate, poly(NSP-co-MMA), Figure 35, and investigated the wettability changes of such copolymer films upon irradiation. They observed a significant decrease of water contact angles $\left(\approx-15^{\circ}\right)$ and an increase in the diameter of water droplets $(\approx+10 \%)$, i.e., an increase of film hydrophilicity, Figure 36 . No change was detected in the control surfaces coated with PMMA. Then, they cast glass plates with a poly(NSP-co-MMA) film for platelets and mesenchymal stem cells. The authors found that UV light induced a considerable detachment of both platelets and mesenchymal cells due to the different surface energy between poly(trans-NSP-co-MMA) and poly(cis-NSP-co-MMA) films and/or to the change in the switching movement of the closed spiropyran form to the open merocyanine form. No significant detachment was found with control pure PMMA films. Similar results were obtained with fibrinogen and related to the switching movement during photo-isomerization.

Figure 35. Photo-switching in poly(NSP-co-MMA).
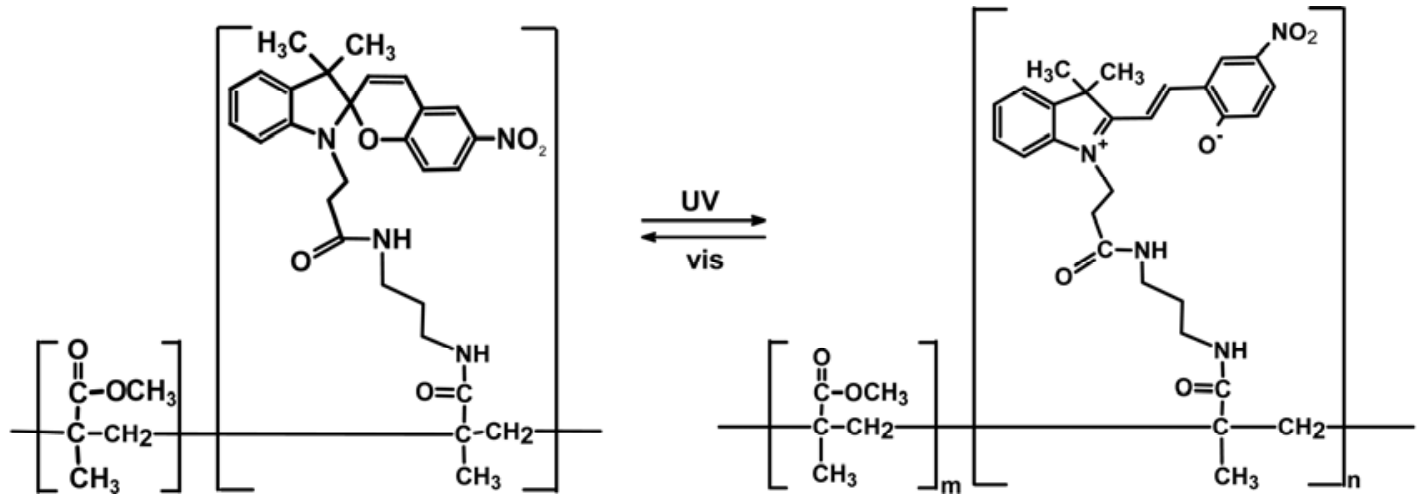
Figure 36. UV induced changes in the hydrophobicity on poly(NSP-co-MMA) coated glass plates.

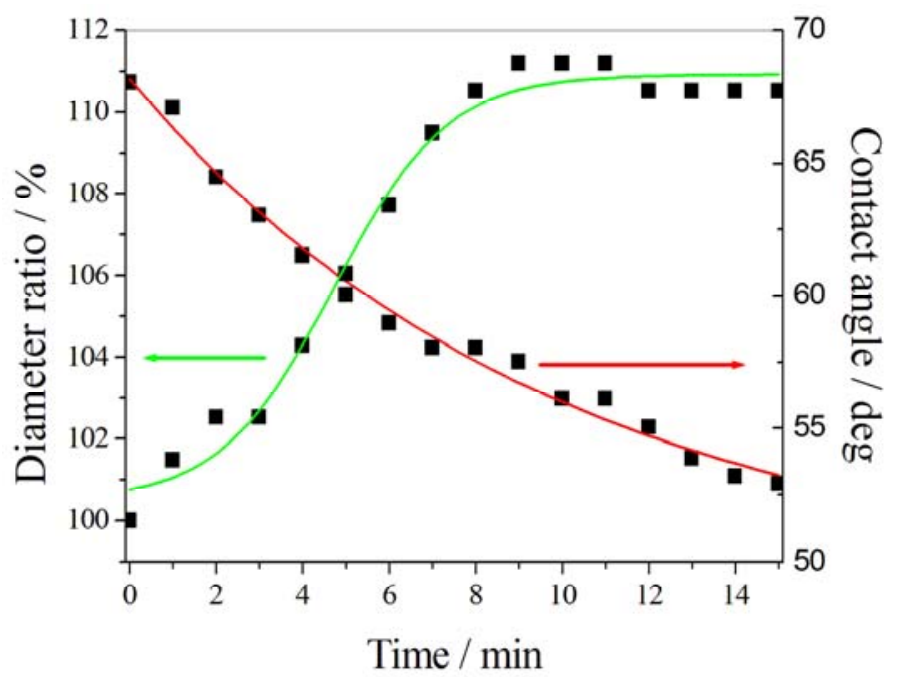

Another class of attractive soft materials is represented by spherical light-driven membrane gates. These are used, for instance, in many advanced therapies using hydrophobic, poorly water-soluble agents and can seriously be affected by shortcomings such as poor adsorption and bioavailability, embolization of blood vessels, and toxicity. Recently, the photo-isomerization of stilbene chromophore in a photo-responsive dialkoxycyanostilbene polymethacrylate and poly(ethylene oxide) has been demonstrated to be a viable route for the build up of controllable nanodevices for this specific applications [255].

The degradation of self-assembled superstructures was ascribed to the conformational change of stilbene chromophores by UV irradiation.

Jun-ichi Kikuchi and co-workers [256-258] have investigated several systems as molecular switch: as an example, the photo-induced switching behavior of assembly of liposomal membranes with a gemini peptide lipid having L-histidyl residues and an AZB spacer, $N^{2}, N^{2}$-azobenzene-4,4'-dyolbis( $N, N$-dihexadecyl-L-histidinamide), Figure 37. The authors have used the synthesized gemini peptide lipid as a molecular switch in membranes of phosphatidylcholine liposomes in a solution of $\mathrm{Cu}^{2+}$ ions. When the gemini peptide lipids are in their trans form (dark conditions) the $\mathrm{Cu}^{2+}$-binding affinity of imidazolyl groups is rather low. Upon irradiation with UV light the metal-binding affinity increases due to the photo-isomerization to the cis-form and induces the assembly of liposomes, Figure 38. The disassembly of liposomal membranes can be obtained by Vis irradiation and was repeatable in the liquid crystalline state of lipids. The two imidazolyl groups present in each gemini peptide are far more than $0.6 \mathrm{~nm}$ apart from each other and, consequently cannot act as a bidentate ligand for a metal ion in the trans-form. After UV irradiation $(15 \mathrm{~min})$ the cis-form is capable of forming metal chelates and inducing assembly among liposomes. This result is confirmed by zeta potential and hydrodynamic diameter $(210 \mathrm{~nm} \rightarrow 500 \mathrm{~nm}$ ) changes from vesicles containing the L-histidyl groups. 
Figure 37. Structural formulas of lipids used in [256] and metal chelates induced by UV irradiation.

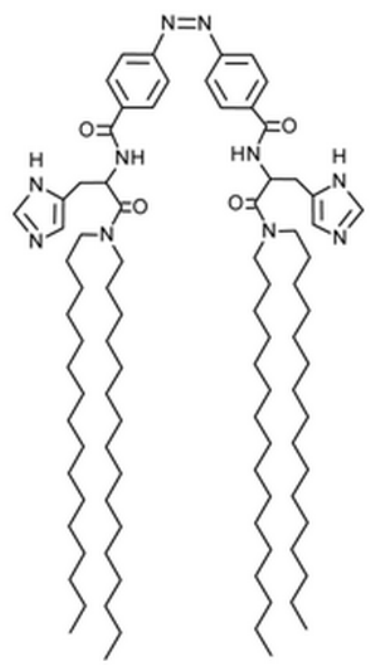

7

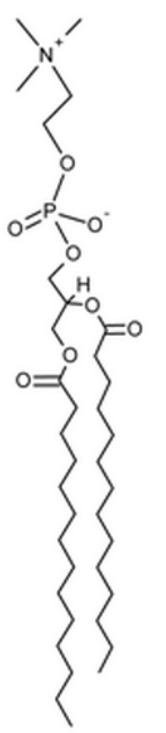

8

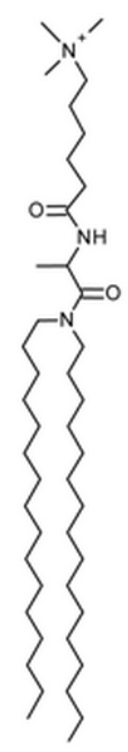

9

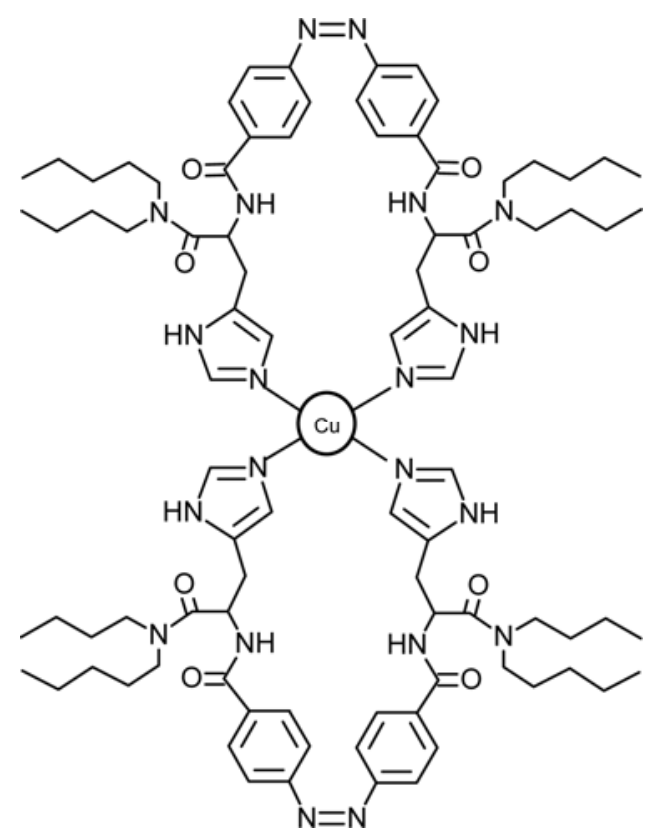

Figure 38. Photo-assembly of liposomes induced by metal chelates from gemini peptide lipids 7.

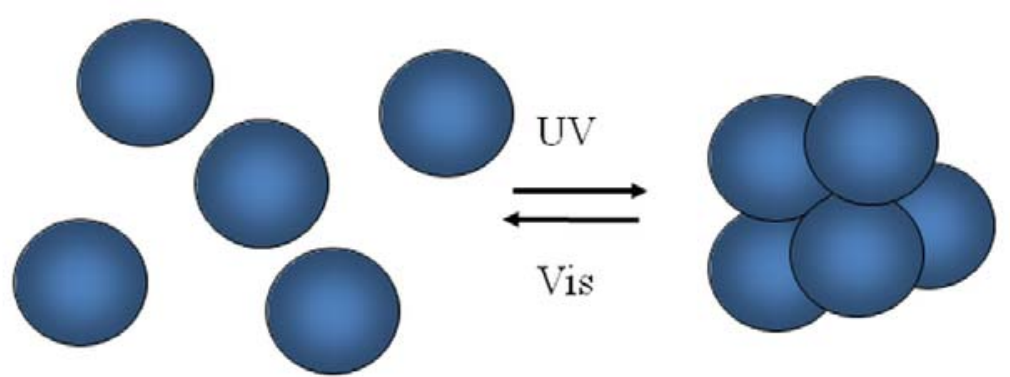


On the basis of these results, the authors have built an example of a molecular communication system formed by the previously described liposomes (small and giant dimensions, 100-200 nm and $10 \mu \mathrm{m}$, respectively) in an aqueous solution of $\mathrm{Cu}^{2+}$ or $\mathrm{Zn}^{2+}$ ions. The small liposomes act as a carry information system, while the giant liposomes are the receiver system. Upon UV irradiation (activation of cis-form in gemini peptide lipids) the migration and assembly of small liposomes around the giant ones was observed due to the increase of $\mathrm{Zn}^{2+}$-binding affinity (Figure 39). The migration was followed by changes in molar circular dichroism, hydrodynamic diameter, and optical microscopy observations.

Figure 39. Photo-induced migration and assembly of small liposomes.

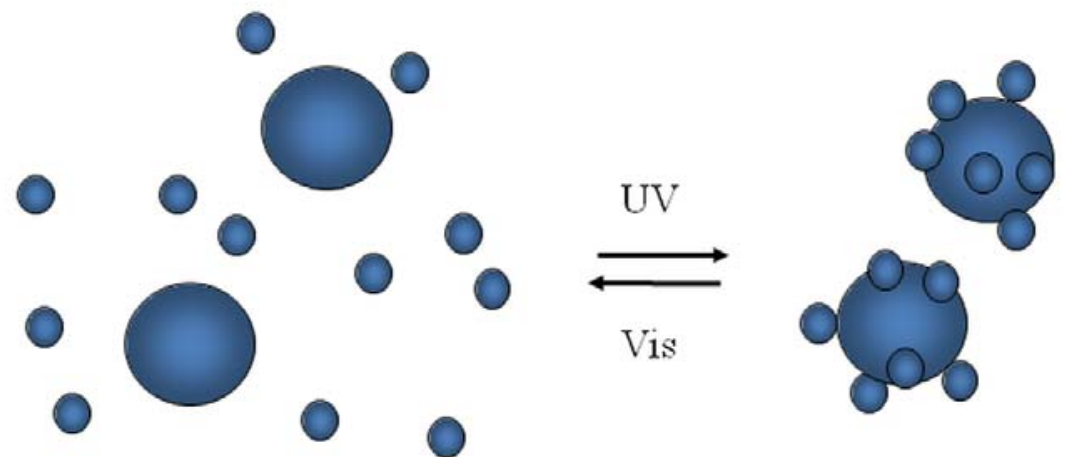

The molecular switch in the receiver was also able to tune the activity of an enzyme. The authors used bilayer vesicles from cationic peptide lipids, $N, N$-dihexadecyl- $N^{\alpha}$-[6-(trimethylammonium) hexanoyl]-L-alaninamide bromide (9), and gemini peptide lipids in $\mathrm{Cu}^{2+}$ aqueous solution. Since cationic bilayer vesicles are able to immobilize L-lactate dehydrogenase [259] and $\mathrm{Cu}^{2+}$ ions [260] able to inhibit the enzyme activity, the authors immobilized L-lactate dehydrogenase enzyme on bilayer vesicles and used UV/Vis light to control the binding/release of $\mathrm{Cu}^{2+}$ ions and, consequently to amplify/reduce the enzyme activity as shown in Figure 40. Even if the molecular switch has analogous binding affinity towards $\mathrm{Cu}^{2+}$ and $\mathrm{Zn}^{2+}$ ions, the enzymatic activity was specifically inhibited only by $\mathrm{Cu}^{2+}$ ions.

Figure 40. Photo-control of enzymatic activity.
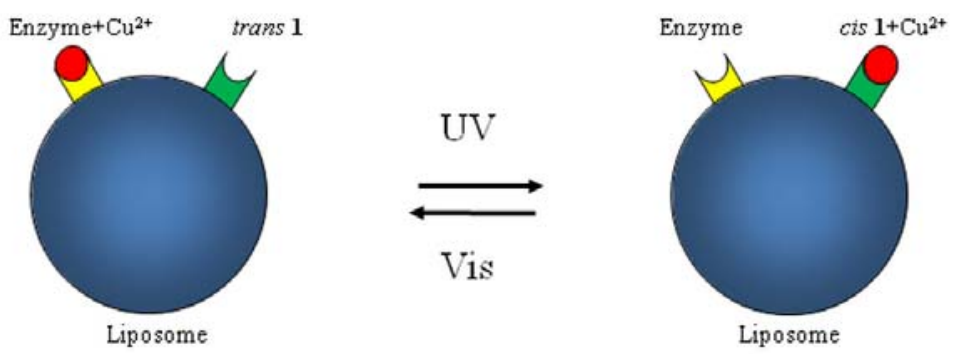

Another photo-responsive device was fabricated from an AZB contained organoalkoxysilylated lipid with two triethoxysilyl heads, a hydrophobic double-chain segment, an AZB moiety and a 
connector unit (Figure 41). Such lipids can self-assemble into photo-responsive cerasomes (spherical vesicles with a $100 \mathrm{~nm}$ diameter) with a silicate surface and are able to undergo structural transformation upon UV irradiation, allowing the release of a guest molecule from the liposome membrane. The loading/release properties of liposomes are due to the internal liposomal bilayer structure, which is characterized by low rigidity and density, to the external atomic layer of polyorganosiloxane, which imparts higher morphology stability to cerasomes than that shown by conventional liposomes, and to the photo-isomerizable moieties, which control the release of loaded molecule by light without changing the average liposome size. As a model drug, the release of Nile Red molecules from the hydrophobic compartment to phosphate buffered saline solution was investigated as a function of irradiation time by fluorescence spectroscopy. The UV exposure determines the cis-isomerization of photo-responsive tails enhancing the repulsive interactions among amphiphilic moieties and increasing the Nile Red permeability across the membrane. After UV irradiation for $20 \mathrm{~min}$ about $50 \%$ of Nile Red was released, while no release was observed in dark conditions.

Figure 41. Azobenzene contained organoalkoxysilylated lipid.

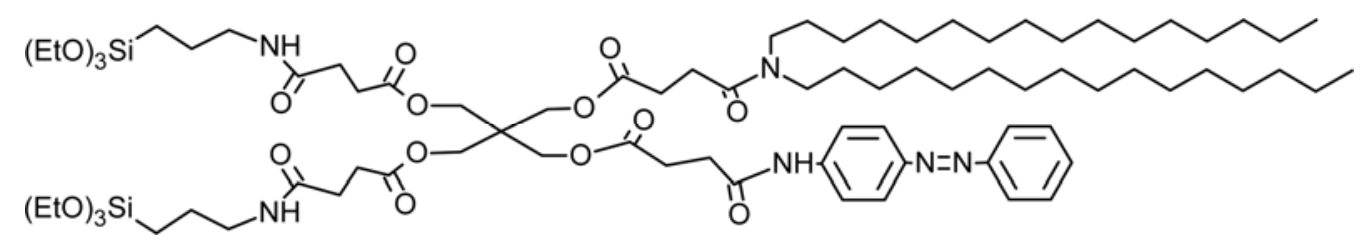

AZB amphiphiles have been used to control the phase separation in multicomponent giant vesicles [261]. A change in the conformation of the photo-responsive amphiphile (KAON12, 40\% mol), according to Figure 42, can switch reversible lateral segregations (a kind of liquid order $\rightarrow$ liquid disorder transition) in vesicles of lipid mixtures of 1,2-dioleoyl-sn-glycero-3-phosphocholine, 1,2-dipalmitoyl-sn-glycero-3-phosphocholine, and cholesterol (24, 12 and $24 \%$ mol, respectively). Before UV irradiation, i.e., in the trans form of KAON12, the membrane surface appears homogeneous without segregation domains; then many small segregation domains appear. The process is reversible by green light irradiation, which "erases" the induced segregations. The phase separation appears as a consequence of a photo-induced increase in the interfacial energy at the domain edges (line tension).

Even in the case of a non-reversible process photo-responsive amphiphiles can be useful in interesting biological applications. Benkoski et al. [262] have presented a method for releasing tethered liposomes from a supported lipid bilayer as a function of flow rate and UV irradiation. The tethering is achieved by an amphiphilic molecule with a photo-responsive polymer, poly(2-vinyl-8hydroxyquinoline-r-8-vinyl-1-naphthoic acid), PVHQ, as the hydrophobic block and DNA as the hydrophilic block. PVHQ shows side groups that can undergo excited state proton transfer in water with a dramatic shift in pKa under UV exposure $\left(90 \mathrm{~mW} / \mathrm{cm}^{2}\right)$. Upon excitation PVHQ undergoes both the loss of a proton at the hydroxyl group and the gain of a proton on the nitrogen heteroatom in the quinoline ring. The increase in polarity converts the polymer from a lipophilic molecule into a hydrophilic one, changing the partitioning of the molecule in and out of the lipid membrane and allowing the release of tethered liposomes. In their paper the authors tethered 1-palmitoyl-2-oleoyl-sn- 
glycero-phosphocholinevesicles to a lipid bilayer by a tether of DNA; the ends of which were formed by PVHQ-DNA and cholesterol-DNA conjugates. Liposomes were strongly bound to substrates by a DNA tether in the absence of UV light or in the presence of slow buffer flow. At high flow rate of buffer solution $(0.3 \mathrm{~mL} / \mathrm{s})$, liposomes desorbed, but in presence of UV light the critical buffer flow to obtain liposome release was reduced to half $(0.1-0.2 \mathrm{~mL} / \mathrm{s})$. Desorption in the absence of buffer flow may be possible at high UV intensity. No release was observed even at high flow rate if both ends of the tether were formed by cholesterol-DNA conjugates.

Figure 42. Chemical formula of KAON12.
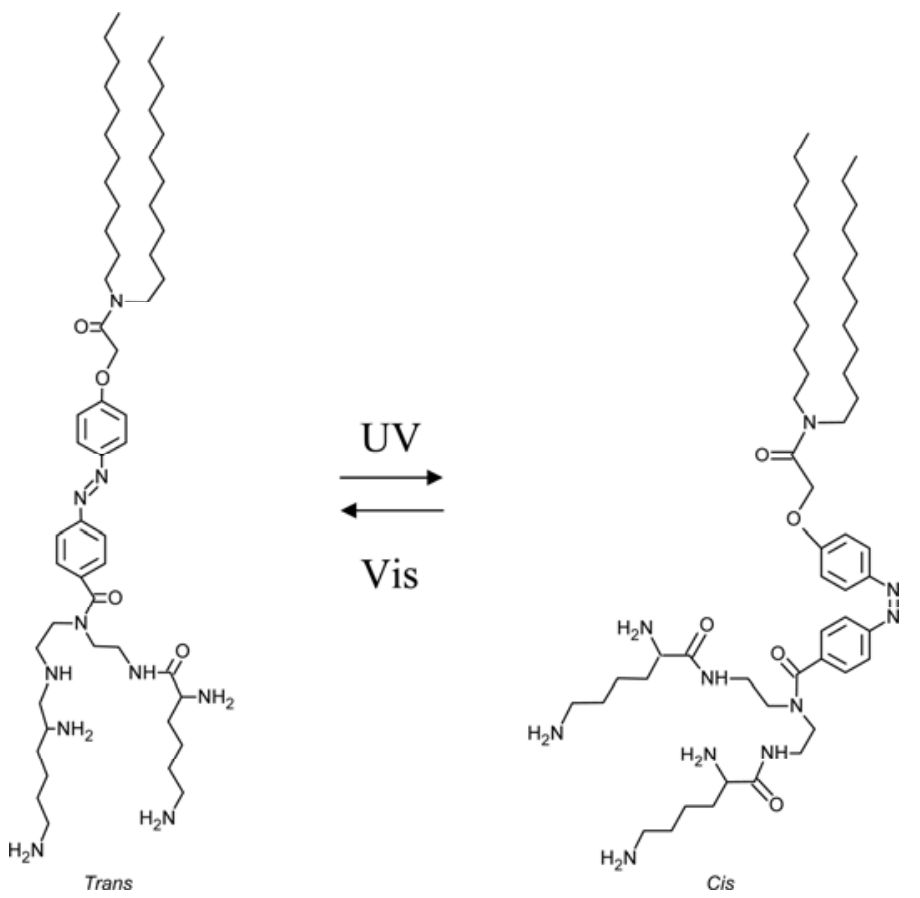

Photo-responsive amphiphiles can be used to control vesicle formation or disruption in model systems for targeted drug delivery. In such systems, drug molecules contained in vesicles are released when triggered by light as an external stimulus [263-265]. A Malachite Green Leuconitrile derivative, MGL, when ionized photo-chemically (Figure 43), exhibits both hydrophilicity and hydrophobicity by its triphenylmethyl cation and its long alkyl chain, respectively. Upon UV irradiation the photo-generated amphiphilicity of MGL can perturb the vesicle bilayer of two single-tailed amphiphiles with oppositely charged head groups consisting of cetyltrimethylammonium chloride, CTAC, and sodium octyl sulfate, SOS [266]. The destabilized bilayer induces a remarkable change in vesicle aggregation depending on the mixing ratio of CTAC/SOS. A small amount of MGL is sufficient to induce an increase of the average size of the vesicle diameter from 116 to $243 \mathrm{~nm}$ in the $[\mathrm{CTAC}] /[\mathrm{SOS}]=0.48$ system, whereas this led to an increase in vesicle size polydispersity in $[\mathrm{CTAC}] /[\mathrm{SOS}]=0.18$ system because the bilayer destabilization proceeds through different processes such as disruption, transformation into smaller vesicles and micelles, rearrangement of bilayer packing, and fusion. 
Figure 43. Chemical formula of Malachite Green Leuconitrile derivative.
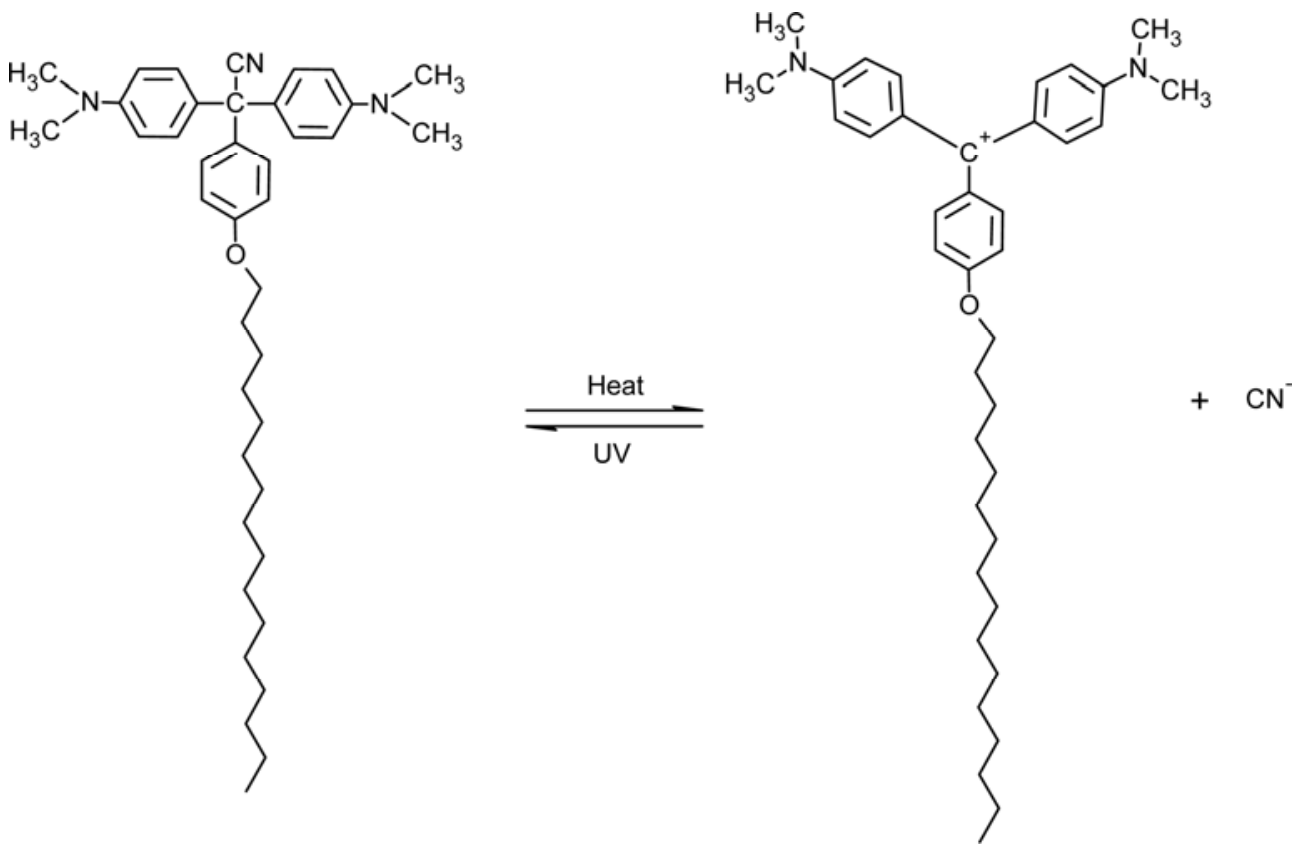

Uda et al. [267] have characterized the photo-induced morphological changes in phosphatidylcholine vesicles containing small amounts of MGL (less than $5 \mathrm{~mol} \%$ ). Under dark irradiation, the vesicles show spherical with uni- or oligo-lamellar structures. UV irradiation induces non-spherical vesicle morphology. These morphological changes may be accompanied by vesicle fusion $(0<\mathrm{MGL}<1.4 \mathrm{~mol} \%$ ) or photo-induced membrane solubilization (MGL $>2-3 \mathrm{~mol} \%$ ) and the release of vesicle encapsulated drug (or dye) is promoted as the concentration of MGL increases. Membrane solubilization is due to increased destabilization of the vesicle membrane of photo-ionized MGL and is responsible for the opening morphology of the vesicles.

Matsumura et al. [268] have synthesized a photo-responsive azobenzene-modified amphiphile, 4-butylazobenzene-4'-(oxyethyl)trimethylammoniumbromide (AZTMA), and investigated the photo-chemical control of vesicle disintegration and reformation in aqueous solution by mixing the cationic surfactant AZTMA with an anionic surfactant sodium dodecylbenzenesulfonate, SDBS (Figure 44).

Figure 44. Chemical formula of AZTMA.

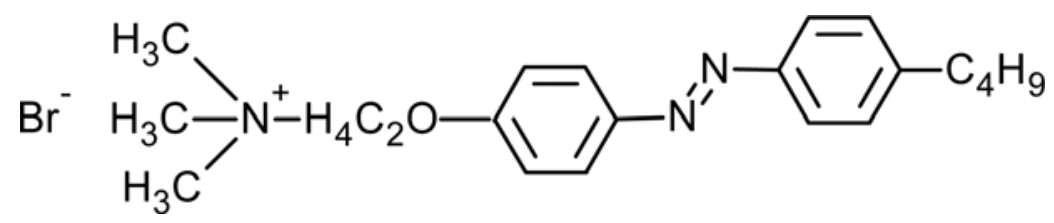

Vesicles spontaneously form at wide-ranging composition of the trans-AZTMA/SDBS system. Upon UV irradiation, the stability of the vesicles is reduced because of increases in the critical packing parameter, CPP, as a result of the bulky structure of cis-AZTMA. CPP is given by $V / a_{0} l_{c}$, in which $V$ is the volume of the hydrophobic group, $a_{0}$ is the surface area of the hydrophilic group, and $l_{c}$ is the length of the hydrophobic group [269]. The reformation of vesicles was observed after visible light 
irradiation. In addition, UV light irradiation raised the critical micelle concentrations of AZTMA. Thus, in the AZTMA-rich composition, a solution, which was in a micellar state before light irradiation, changed to a vesicular state after UV light irradiation and visible light irradiation allowed the return to a micellar solution as confirmed by change in the scattered light intensity and the electroconductivity measurements [270].

\section{Conclusions}

This paper reviews the recent progress in light-driven materials and membranes. Different classes of photoswitching and related mechanisms are examined. The advantages of using photo-switching derivates in membranes are discussed. The attractive opportunity to direct changing surface properties towards the construction of molecular machines is examined as well as the construction of programmable valved gates towards selective transport of ions, liquids and gases. Different categories of polymeric adaptive systems are considered and highlighted applications of photo-responsive membranes in biotechnology, chemistry and biology are reported.

\section{List of Abbreviations}

AZB: azobenzene

AZTMA: 4-butylazobenzene-4'-(oxyethyl)trimethylammoniumbromide

BSP: benzospiropyran

CA: contact angle

CD: circular dichroism

CPP: critical packing parameter

CTAC: cetyltrimethylammonium chloride

DMF: $N, N$-dimethylformamide

$E, E_{\text {appl }}$ : electric field across liquid crystal droplet, applied external field

FM: 4-\{4-[2,6-bis(n-butylamino)pyridine-4-yl]-phenylazo\}-phenyl methacrylate

$F_{y}$ : net force on the drop

G0, G1, G2: first, second, third generation dendrimers

h: Planck's constant

MB: methylene blue

MC: merocyanine

MGL: malachite green leuconitrile

MIP: molecularly imprinted polymer

MMA, PMMA: methylmethacrylate, polymethylmethacrylate

PA: polyacrylamide

PDLC: polymer dispersed liquid crystals

PEG: poly(ethylene glycol)

PEG-CA: cinnamylidene acetate modified PEG

PET: polyethylene terephthalate

PGA: poly(L-glutamic acid)

PMO: periodic mesoporous organosilica 
PM6AzCOOH: carboxylic azopolymer

PNA: 2-nitro-4'-methoxyazobenzene

poly(NSP-co-MMA): nitrobenzospiropyran-methyl methacrylate copolymer

PVHQ: poly(2-vinyl-8-hydroxyquinoline-r-8-vinyl-1-naphthoic acid)

SAM: self-assembled monolayer

SP: spiropyran

SPMMA/MMA: spirobenzopyran/methylmethacrylate copolymer

TPMLH: bis-[4-\{dimethylamino\}phenyl] \{4-vinyl-phenyl\} methyl leucohydroxide

SDBS: sodium dodecylbenzenesulfonate

SOS: sodium octyl sulfate

$\mathrm{S}_{\text {trans/cis }}$ : trans/cis selectivity

$V$ : volume of the hydrophobic group

$w$ : drop width

$a_{0}$ : surface area of the hydrophilic group

$l_{c}$ : length of the hydrophobic group

UV: ultraviolet light

Vis: visible light

$\alpha_{(a / b)}:$ mixture separation factor

$\Delta$ : heat or thermal relaxation

$\Delta \mathrm{E}$ : energy band-gap

$v, v$ ': frequency

$\theta$ : contact angle value

$\gamma_{L V}$ : surface free energy of the liquid-vapor interface

$\gamma_{S L}$ : surface free energy of the solid-liquid interface

$\gamma_{S v}$ : surface free energy of the solid-vapor interface

$\sigma_{\text {matrix }}, \sigma_{\mathrm{LC}}$ : polymer matrix electric conductivity, liquid crystal electric conductivity

\section{References}

1. Fendler, J.H. Membrane Mimetic Chemistry; John Wiley Press: New York, NY, USA, 1982.

2. Kotyk, A.; Janacek, K.; Koryta, J. Biophysical Chemistry of Membrane Functions; John Wiley Press: New York, NY, USA, 1988.

3. Kinoshita, T. Biomembrane mimetic systems. Prog. Polym. Sci. 1995, 20, 527-583.

4. Balzani, V. Supramolecular Photo-Chemistry; Reidel Publishing: Dordrecht, The Netherlands, 1987.

5. Irie, M. Photo-responsive polymers. Adv. Polym. Sci. 1990, 94, 27-67.

6. Kumano, A.; Niwa, O.; Kajiyama, T.; Takayanagi, M.; Kano, K.; Shinkai, S. Photo-induced ion permeation through ternary composite membrane composed of polymer/liquid crystal/ azobenzene bridged crown ether. Chem. Lett. 1983, 12, 1327-1330.

7. Anzai, J.; Hasebe, Y.; Ueno, A.; Osa, T. Photo-excitable membranes. Photo-induced potential changes across poly(vinyl chloride) membranes doped with a photo-sensitive crown ether having lipophilic side chain. J. Polym. Sci. A-Polym. Chem. 1988, 26, 1519-1529. 
8. Anzai, J.; Sasaki, A.; Ueno, A.; Osa, T. Photo-chemically-induced asymmetric membranepotential across poly(vinyl-chloride) spirobenzopyran membranes. Chem. Lett. 1985, 14, 1443-1446.

9. Smetz, G.; Braeken, J.; Irie, M. Photo-mechanical effects in photo-chromic systems. Pure Appl. Chem. 1978, 50, 845-856.

10. Shinkai, S.; Kinda, H.; Manabe, O. Photo-responsive complexation of metal cations with an azobenzene-crown-azobenzene bridge immobilized in polymer supports. J. Am. Chem. Soc. 1982, 104, 2933-2934.

11. Irie, M.; Tanaka, H. Photo-responsive polymers. 5. Reversible solubility change of polystyrene having azobenzene pendant groups. Macromolecules 1983, 16, 210-214.

12. Ishihara, K.; Negishi, N.; Shinohara, I. Adsorption of photo-chromic azo dye onto styrene-divinylbenzene copolymer. J. Polym. Sci. Polym. Lett. Ed. 1981, 19, 593-587.

13. Negishi, N.; Iida, K.; Ishihara, K.; Shinohara, I. Photo-regulated binding ability of a polymeric adsorbent containing a spiro[2H-chromen-2,2'-indoline] moiety. Makromol. Chem.-Rapid 1981, 2, 617-620.

14. Malcolm, B.R.; Pieroni, O. The photo-response of an azobenzene-containing poly(L-lysine) in the monolayer state. Biopolymers 1990, 29, 1121-1123.

15. Morishima, Y.; Tsuji, M.; Kamachi, M.; Hatada, K. Photo-chromic isomerization of azobenzene moieties compartmentalized in hydrophobic microdomains in a microphase structure of amphiphilic polyelectrolytes. Macromolecules 1992, 25, 4406-4410.

16. Crano, J.C.; Flood, T.; Knowles, D.; Kumar, A.; van Gemert, B. Photocromic compounds: Chemistry and application in ophthalmic lenses. Pure Appl. Chem. 1996, 68, 1395-1398.

17. Minkin, V.I. Photo-, thermo-, solvato-, and electrochromic spiroheterocyclic compounds. Chem. Rev. 2004, 104, 2751-2776.

18. Radu, A.; Byrne, R.; Alhashimy, N.; Fusaro, M.; Scarmagnani, S. Diamond, D. N,S co-doped and N-doped Degussa P-25 powders with visible light response prepared by mechanical mixing of thiourea and urea. Reactivity towards E. coli inactivation and phenol oxidation. J. Photoc. Photobio A 2009, 206, 109-115.

19. Gorner, H.; Chibisov, A.K. Complexes of spiropyran-derived merocyanines with metal ions thermally activated and light-induced processes. J. Chem. Soc. Faraday T. 1998, 94, 2557-2564.

20. Andersson, J.; Li, S.; Lincoln, P.; Andreasson, J. Photoswitched DNA-binding of a photochromic spiropyran. J. Am. Chem. Soc. 2008, 130, 11836-11837.

21. Ipe, B.I.; Mahima, S.; Thomas, K.G. Light-induced modulation of self-assembly on spiropyran-capped gold nanoparticles: A potential system for the controlled release of amino acid derivatives. J. Am. Chem. Soc. 2003, 125, 7174-7175.

22. Scarmagnani, S.; Slater, C.; Benito-Lopez, F.; Diamond, D.; Walsh, Z.; Paull, B.; Macka, M. Photoreversible ion-binding using spiropyran modified silica microbeads. Int. J. Nanomanufacturing 2010, 5, 38-52.

23. De Gennes, P.G.; Prost, J. The Physics of Liquid Crystals, 2nd ed.; Clarendon Press: Oxford, UK, 1993. 
24. Seki, T.; Tamaki, T.; Suzuki, Y.; Kawanishi, K.; Ichimura, K.; Aoki, K. Photo-chemical alignment regulation of a nematic liquid crystal by Langmuir-Blodgett layers of azobenzene polymers as "command surfaces". Macromolecules 1989, 22, 3505-3506.

25. Seki, T.; Fukuda, R., T.; Ichimura, K. Alignment photo-regulation of liquid crystals on precisely area controlled azobenzene Langmuir-Blodgett monolayers. Thin Solid Films 1994, 243, $675-678$.

26. Seki, T.; Sakuragi, M.; Kawanishi, K.; Suzuki, Y.; Tamaki, T.; Fukuda, R.; Ichimura, K. "Command surfaces" of Langmuir-Blodgett films. Photo-regulation of liquid crystal alignment by molecularly tailored surface azobenzene layers. Langmuir 1993, 9, 211-218.

27. Zolot'ko, A.S.; Kitaeva, V.F.; Kroo, N.; Sobolev, N.N.; Chillag, L. The effect of an optical field on the nematic phase of the liquid crystal OCBP. JETP Lett. 1980, 32, 158-162.

28. Durbin, S.D.; Arakelian, S.M.; Shen, Y.H. Optical-field-induced birefringence and Freedericksz transition in a nematic liquid crystal. Phys. Rev. Lett. 1981, 47, 1411-1414.

29. Khoo, I.C. Optically induced molecular reorientation and third-order nonlinear optical processes in nematic liquid crystals. Phys. Rev. A 1981, 28, 2077-2081.

30. Janossy, I.; Csillag, L.; Lloyd, A.D. Temperature dependence of the optical Freedericksz transition in dyed nematic liquid crystals. Phys. Rev. A 1991, 44, 8410-8413.

31. Zebger, I.; Rutloh, M.; Hoffmann, U.; Stumpe, J.; Siesler, H.W.; Hvilsted, S. Photoorientation of a liquid crystalline polyester with azobenzene side groups.1. Effects of irradiation with linearly polarized blue light. J. Phys. Chem. A 2002, 106, 3454-3462.

32. Folks, W.R.; Keast, S.; Krentzel, T.A.; Zalar, B.; Zeng, H.; Reznikov, Yu.A.; Neubert, M.; Kumar, S.; Finotello, D.; Lavrentovich, O.D. Photocontrol of smectic spacing. Mol. Cryst. Liq. Cryst. 1998, 320, 77-88.

33. Lansac, Y.; Glaser, M.A.; Clark, N.A.; Lavrentovich, O.D. Photocontrolled nanophase segregation in a liquid-crystal solvent. Nature 1999, 398, 54-57.

34. Voloschenko, D.; Lavrentovich, O.D. Light-induced director-controlled microassembly of dye molecules from a liquid crystal matrix. J. Appl. Phys. 1999, 86, 4843-4846.

35. Chandran, S.P.; Mondiot, F.; Mondain-Monval, O.; Loudet, J.C. Photonic control of surface anchoring on solid colloids dispersed in liquid crystals. Langmuir 2011, 27, 15185-15198.

36. De Filpo, G.; Nicoletta, F.P.; Chidichimo, G. Cholesteric emulsions for colored displays. Adv. Mater. 2005, 17, 1150-1152.

37. Kinoshita, T.; Sato, M.; Takizawa, A.; Tsujita, Y. Photo-control of polypeptide membrane permeabilities by cis-trans isomerism in side chain azobenzene groups. J. Chem. Soc. Chem. Comm. 1984, 14, 929-930.

38. Kinoshita, T.; Sato, M.; Takizawa, A.; Tsujita, Y. Photo-control of polypeptide membrane functions by cis-trans isomerization in side-chain azobenzene groups. Macromolecules 1986, 19, 51-55.

39. Sato, M.; Kinoshita, T.; Takizawa, A.; Tsujita, Y. Photo-induced conformational transition of polypeptides containing azobenzenesulfonate in the side chains. Macromolecules 1988, 21, $1612-1616$. 
40. Sato, M.; Kinoshita, T.; Takizawa, A.; Tsujita, Y.; Osada, T. Photo-control of polypeptide membrane structure and functions by cis-trans isomerization in side-chain azobenzenesulfonate groups. Polym. J. 1989, 21, 533-541.

41. Sato, M.; Kinoshita, T.; Takizawa, A.; Tsujita, Y.; Ito, R. Permeability changes of a porous membrane by an adsorbed photo-responsive polypeptide. Polym. J. 1989, 21, 761-769.

42. Kinoshita, T.; Sato, M.; Takizawa, A.; Tsujita, Y. Photo-induced reversible conformational transition of polypeptide solid membranes. J. Am. Chem. Soc. 1986, 108, 6399-6401.

43. Sato, M.; Kinoshita, T.; Takizawa, A.; Tsujita, Y. Photo-induced conformational transition of polypeptide membrane composed of poly(L-glutamic acid) containing pararosaniline groups in the side chains. Macromolecules 1988, 21, 3419-3424.

44. Sato, M.; Kinoshita, T.; Takizawa, A.; Tsujita, Y.; Osada, T. Photo-control of polypeptide membrane functions by photo-dissociation of pararosaniline side-chain groups. Polym. J. 1988, 20, 729-738.

45. Sato, M.; Kinoshita, T.; Takizawa, A.; Tsujita, Y.; Osada, T. Photo-control of the structure and functions of a polypeptide membrane composed of poly(L-glutamic acid) containing pararosaniline leucocyanide groups in the side-chains. Polym. J. 1989, 21, 369-376.

46. Aoyama, M.; Youda, A.; Watanabe, J.; Inoue, S. Synthesis and circular dichroic and photoresponsive properties of a graft copolymer containing an azoaromatic polypeptide branch and its membrane. Macromolecules 1990, 23, 1458-1463.

47. Aoyama, M.; Watanabe, J.; Inoue, S. Photo-regulation of permeability across a membrane from graft copolymer containing a photo-responsive polypeptide branch. J. Am. Chem. Soc. 1990, 112, $5542-5545$.

48. Higuchi, M.; Kinoshita, T. Photo-responsive behavior of self-assembling systems by amphiphilic $\alpha$-helix with azobenzene unit. J. Photochem. Photobiol. B Biol. 1998, 42, 143-150.

49. Higuchi, M.; Minoura, N.; Kinoshita, T. Photo-control of molecular orientation of a photo-responsive amphiphilic $\alpha$-helix in a lipid monolayer. Langmuir 1997, 13, 1616-1622.

50. Klajn, R. Immobilized azobenzenes for the construction of photoresponsive materials. Pure Appl. Chem. 2010, 82, 2247-2279.

51. Han, M.; Ishikawa, D.; Honda, T.; Ito, E.; Hara, M. Light-driven molecular switches in azobenzene self-assembled monolayers: effect of molecular structure on reversible photoisomerization and stable cis state. Chem. Commun. 2010, 46, 3598-3600.

52. Takamatsu, D.; Fukui, K.; Aroua, S.; Yamakoshi, Y. Photoswitching tripodal single molecular tip for noncontact AFM measurements: synthesis, immobilization, and reversible configurational change on gold surface. Org. Biomol. Chem. 2010, 8, 3655-3664.

53. Tamada, K.; Akiyama, H.; Wei, T.X.; Kim, S.A. Photoisomerization reaction of unsymmetrical azobenzene disulfide self-assembled monolayers: modification of azobenzene dyes to improve thermal endurance for photoreaction. Langmuir 2003, 19, 2306-2312.

54. Nagahiro, T.; Akiyama, H.; Hara, M.; Tamada, K. Photoisomerization of azobenzene containing self-assembled monolayers investigated by Kelvin probe work function measurements. J. Electron Spectrosc. Relat. Phenom. 2009, 172, 128-133. 
55. Bouwstra, J.A.; Schouten, A.; Kroon, J. Structural studies of the system trans-azobenzene /transstilbene. I. A reinvestigation of the disorder in the crystal structure of trans-azobenzene, $\mathrm{C}_{12} \mathrm{H}_{10} \mathrm{~N}_{2}$. ACTA Crystallogra. A 1983, 39, 1121-1123.

56. Jung, U.; Muller, M.; Fujimoto, N.; Ikeda, K.; Uosaki, K.; Cornelissen, U.; Tuczek, F.; Bornholdt, C.; Zargarani, D.; Herges, R.; Magnussen, O. Gap-mode SERS studies of azobenzene-containing self-assembled monolayers on $\mathrm{Au}(111)$. J. Colloid Interf. Sci. 2010, 341, $366-375$.

57. Good, R.J.; van Oss, C.J. The modern theory of contact angles and the hydrogen bond components of surface energies. In Modern Approaches to Wettability; Schrader, M.E., Loeb, G.L., Eds.; Plenum Press: New York, NY, USA, 1992.

58. Siewierski, L.M.; Brittain, W.J.; Pdtrash, S.; Foster, M.D. Photoresponsive monolayers containing in-chain azobenzene. Langmuir 1996, 12, 5838-5844.

59. Tylkowski, B.; Peris, S.; Giamberini, M.; Garcia-Valls, R.; Reina, J.A.; Ronda, J.C. Light-induced switching of the wettability of novel asymmetrical poly(vinyl alcohol)-co-ethylene membranes blended with azobenzene polymers. Langmuir 2010, 26, 14821-14829.

60. Berkovic, G.; Krongauz, V.; Weiss, V. Spiropyrans and spirooxazines for memories and switches. Chem. Rev. 2000, 100, 1741-1754.

61. Nayak, A.; Liu, H.; Belfort, G. An optically reversible switching membrane surface. Angew. Chem. Int. Ed. 2006, 45, 4094-4098.

62. Vlassiouk, I.; Park, C.D.; Vail, S.A.; Gust, D.; Smirnov, S. Control of nanopore wetting by a photocromic spiropyran-A light-controlled valve and electrical switch. Nano Lett. 2006, 6, 1013-1017.

63. Uchida, K.; Izumi, N.; Sukata, S.; Kojima, Y.; Nakamura, S.; Irie, M. Photoinduced reversible formation of microfibrils on a photochromic diarylethene microcrystalline surface. Angew. Chem. Int. Ed. 2006, 45, 6470-6473.

64. Lim, H.S.; Han, J.T.; Kwak, D.; Jin, M.; Cho, K. Photoreversibly switchable superhydrophobic surface with erasable and rewritable pattern. J. Am. Chem. Soc. 2006, 128, 14458-14459.

65. Berna, J.; Leigh, D.; Lubomska, M.; Mendoza, S.; Perez, E.; Rudolf, P.; Teobaldi, G.; Zerbetto, F. Macroscopic transport by synthetic molecular machines. Nat. Mater. 2005, 4, 704-710.

66. Delorme, N.; Bardeau, J.; Bulou, A.; Poncin-Epaillard, F. Azobenzene-containing monolayer with photoswitchable wettability. Langmuir 2005, 21, 12278-12282.

67. Jiang, W.; Wang, G.; He, Y.; Wang, X.; An, Y.; Song, Y.; Jiang, L. Photo-switched wettability on an electrostatic self-assembly azobenzene monolayer. Chem. Commun. 2005, 28, 3550-3552.

68. Ichimura, K.; Oh, S.K.; Nakagawa, M. Light-driven motion of liquids on a photoresponsive surface. Science 2000, 288, 1624-1626.

69. Yang, D.; Piech, M.; Bell, N.S.; Gust, D.; Vail, S.; Garcia, A.A.; Schneider, J.; Park, C.D.; Hayes, M.A.; Picraux, S.T. Photon control of liquid motion on reversibly photoresponsive surfaces. Langmuir 2007, 23, 10864-10872.

70. Kumar, S.K.; Hong, J.-D. Photoresponsive ion gating function of an azobenzene polyelectrolyte multilayer spin-self-assembled on a nanoporous support. Langmuir 2008, 24, 4190-4193. 
71. Sumaru, K.; Ohi, K.; Takagi, T.; Kanamori, T.; Shinbo, T. Photoresponsive properties of poly( $N$-isopropylacrylamide) hydrogel partly modified with spirobenzopyran. Langmuir 2006, $22,4353-4356$.

72. Zhou, X.F.; Yu, C.Z.; Tang, J.W.; Yan, X.X.; Zhao, D.Y. The effect of water content on the preparation of mesoporous monoliths and films. Micropo. Mesopor. Mat. 2005, 79, 283-289.

73. Slowing, I.I.; Vivero-Escoto, J.L.; Wu, C.W.; Lin, V.S.Y. Mesoporous silica nanoparticles as controlled release drug delivery and gene transfection carriers. Adv. Drug Deliv. Rev. 2008, 60, $1278-1288$.

74. Maeda, K.; Nishiyama, T.; Yamazaki, T.; Suzuki, T.; Seki, T. Reversible photoswitching liquid-phase adsorption on azobenzene derivative-grafted mesoporous silica. Chem. Lett. 2006, $35,736-737$.

75. Ogawa, M.; Ishii, T.; Miyamoto, N.; Kuroda, K. Photocontrol of the basal spacing of azobenzene-magadiite intercalation compound. Adv. Mater. 2001, 13, 1107-1109.

76. Alvaro, M.; Ferrer, B.; Garcia, H.; Rey, F. Photochemical modification of the surface area and tortuosity of a trans-1,2-bis(4-pyridyl)ethylene periodic mesoporous MCM organosilica. Chem. Commun. 2002, 18, 2012-2013.

77. Liu, N.; Chen, Z.; Dunphy, D.R.; Jiang, Y.B.; Assink, R.A.; Brinker, C.J. Photoresponsive nanocomposite formed by self-assembly of an azobenzene-modified silane. Angew. Chem. Int. 2003, 42, 1731-1734.

78. Liu, N.; Dunphy, D.R.; Atanassov, P.; Bunge, S.D.; Chen, Z.; Lopez, G.P.; Boyle, T.J.; Brinker, J. Photoregulation of mass transport through a photoresponsive azobenzene-modified nanoporous membrane. Nano Lett. 2004, 4, 551-554.

79. Banghart, M.R.; Volgraf, M.; Trauner, D. Engeneering light-gated ion channels. Biochemistry 2006, 45, 15129-15141.

80. Sata, T. Studies on anion exchange membranes having permselectivity for specific anions in electrodialysis - Effect of hydrophilicity of anion exchange membranes on permselectivity of anions. J. Membrane Sci. 2000, 167, 1-31.

81. Sata, T.; Matsusaki, K. Generation of light-induced electrical potential from ion exchange membranes containing 4,4'-bipyridine moiety II. Effect of species of anion exchange membranes on photovoltage. J. Polym. Sci. Polym. Chem. Ed. 1996, 34, 2123-2134.

82. Sata, T.; Matsuo, Y.; Yamaguchi, T.; Matsusaki, K. Preparation and transport properties of anion-exchange membranes containing viologen moieties as anion exchange groups in the presence or absence of photoirradiation. J. Chem. Soc. Faraday Trans. 1997, 93, 2553-2560.

83. Sata, T.; Shimokawa, Y.; Matsusaki, K. Preparation of ion-permeable membranes having an azobenzene moiety and their transport properties in electrodialysis. J. Membrane Sci. 2000, 171, 31-43.

84. Byrne, R.; Ventura, C.; Lopez, F.B.; Walther, A.; Heise, A.; Diamond, D. Characterisation and analytical potential of a photo-responsive polymeric material based on spiropyran. Biosens. Bioelectron. 2010, 26, 1392-1398.

85. Byrne, R.; Diamond, D. Chemo/bio-sensor networks. Nat. Mater. 2006, 5, 421-424. 
86. Zakharova, M.I.; Coudret, C.; Pimienta, V.; Micheau, J.C.; Delbaere, S.; Vermeersch, G.; Metelitsa, A.V.; Voloshin, N.; Minkin, V.I. Quantitative investigations of cation complexation of photochromic 8-benzothiazole-substituted benzopyran: Towards metal-ion sensors. Photochem. Photobiol. Sci. 2010, 9, 199-207.

87. Fries, K.H.; Driskell, J.D.; Samanta, S.; Locklin, J. Spectroscopic analysis of metal ion binding in spiropyran containing copolymer thin films. Anal. Chem. 2010, 82, 3306-3314.

88. Ito, Y.; Park, Y.S. Signal-responsive gating of porous membranes by polymer brushes. Polym. Adv. Technol. 2000, 11, 136-144.

89. Irie, M.; Menju, A.; Hayashi, K. Photoresponsive polymers: Reversible solution viscosity change of poly(methyl methacrylate) having spirobenzopyran side groups. Macromolecules 1979, 12, 1176-1180.

90. Irie, M.; Iwanaga, T.; Taniguchi, Y. Photoresponsive polymers. 7. Reversible solubility change of polystyrene having pendant spirobenzopyran groups and its application to photoresists. Macromolecules 1985, 18, 2418-2422.

91. Balazs, A.C.; Kuksenok O.; Alexeev, A. Modeling the interactions between membranes and inclusions: Designing self-cleaning films and resealing pores. Macromol. Theor. Simul. 2009, 18, $11-24$.

92. Weh, K.; Noack, M.; Ruhmann, R.; Hoffmann, K.; Toussaint P.; Caro, J. Modification of the transport properties of a polymethacrylate-azobenzene membrane by photochemical switching. Chem. Eng. Technol. 1998, 21, 408-412.

93. Okahata, Y.; Lim, H.; Hachiya, S. Bilayer coated capsule membranes. Part 2. Photoresponsive permeability control of sodium chloride across a capsule membrane. J. Chem. Soc. Perkin Trans. 2 1984, 6, 989-994.

94. Balasubramanian, D.; Subramani, S.; Kumar, C. Dopamine inhibits adenylate cyclase in human prolactin-secreting pituitary adenomas. Nature 1975, 254, 252-254.

95. Tachibana, H.; Nakamura, T.; Matsumoto, M.; Komizu, H.; Manda, E.; Niino, H.; Yabe, A.; Kawabata, Y. Photochemical switching in conductive Langmuir-Blodgett films. J. Am. Chem. Soc. 1989, 111, 3080-3081.

96. Anzai, J.; Osa, T. Photosensitive artificial membranes based on azobenzene and spirobenzopyran derivatives. Tetrahedron 1994, 50, 4039-4070.

97. Pyrasch, M.; Toutianoush, A.; Jin, W.; Schnepf, J.; Tieke, B. Self-assembled films of Prussian blue and analogues: Optical and electrochemical properties and application as ion-sieving membranes. Chem. Mater. 2003, 15, 245-254.

98. Balachandra, A.M.; Dai, J.; Bruening, M.L. Enhancing the anion-transport selectivity of multilayer polyelectrolyte membranes by templating with $\mathrm{Cu}^{2+}$. Macromolecules 2002, 35, 3171-3178.

99. Hong, S.U.; Malaisamy, R.; Bruening, M.L. Separation of fluoride from other monovalent anions using multilayer polyelectrolyte nanofiltration membranes. Langmuir 2007, 23, 1716-1722.

100. Sullivan, D.M.; Bruening, M.L. Ultrathin, gas-selective polyimide membranes prepared from multilayer polyelectrolyte films. Chem. Mater. 2003, 15, 281-287.

101. Krasemann, L.; Tieke, B. Ultrathin self-assembled polyelectrolyte membranes for pervaporation. J. Membr. Sci. 1998, 150, 23-30. 
102. Sun, L.; Baker, G.L.; Bruening, M.L. Polymer brush membranes for pervaporation of organic solvents from water. Macromolecules 2005, 38, 2307-2314.

103. Jin, W.; Toutianoush, A.; Tieke, B. Use of polyelectrolyte layer-by-layer assemblies as nanofiltration and reverse osmosis membranes. Langmuir 2003, 19, 2550-2553.

104. Hiller, J.; Rubner, M.F. Reversible molecular memory and $\mathrm{pH}$-switchable swelling transitions in polyelectrolyte multilayers. Macromolecules 2003, 36, 4078-4083.

105. Park, M.-K.; Deng, S.; Advincula, R.C. pH-sensitive bipolar ion-permselective ultrathin films. J. Am. Chem. Soc. 2004, 126, 13723-13731.

106. Antipov, A.A.; Sukhorukov, G.B.; Mohwald, H. Influence of the ionic strength on the polyelectrolyte multilayers permeability. Langmuir 2003, 19, 2444-2448.

107. Ito, Y.; Inaba M.; Chung, D.J.; Imanishi, Y. Control of water permeation by $\mathrm{pH}$ and ionic strength through a porous membrane having poly(carboxylic acid) surface-grafted. Macromolecules 1992, 25, 7313-7316.

108. Jaber, J.A.; Schlenoff, J.B. Polyelectrolyte multilayers with reversible thermal responsivity. Macromolecules 2005, 38, 1300-1306.

109. Kharlampieva, E.; Kozlovskaya, V.; Tyutina, J.; Sukhishvili, S.A. Hydrogen-bonded multilayers of thermoresponsive polymers. Macromolecules 2005, 38, 10523-10531.

110. Kocer, A.; Walko, M.; Meijberg, W.; Feringa, B.L. A light-actuated nanovalve derived from a channel protein. Science 2005, 309, 755-758.

111. Hamada, T.; Sugimoto, R.; Vestergaard, M.C.; Nagasaki, T.; Takagi, M. Membrane disk and sphere: Controllable mesoscopic structure for the capture and release of a targeted object. J. Am. Chem. 2010, 132, 10528-10532.

112. Moniruzzaman, M.; Fernando, G.F.; Sabey, C.; Winter, D.; Badcock, R.A.; Akhavan, J.; Krofli, E. Synthesis and characterization of a novel class of photo-actuating and photo-rheological polymers. Proc. SPIE-Int. Soc. Opt. Eng. 2004, 5464, 209-220.

113. Ueda, M.; Kudo, K.; Ichimura, K. Photo-chromic behavior of a spirobenzopyran chemisorbed on a colloidal silica surface. J. Mater. Chem. 1995, 5, 1007-1011.

114. Ueda, M.; Kim, H.-B.; Ichimura, K. Photo-controlled aggregation of colloidal silica. J. Mater. Chem. 1994, 4, 883-889.

115. Bell, N.S.; Piech, M. Photo-physical effects between spirobenzopyran-methyl methacrylate-functionalized colloidal particles. Langmuir 2006, 22, 1420-1427.

116. Rosario, R.; Gust, D.; Garcia, A.A.; Hayes M.; Taraci, J.L.; Clement, T.; Dailey, J.W.; Picraux, S.T. Lotus effect amplifies light-induced contact angle switching. J. Phys. Chem. B 2004, 108, 12640-12642.

117. And, E.; Miyazaki, J.; Moriomoto, K.J. Aggregation of photo-chromic spiropyran in Langmuir-Blodgett-films. Thin Solid Films 1985, 133, 21-28.

118. Park, Y.S.; Ito, Y.; Imanishi, Y. Photo-controlled gating by polymer brushes grafted on porous glass filter. Macromolecules 1998, 31, 2606-2610.

119. Chung, D.J.; Ito, Y.; Imanishi, Y. Preparation of porous membranes grafted with poly(spiropyran-containing methacrylate) and photo-control of permeability. J. Appl. Polym. Sci. 1994, 51, 2027-2033. 
120. Kalisky, Y.; Williams, D.J. Laser photo-lysis studies of photo-induced aggregation in polymers containing spiropyran units. Macromolecules 1984, 17, 292-296.

121. Kimura, K.; Sumida, M.; Yokoyama, M. Drastic metal-ion enhancement in photo-induced aggregation of copolymers carrying crown ether and spirobenzopyran moieties. Chem. Commun. 1997, 15, 1417-1418.

122. Kimura, K.; Sakamoto, H.; Nakamura, T. Application of photo-responsive polymers carrying crown ether and spirobenzopyran side chains to photo-chemical valve. J. Nanosci. Nanotechnol. 2006, 6, 1741-1749.

123. Krongauz, V.A.; Goldburt, E.S. Crystallization of poly(spiropyran methacrylate) with cooperative spiropyran-merocyanine conversion. Macromolecules 1981, 14, 1382-1386.

124. Fyles, T.M. Electrostatic ion binding by synthetic receptors. In Cation Binding by Macrocycles: Complexation of Cationic Species by Crown Ethers; Inoue, Y., Gokel, G.W., Eds.; Marcel-Dekker: New York, NY, USA, 1990; pp. 203-251.

125. Shinkai, S. Dynamic control of cation binding. In Cation Binding by Macrocycles: Complexation of Cationic Species by Crown Ethers; Inoue, Y., Gokel, G.W., Eds.; Marcel-Dekker: New York, NY, USA, 1990; pp. 397-428.

126. Sakamoto, H.; Takagaki, H.; Nakamura, M.; Kimura K. Photo-responsive liquid membrane transport of alkali metal ions using crowned spirobenzopyrans. Anal. Chem. 2005, 77, 1999-2006.

127. Sakamoto, H.; Yokohata, T.; Yamakura, T.; Kimura, K. Liquid-liquid extraction of alkali metal ions with photo-chromic crowned spirobenzopyrans. Anal. Chem. 2002, 74, 2522-2528.

128. Nakamura, M.; Takahashi, K.; Fujioka, T.; Kado, S.; Sakamoto, H.; Kimura, K. Evaluation of photo-induced changes in stability constants for metal-ion complexes of crowned spirobenzopyran derivatives by electrospray ionization mass spectrometry. J. Am. Soc. Mass Spectrom. 2003, 14, 1110-1115.

129. Haupt, K.; Mosbach, K. Molecularly imprinted polymers and their use in biomimetic sensors. Chem. Rev. 2000, 100, 2495-2504.

130. Wulff, G. Enzyme-like catalysis by molecularly imprinted polymers. Chem. Rev. 2002, 102, $1-27$.

131. Hilt, J.Z.; Byrne, M.E. Configurational biomimesis in drug delivery: Molecular imprinting of biologically significant molecules. Adv. Drug Deliv. Rev. 2004, 56, 1599-1620.

132. Alexander, C.; Andersson, H.S.; Andersson, L.I.; Ansell, R.J.; Kirsch, N.; Nicholls, I.A.; O'Mahony, J.; Whitcombe, M.J. Molecular imprinting science and technology: A survey of the literature for the years up to and including 2003. J. Mol. Recognit. 2006, 19, 106-180.

133. Zhang, H.; Ye, L.; Mosbach, K. Non-covalent molecular imprinting with emphasis on its application in separation and drug development. J. Mol. Recognit. 2006, 19, 248-259.

134. Ye, L.; Mosbach, K. Molecular imprinting: Synthetic materials as substitutes for biological antibodies and receptors. Chem. Mater. 2008, 20, 859-868.

135. Sellergren, B. Molecularly imprinted polymers: Shaping enzyme inhibitors. Nat. Chem. 2010, 2 , 7-8.

136. Andersson, L.I. Molecular imprinting: Developments and applications in the analytical chemistry field. J. Chromatogr. B 2000, 745, 3-13. 
137. Sellergren, B. Imprinted polymers with memory for small molecules, proteins, or crystals. Angew. Chem. Int. Ed. Engl. 2000, 39, 1031-1037.

138. Ye, L.; Haupt, K. Molecularly imprinted polymers as antibody and receptor mimics for assays, sensors and drug discovery. Anal. Bioanal. Chem. 2004, 378, 1887-1897.

139. Sellergren, B.; Hall, A.J. In Molecularly Imprinted Polymers: Man-Made Mimics of Antibodies and Their Applications in Analytical Chemistry; Sellergren, B., Ed.; Elsevier: Amsterdam, The Netherlands, 2001; Chapter 4.

140. Zhang, H.; Piacham, T.; Drew, M.; Patek, M.; Mosbach, K.; Ye, L. Molecularly imprinted nanoreactors for regioselective huisgen 1,3-dipolar cycloaddition reaction. J. Am. Chem. Soc. 2006, $128,4178-4179$.

141. Liu, J.Q.; Wulff, G. Functional mimicry of carboxypeptidase A by a combination of transition state stabilization and a defined orientation of catalytic moieties in molecularly imprinted polymers. J. Am. Chem. Soc. 2008, 130, 8044-8054.

142. Cutivet, A.; Schembri, C.; Kovensky, J; Haupt, K. Molecularly imprinted microgels as enzyme inhibitors. J. Am. Chem. Soc. 2009, 131, 14699-14702.

143. Puoci, F.; Iemma, F.; Picci, N. Stimuli-responsive molecularly imprinted polymers for drug delivery: A review. Curr. Drug Deliv. 2008, 5, 85-96.

144. El Khoury, J.M.; Zhou, X.L.; Qu, L.T.; Dai, L.M.; Urbas, A.; Li, Q. Organo-soluble photoresponsive azo thiol monolayer-protected gold nanorods. Chem. Commun. 2009, 16, 2109-2111.

145. Gong, C.B.; Wong, K.L.; Lam, M.H.-W. Photoresponsive molecularly imprinted hydrogels for the photoregulated release and uptake of pharmaceuticals in the aqueous media. Chem. Mater. 2008, 20, 1353-1358.

146. Gomy, C.; Schmitzer, A.R. Synthesis and photoresponsive properties of a molecularly imprinted polymer. Org. Lett. 2007, 9, 3865-3868.

147. Kempe, H.; Kempe, M. Development and evaluation of spherical molecularly imprinted polymer beads. Anal. Chem. 2006, 78, 3659-3666.

148. Takeuchi, T.; Akeda, K.; Murakami, S.; Shinmori, H.; Inoue, S.; Lee, W.S.; Hishiya, T. Photoresponsive porphyrin-imprinted polymers prepared using a novel functional monomer having diaminopyridine and azobenzene moieties. Org. Biomol. Chem. 2007, 5, 2368-2374.

149. Yagai, S.; Karatsu, T.; Kitamura, A. Photocontrollable self-assembly. Chem. Eur. J. 2005, 11, 4054-4063.

150. Minoura, N.; Idei, K.; Rachkov, A.; Uzawa H.; Matsuda K. Molecularly imprinted polymer membranes with photoregulated template binding. Chem. Mater. 2003, 15, 4703-4704.

151. Minoura, N.; Idei, K.; Rachkov, A.; Choi, Y.; Ogiso, M.; Matsuda, K. Binding efficiency and transport properties of molecularly imprinted polymer thin films. Macromolecules 2004, 37, 9571-9576.

152. Marx-Tibbon, S.; Willner, I. Photostimulated imprinted polymers: A light-regulated medium for transport of amino acids. J. Chem. Soc., Chem. Commun. 1994, 10, 1261-1262.

153. Gong, C.; Lam, M.H.; Yu, H. The fabrication of a photoresponsive molecularly imprinted polymer for the photoregulated uptake and release of caffeine. Adv. Funct. Mater. 2006, 16, 1759-1767. 
154. Stephens, D.A.; Bohn, P.W. Absorption spectrometry of bound monolayers on integrated optical structures. Anal. Chem. 1989, 61, 386-390.

155. Matsuda, N.; Takatsu, A.; Kato, K. Absorption spectra of rhodamine $6 \mathrm{G}$ by slab optical waveguide spectroscopy. Chem. Lett. 1996, 2, 105-106.

156. Mendes, S.B.; Li, L.; Burke, J.J. Broad-band attenuated total reflection spectroscopy of a hydrated protein film on a single mode planar waveguide. Langmuir 1996, 12, 3374-3376.

157. Mitsuishi, M.; Tanuma, T.; Matsui, J.; Chen J.; Miyashita, T. In situ monitoring of photo-crosslinking reaction of anthracene chromophores in polymer Langmuir-Blodgett films by an integrated optical waveguide technique. Langmuir 2001, 17, 7449-7451.

158. Bradshaw, J.T.; Mendes, S.B.; Armstrong, N.R.; Saavedra, S.S. Broadband coupling into a single-mode, electroactive integrated optical waveguide for spectroelectrochemical analysis of surface-confined redox couples. Anal. Chem. 2003, 75, 1080-1088.

159. Ogawa, K.; Harada, J.; Fujiwara, T.; Takahashi, H. UV-vis absorption spectra of powdered materials: Direct measurements by optical waveguide spectroscopy. Chem. Lett. 2004, 33, 1446-1447.

160. Fujita, K.; Taniguchi, K.; Ohno, H. Dynamic analysis of aggregation of methylene blue with polarized optical waveguide spectroscopy. Talanta 2005, 65, 1066-1070.

161. Fang, L.; Chen, S.; Zhang, Y.; Zhang, H. Azobenzene-containing molecularly imprinted polymer microspheres with photoresponsive template binding properties. J. Mater. Chem. 2011, 21, 2320-2329.

162. Jiang, G.S.; Zhomg, S.A.; Chen, L.; Blakey, I.; Whitaker, A. Synthesis of molecularly imprinted organic-inorganic hybrid azobenzene materials by sol-gel for radiation induced selective recognition of 2,4-dichlorophenoxyacetic acid. Radiat. Phys. and Chem. 2011, 80, 130-135.

163. Gehrke, S.H. Mass transfer in pH-sensitive hydrogels. Chem. Eng. Sci. 1989, 44, 559-566.

164. Bell, C.L.; Peppas, N.A. Water, solute and protein diffusion in physiologically responsive hydrogels of poly(methacrylic acid-gethylene glycol). Biomaterials 1996, 17, 1203-1218.

165. Gudeman, L.F.; Peppas, N.A. pH-sensitive membranes from poly(vinyl alcohol)/poly(acrylic acid) interpenetrating networks. J. Membrane Sci. 1995, 107, 239-248.

166. Brannon-Peppas, L.; Peppas, N.A. Equilibrium swelling behavior of pH-sensitive hydrogels. Chem. Eng. Sci. 1991, 46, 715-722.

167. Peppas, N.A.; Khare, A.R. Preparation, structure and diffusional behavior of hydrogels in controlled release. Adv. Drug Deliv. Rev. 1993, 11, 1-35.

168. Peppas, N.A.; Hariharan, D.; Khare, A.R. Bioresponsive hydrogels for controlled release of solutes. Polym. Mater. Sci. Eng. 1992, 66, 83-84.

169. Brazel, C.S.; Peppas, N.A. Temperature and pH-sensitive hydrogels for controlled release of antithrombogenic agents. Mater. Res. Soc. Symp. Proc. 1994, 331, 211-216.

170. Hoffman, A.S. 'Intelligent' polymers in medicine and biotechnology. Artif. Organs 1995, 19, $458-467$.

171. Galaev, I.Y.; Mattiasson, B. Thermoreactive water-soluble polymers, nonionic surfactants, and hydrogels as reagents in biotechnology. Enzym. Microb. Tech. 1993, 15, 354-366. 
172. Park, T.G.; Hoffman, A.S. Thermal cycling effects on the bioreactor performances of immobilized b-galactosidase in temperature-sensitive hydrogel beads. Enzym. Microb. Tech. 1993, 15, 476-482.

173. Langer, R.; Peppas, N.A. Chemical and physical structure of polymers as carriers for controlled release of bioactive agents: a review. JMS-Rev. Macromol. Chem. Phys. 1983, 23, 61-126.

174. Andreopoulos, F.M.; Beckman, E.; Russel, A.J. Photoscissable hydrogel synthesis via rapid photopolymerization of novel PEG-based polymers in the absence of photoinitiators. $J$. Am. Chem. Soc. 1996, 118, 6235-6240.

175. Andreopoulos, F.M.; Beckman, E.; Russel, A.J. Light-induced tailoring of PEG-hydrogel properties. Biomaterials 1998, 19, 1343-1352.

176. Kodzwa, M.G.; Staben, M.E.; Rethwisch, D.G. Photoresponsive control of ion-exchange in leucohydroxide containing hydrogel membranes. J. Membrane Sci. 1999, 158, 85-92.

177. Irie, M.; Kunwatchakun, D. Photoresponsive polymer 8. Reversible photostimulated dilation of polyacrylamide gels having triphenilmethane leuco-derivate. Macromolecules 1986, 19 , 2476-2480.

178. Mamada, A.; Tanaka, T.; Kungwatchakun, D.; Irie, M. Photoinduced phase transition of gels. Biomacromolecules 1990, 19, 1517-1519.

179. Ishikawa, M.; Kitamura, N.; Masuhara, H.; Irie, M. Size effect on photoinduced volume change of polyacrylamide microgels containg triphenylmathane leucoderivates. Makromol. Chem. Rapid Commun. 1991, 12, 887.

180. Tanaka, T.; Fillmore, D.; Sun, S.T.; Nishio, I.; Swislow, G.; Shah, A. Phase transitions in ionic gels. Phys. Rev. Lett. 1980, 45, 1636-1639.

181. Sasaki, H.; Ueno, A.; Osa, T. Photoinduced extraction and active transport of anions by a triphenylmethane derivative. Bull. Chem. Soc. 1988, 61, 2325-2326.

182. Willner, I.; Sussan, S.; Rubin, S. Photostimulated transport of carboxylate and phenolate anions across a liquid-liquid membrane using a photochromic cationic copolymer as carrier. J. Chem. Soc. Chem. Commun. 1992, 2, 100-101.

183. Willner, I.; Rubin, S.; Shatzmiller, R.; Zor, T. Reversible light stimulated activation and deactivation of $\alpha$-chymotrypsin by its immobilization in photoisomerizable copolymers. $J$. Am. Chem. Soc. 1993, 115, 8690-8694.

184. Murata, K.; Aoki, M.; Suzuki, T.; Harada, T.; Kawabata, H.; Komori, T.; Ohseto, F.; Ueda, K.; Shinkai, S. Thermal and light control of the sol-gel phase transition in cholesterol-based organic gels. Novel helical aggregation modes as detected by circular dichroism and electron microscopic observation. J. Am. Chem. Soc. 1994, 116, 6664-6676.

185. Mamiya, J.; Kanie, K.; Hiyama, T.; Ikeda T.; Kato, T. A rodlike organogelator: Fibrous aggregation of azobenzene derivatives with a syn-chiral carbonate moiety. Chem. Commun. 2002, 17, 1870-1871.

186. Moriyama, M.; Mizoshita, M.; Yokota, T.; Kishimoto, K.; Kato, T. Photoresponsive anisotropic soft solids: Liquid-crystalline physical gels based on a chiral photochromic gelator. Adv. Mater. 2003, 15, 1335-1338. 
187. Yagai, S.; Nakajima, T.; Kishikawa, K.; Kohmoto, S.; Karatsu, T.; Kitamura, A. Hierarchical organization of photoresponsive hydrogen-bonded rosettes. J. Am. Chem. Soc. 2005, 127, 11134-11139.

188. Ishi-I, T.; Shinkai, S. Dye-based organogels: Stimuli-responsive soft materials based on one-dimensional self-assembling aromatic dyes. Top. Curr. Chem. 2005, 258, 119-160.

189. Zhou, Y.F.; Xu, M.; Yi, T.; Xiao, S.Z.; Zhou, Z.G.; Li, F.Y.; Huang, C.H. Morphology-tunable and photoresponsive properties in a self-assembled two-component gel system. Lagmuir 2007, 23, 202-208.

190. Deindorfen, P.; Davis, R.; Zentel, R. Photoresponsive anisotropic and isotropic gels of semicarbazide-azobenzene organogelators: The use of magnetic polymer colloids to detect gel-sol transformation. Soft Matter 2007, 3, 1308-1311.

191. Kitahara, T.; Fujita, N.; Shinkai, S. Photoresponsive fluorescence color change derived from TICT in an organogel system. Chem. Lett. 2008, 37, 912-920.

192. Palui, G.; Banerjee, A. Fluorescent gel from a self-assembling new chromophoric moiety containing azobenzene based tetraamide. J. Phys. Chem. B 2008, 112, 10107-10115.

193. Suzuki, T.; Shinkai, S.; Sada, K. Supramolecular crosslinked linear poly(trimethylene iminium trifluorosulfonimide) polymer gels sensitive to light and thermal stimuli. Adv. Mater. 2006, 18, 1043-1046.

194. Pouliquen, G.; Tribet, C. Light-triggered association of bovine serum albumin and azobenzene-modified poly(acrylic acid) in dilute and semidilute solutions. Macromolecules 2006, 39, 373-383.

195. Ruchmann, J.; Fouilloux, S.; Tribret, C. Light-responsive hydrophobic association of surfactants with azobenzene-modified polymers. Soft Matter 2008, 4, 2098-2108.

196. Pouliquen, G.; Amiel, C.; Tribret, C. Photoresponsive viscosity and host-guest association in aqueous mixtures of poly-cyclodextrin with azobenzene-modified poly(acrylic) acid. J. Phys. Chem. B 2007, 111, 5587-5595.

197. Deshmukh, S.; Bromberg, L.; Smith, K.A.; Hatton, T.A. Photoresponsive behavior of amphiphilic copolymers of azobenzene and $N, N$-dimethylacrylamide in aqueous solutions. Langmuir 2009, 25, 3459-3466.

198. Kasha, M.; Rawls, H.R.; Ashraf El-Bayoumi, M. The exciton model in molecular spectroscopy. Pure Appl. Chem. 1965, 11, 371-392.

199. Pedrosa, J.M.; Romero, M.T.M.; Camacho, L.; Mobius, D. Organization of an amphiphilic azobenzene derivative in monolayers at the air-water interface. J. Phys. Chem. B 2002, 106, 2583-2591.

200. Deng, Y.; Li, Y.; Wang, X. Colloidal sphere formation, H-aggregation, and photoresponsive properties of an amphiphilic random copolymer bearing branched azo side chains. Macromolecules 2006, 39, 6590-6598.

201. Whitten, D.G.; Chen, L.H.; Geiger, H.C.; Perlstein, J.; Song, X.D. Self-assembly of aromatic-functionalized amphiphiles: The role and consequences of aromatic-aromatic noncovalent interactions in building supramolecular aggregates and novel assemblies. $J$. Phys. Chem. B 1998, 102, 10098-10111. 
202. Chen, D.; Liu, H.; Kobayashi, T.; Yu, H. Multiresponsive reversible gels based on a carboxylic azopolymer. J. Mat. Chem. 2010, 20, 3610-3614.

203. Sumaru, K.; Kameda, M.; Kanamori, T.; Shinbo, T. Reversible and efficient proton dissociation of spirobenzopyran-functionalized poly( $N$-isopropylacrylamide) in aqueous solution triggered by light irradiation and temporary temperature rise. Macromolecules 2004, 37, 7854-7856.

204. Benito-Lopez, F.; Byrne, R.; Raduta, A.M.; Vrana, N.E.; McGuinness, G.; Diamond, D. Ionogel-based light-actuated valves for controlling liquid flow in microfluidic manifolds. Lab Chip 2010, 10, 195-201.

205. Deloncle, R.; Caminade, A.-M. Stimuli-responsive dendritic structure: the case of light-driven azobenzene-containing dendrimers and dendrons. J. Photochem. Photobiol. C photo. 2010, 11, $25-45$.

206. Zhang, W.; Xie, J.; Yang, Z.; Shi, W. Aggregation behaviors and photo-responsive properties of azobenzene constructed phosphate dendrimers. Polymer 2007, 48, 4466-4481.

207. Kresge, C.T.; Leonowicz, M.E.; Roth, W.J.; Vartuli, J.C.; Beck, J.S. Ordered mesoporous molecular-sieves synthesized by a liquid-crystal template mechanism. Nature 1992, 359, $710-712$.

208. Lu, Y.; Ganguli, R.; Drewien, C.A.; Anderson, M.T.; Brinker, C.J.; Gong, W.L.; Guo, Y.X.; Soyez, H.; Dunn, B.; Huang, M.H.; Zink, J.I. Continuous formation of supported cubic and hexagonal mesoporous films by sol gel dip-coating. Nature 1997, 389, 364-368.

209. Wirnsberger, G.; Scott, B.J.; Stucky, G.D. pH Sensing with mesoporous thin films. Chem. Commun. 2001, 1, 119-120.

210. Melosh, N.A.; Lipic, P.; Bates, F.S.; Wudl, F.; Stucky, G.D.; Fredrickson, H.G.; Chmelka, B.F. Molecular and mesoscopic structures of transparent block copolymer-silica monoliths. Macromolecules 1999, 32, 4332-4342.

211. Grosso, D.; Balkenende, A.R.; Albouy, P.A.; Ayral, A; Amenitsch, H.; Babonneau, F. Two-dimensional hexagonal mesoporous silica thin films prepared from block copolymers: Detailed characterization and formation mechanism. Chem. Mater. 2001, 13, 1848-1856.

212. Feng, X.; Fryxell, G.E.; Wang, L.-Q.; Kim, A.Y.; Liu, J.; Kemner, K.M. Functionalized monolayers on ordered mesoporous supports. Science 1997, 276, 923-926.

213. Inagaki, S.; Guan, S.; Fukushima, Y.; Oshuna, T.; Terasaki, O. Novel mesoporous materials with a uniform distribution of organic groups and inorganic oxide in their frameworks. J. Am. Chem. Soc. 1999, 121, 9611-9614.

214. Asefa, T.; MacLachlan, M.J.; Grondey, H.; Coombs, N.; Ozin, G.A. Metamorphic channels in periodic mesoporous methylene silica. Angew. Chem. Int. Ed. 2000, 39, 1808-1811.

215. MacLachlan, M.J.; Asefa, T.; Ozin, G.A. Writing on the wall with a new synthetic quill. Chem. Eur. J. 2000, 6, 2507-2511.

216. Jeong, H.-K.; Nair, S.; Vogt, T.; Dickinson, L.C.; Tsapatsis, M.A. Highly crystalline layered silicate with three-dimensionally microporous layers. Nat. Mater. 2003, 2, 53-58.

217. Weh, K.; Noack, M.; Sieber, I.; Caro, J. Permeation of single gases and gas mixtures through faujasite-type molecular sieve membranes. Micropor. Mesopor. Mat. 2002, 54, 27-36. 
218. Lassinantti, M.; Jareman, F.; Hedlund, J.; Creaser, D.; Sterte, J. Preparation and evaluation of thin ZSM-5 membranes synthesized in the absence of organic template molecules. Catal. Today 2001, 67, 109-119.

219. Wan, Y.S.S.; Chau, J.L.H.; Gavriilidis, A.; Yeung, K.L. Design and fabrication of zeolite-based microreactors and membrane microseparators. Micropor Mesopor. Mat. 2001, 42, 157-175.

220. Hedlund, J.; Noack, M.; Kolsch, P.; Creaser, D.; Caro, J.; Sterte J. ZSM-5 membranes synthesized without organic templates using a seeding technique. J. Membrane Sci. 1999, 159, 263-273.

221. Noack, M.; Kolsch, P.; Venzke, D.; Toussaint, P.; Caro, J. A new one-dimensional-membilkne: aligned $\mathrm{AlPO}_{4} 5$ molecular sieve crystals in a nickel foil. Stud. Surf. Sci. Catal. 1995, 98, 276-277.

222. Kolsch, P.; Venzke, D.; Noack, M.; Toussaint, P.; Caro, J. Zeolite-in-metal membranes reparation and testing. J. Chem. Soc. Chem. Commun. 1994, 21, 2491-2492.

223. Kolsch, P.; Venzke, D.; Noack, M.; Lieske, E.; Toussaint, P.; Caro, J. Preparation and testing of silicalite-in-metal-membranes. Stud. Surf. Sci. Catal. 1994, 84, 1075-1082.

224. Noack, M.; Kolsch, P.; Venzke, D.; Toussaint, P.; Caro, J. New one dimensional membrane: aligned $\mathrm{AlPO}_{4} 5$ molecular sieve crystals in a nickel foil. Microporous Mater. 1994, 3, 201-206.

225. Matsukata, M.; Nishiyama, N.; Ueyama, K. Zeolitic membrane synthesized on a porous alumina support. J. Chem. Soc. Chem. Commun. 1994, 3, 339-340.

226. Ozin, G.A.; Kuperman, A.; Stein, A. Advanced zeolite materials science. Angew. Chem. 1989, 101, 373-390.

227. Weh, K.; Noack, M. Modification of gas permeation by optical switching of molecular sieve-azobezene membranes. In Host-guest-Systems Based on Nanoporous Crystals; Laeri, F., Schüth, F., Simon, U., Wark, M., Eds.; Wiley-VCH Verlag GmbH \& Co. KGaA: Weinheim, Germany, 2003; pp. 484-500.

228. Kim, Y.; Dutta, P.K. Photo-chemical studies with a zeolite Y membrane formed via secondary growth. Res. Chem. Intermediat. 2004, 30, 147-161.

229. Weh, K.; Noack, M.; Hoffmann, K.; Schroder, K.P.; Caro, J. Change of gas permeation by photo-induced switching of zeolite-azobenzene membranes of type MFI and FAU. Micropor. Mesopor. Mat. 2002, 54, 15-26.

230. Noack, M.; Koelsch, P.; Caro, J.; Weh, K. Gas permeable membrane and use thereof for controlling gas passage. Eur. Patent 1,095,694, 2 May 2001.

231. Liu, N.; Yu, K.; Smarsly, B.; Dunphy, D.R.; Jiang, Y.-B.; Brinker, C.J. Self-directed assembly of photo-active hybrid silicates derived from an azobenzene-bridged silsesquioxane. J. Am. Chem. Soc. 2002, 124, 14540-14541.

232. Schomburg, C.; Wohrle, G.; Schultz-Ekloff, G. In situ synthesis of azo dyes in mesoporous Y zeolites. Zeolites 1996, 17, 232-236.

233. Alvaro, M.; Benitez, M.; Das, D.; Garcia, H.; Peris, E. Reversible porosity changes in photo-responsive azobenzene-containing periodic mesoporous silicas. Chem. Mater. 2005, 17, 4958-4964. 
234. Sugiura, S.; Sumaru, K.; Ohi, K.; Hiroki, K.; Takagi, T.; Kanamori, T. Photoresponsive polymer gel microvalves controlled by local light irradiation. Sensor. Actuator. A Phys. 2007, 140, 176-184.

235. Arana, J.; Melian, J.A.H.; Rodriguez, J.M.D.; Diaz, O.G.; Viera, A.; Pena, J.P.; Sosa, P.M.M.; Jimenez, V.E. $\mathrm{TiO}_{2}$-photocatalysis as a tertiary treatment of naturally treated wastewater. Catal. Today 2002, 76, 279-289.

236. Shon, H.K.; Vigneswaran, S.; Ngo, H.H.; Kim, J.H. Chemical coupling of photocatalysis with flocculation and adsorption in the removal of organic matter. Wat. Res. 2005, 39, 2549-2558.

237. Parsons, S. Advanced Oxidation Processes in Water and Wastewater Treatment; International Water Association Press: London, UK, 2004.

238. Bhatkhande, D.S.; Pangarkar, V.G.; Beenackers, A. Photocatalytic degradation for environmental applications-A review. J. Chem. Technol. Biotechnol. 2002, 77, 102-116.

239. Mozia, S.; Morawski, A.W. Hybridization of photocatalysis and membrane distillation for purification of wastewater. Catal. Today 2006, 118, 181-188.

240. Ho, D.P.; Vigneswaran, S.; Ngo, H.H. Integration of photocatalysis and microfiltration in removing effluent organic matter from treated sewage effluent. Sep. Sci. Technol. 2010, 45, $155-162$.

241. Drzaic, P.S. Liquid Crystal Dispersions; World Scientific Press: Singapore, 1995.

242. Glowacki, E.; Horovitz, K.; Tang, C.W.; Maeshall, K.L. Photoswitchable gas permeation membranes based on liquid crystals. Adv. Funct. Mater. 2010, 20, 2778-2785.

243. Macchione, M.; De Filpo, G.; Nicoletta, F.P.; Chidichimo, G. Photo-chromic reverse mode polymer dispersed liquid crystals. Liq. Cryst. 2000, 27, 917-920.

244. Kwak, S.; Hurditch, R.J. Photochromic compound and articles containing the same. U.S. Patent 4,637,698, 20 January 1987.

245. Nicoletta, F.P.; Cupelli, D.; De Filpo, G.; Chidichimo, G. Electrochromism in switchable nematic emulsions. Appl. Phys. Lett. 2004, 84, 4260-4262.

246. Cupelli, D.; Nicoletta, F.P.; De Filpo, G.; Chidichimo, G.; Fazio, A.; Gabriele, B.; Salerno, G. Fine adjustment of conductivity in polymer-dispersed liquid crystals. Appl. Phys. Lett. 2004, 85, 3292-3294.

247. Cupelli, D.; De Filpo, G.; Chidichimo, G.; Nicoletta, F.P. Photo-switching in polymer dispersed liquid crystals. J. Appl. Phys. 2006, 100, 024508.

248. Cupelli, D.; Nicoletta, F.P.; Manfredi, S.; Vivacqua, M.; Formoso, P.; De Filpo, G.; Chidichimo, G. Self-adjusting smart windows based on polymer-dispersed liquid crystals. Sol. Energy Mater. Sol. Cells 2009, 93, 2008-2012.

249. Macchione, M.; De Filpo, G.; Mashin, A.; Nicoletta, F.P.; Chidichimo, G. Laser-writable, electrically erasable photo-electrochromic organic film. Adv. Mater. 2003, 15, 327-329.

250. Macchione, M.; De Filpo, G.; Nicoletta, F.P.; Chidichimo, G. Improvement of response times in photo-electrochromic organic film. Chem. Mater. 2004, 16, 1400-1401.

251. De Filpo, G.; Nicoletta, F.P.; Chidichimo, G. Flexible nanophoto-electrochromic film. Chem. Mater. 2005, 18, 4662-4666.

252. Argun, A.A.; Cirpan, A.; Reynolds, J.R. The first truly all-polymer electrochromic devices. Adv. Mater. 2003, 15, 1338-1341. 
253. De Filpo, G.; Mormile, S.; Nicoletta, F.P.; Chidichimo, G. Fast, self-supplied, all-solid photo-electrochromic film. J. Power Sources 2010, 195, 4365-4369.

254. Higuchi, A.; Hamamura, A.; Shindo, Y.; Kitamura, H.; Yoon, B.O.; Mori, T.; Uyama, T.; Umezawa, A. Photo-n-modulated changes of cell attachments on poly(spiropyran-co-methyl methacrylate) membranes. Biomacromolecules 2004, 5, 1770-1774.

255. Menon, S.; Thekkayil, R.; Varghese, S.; Das, S. Photoresponsive soft materials: synthesis and photophysical studies of a stilbene-based diblock copolymer. J. Polym. Sci. Pol. Chem. 2011, 49, 5063-5073.

256. Sasaki, Y.; Iwamoto, S.; Mukai, M.; Kikuchi, J. Photo- and thermo-responsive assembly of liposomal membranes triggered by a gemini peptide lipid as a molecular switch. J. Photochem. Photobiol. A Chem. 2006, 183, 309-314.

257. Mukai, M.; Maruo, K.; Kikuchi, J.; Sasaki, Y.; Hiyama, S.; Moritani, Y.; Suda, T. Propagation and amplification of molecular information using a photo-responsive molecular switch. Supramol. Chem. 2009, 21, 284-291.

258. Liang, X.; Yue, X.; Dai, Z.; Kikuchi, J. Photo-responsive liposomal nanohybrid cerasomes. Chem. Commun. 2011, 47, 4751-4753.

259. Kikuchi, J.; Ariga, K.; Miyazaki, T.; Ikeda, K. An artificial signal transduction system. control of lactate dehydrogenase activity performed by an artificial cell-surface receptor. Chem. Lett. 1999, 28, 253-254.

260. Kikuchi, J.; Kamijyo, Y.; Etoh, H.; Murakami, Y. Catalytic performance of a supramolecular bienzyme complex formed with artificial aminotransferase and natural lactate dehydrogenase. Chem. Lett. 1996, 25, 427-428.

261. Yasuhara, K.; Sasaki, Y.; Kikuchi, J. A photo-responsive cholesterol capable of inducing a morphological transformation of the liquid-ordered microdomain in lipid bilayers. Colloid Polym. Sci. 2008, 286, 1675-1680.

262. Benkoski, J.J.; Jesorka, A.; Edvardsson, M.; Hook, F. Light-regulated release of liposomes from phospholipid membranes via photo-responsive polymer-DNA conjugates. Soft Matter 2006, 2 , $710-715$.

263. Hamada, T.; Sato, Y.T.; Yoshikawa, K.; Nagasaki, T. Reversible photo-switching in a cell-sized vesicle. Langmuir 2005, 21, 7626-7628.

264. Ishii, K.; Hamada, T.; Hatakeyama, M.; Sugimoto, R.; Nagasaki, T.; Takagi, M. Reversible control of exo-and endo-budding transitions in a photo-sensitive lipid membrane. ChemBioChem 2009, 10, 251-256.

265. Riske, K.A.; Sudbrack, T.P.; Archilha, N.L.; Uchoa, A.F.; Schröder, A.P.; Marques, C.M.; Baptista, M.S.; Itri, R. Giant vesicles under oxidative stress induced by a membrane-anchored photo-sensitizer. Biophys. J. 2009, 97, 1362-1370.

266. Uda, R.M.; Yamashita, D.; Sakurai, Y.; Kimura, K. Photo-induced increase in vesicle size and role of photo-responsive malachite green leuconitrile derivative in vesicle fusion. Langmuir 2007, 23, 7936-7941.

267. Uda, R.M.; Hiraishi, E; Ohnishi, R; Nakahara, Y; Kimura, K. Morphological changes in vesicles and release of an encapsulated compound triggered by a photo-responsive Malachite Green leuconitrile derivative. Langmuir 2010, 26, 5444-5450. 
268. Matsumura, A.; Tsuchiya, K.; Torigoe, K.; Sakai, K.; Sakai, H.; Abe, M. Photo-chemical control of molecular assembly formation in a catanionic surfactant system. Langmuir 2011, 27, $1610-1617$.

269. Israelachvili, J.N.; Mitchell, D.J.; Ninham, B.W. Theory of self-assembly of hydrocarbon amphiphiles into micelles and bilayers. J. Chem. Soc. Faraday Trans. 2 1976, 72, 1525-1568.

270. Orihara, H.; Matsumura, A.; Saito, Y.; Ogawa, N.; Saji, T.; Yamaguchi, A.; Sakai, H.; Abe, M. Reversible release control of an oily substance using photo-responsive micelles. Langmuir 2001, 17, 6072-6076.

(C) 2012 by the authors; licensee MDPI, Basel, Switzerland. This article is an open access article distributed under the terms and conditions of the Creative Commons Attribution license (http://creativecommons.org/licenses/by/3.0/). 